\title{
Coinfections with Bacteria, Fungi, and Respiratory Viruses in Patients with SARS-CoV-2: A Systematic Review and Meta-Analysis
}

\author{
Saad Alhumaid 1,*(D), Abbas Al Mutair ${ }^{2,3,4}$, Zainab Al Alawi ${ }^{5}$, Abeer M. Alshawi ${ }^{6}$, Salamah A. Alomran ${ }^{6}$, \\ Mohammed S. Almuhanna ${ }^{7}$, Anwar A. Almuslim ${ }^{7}$, Ahmed H. Bu Shafia ${ }^{8}$, Abdullah M. Alotaibi ${ }^{9}$, \\ Gasmelseed Y. Ahmed ${ }^{2}$, Ali A. Rabaan ${ }^{10}$, Jaffar A. Al-Tawfiq 11,12,13 (D) and Awad Al-Omari 14,15
}

Citation: Alhumaid, S.; Al Mutair, A.; Al Alawi, Z.; Alshawi, A.M.; Alomran, S.A.; Almuhanna, M.S.; Almuslim, A.A.; Bu Shafia, A.H.; Alotaibi, A.M.; Ahmed, G.Y.; et al. Coinfections with Bacteria, Fungi, and Respiratory Viruses in Patients with SARS-CoV-2: A Systematic Review and Meta-Analysis. Pathogens 2021, 10, 809. https://doi.org/ 10.3390 / pathogens10070809

Academic Editor: Enrico Lavezzo

Received: 17 June 2021

Accepted: 23 June 2021

Published: 25 June 2021

Publisher's Note: MDPI stays neutral with regard to jurisdictional claims in published maps and institutional affiliations.

Copyright: (c) 2021 by the authors. Licensee MDPI, Basel, Switzerland. This article is an open access article distributed under the terms and conditions of the Creative Commons Attribution (CC BY) license (https:// creativecommons.org/licenses/by/ $4.0 /)$.
1 Administration of Pharmaceutical Care, Al-Ahsa Health Cluster, Ministry of Health, Al-Ahsa 31982, Saudi Arabia

2 Research Center, Almoosa Specialist Hospital, Al-Ahsa 36342, Saudi Arabia; abbas4080@hotmail.com (A.A.M.); g.yousif@almoosahospital.com.sa (G.Y.A.)

3 College of Nursing, Princess Norah Bint Abdul Rahman University, Riyadh 11564, Saudi Arabia

4 School of Nursing, University of Wollongong, Wollongong, NSW 2522, Australia

5 Division of Allergy and Immunology, College of Medicine, King Faisal University, Al-Ahsa 31982, Saudi Arabia; zalalwi@kfu.edu.sa

6 Department of Pharmacy, King Fahad Hofuf Hospital, Al-Ahsa 36441, Saudi Arabia; aalshuui@moh.gov.sa (A.M.A.); saaalomran@moh.gov.sa (S.A.A.)

7 Department of Pharmacy, Maternity and Children Hospital, Al-Ahsa 36422, Saudi Arabia; msalmuhanna@moh.gov.sa (M.S.A.); aaalmuslim@moh.gov.sa (A.A.A.)

8 Department of Pharmacy, Alomran Hospital, Al-Ahsa 36355, Saudi Arabia; abushafia@moh.gov.sa

9 Department of Pharmacy, Prince Sultan Cardiac Center, Al-Ahsa 36441, Saudi Arabia; aalotaibi274@moh.gov.sa

10 Molecular Diagnostic Laboratory, Johns Hopkins Aramco Healthcare, Dhahran 31311, Saudi Arabia; arabaan@gmail.com

11 Infectious Disease Unit, Specialty Internal Medicine, Johns Hopkins Aramco Healthcare, Dhahran 31311, Saudi Arabia; jaffar.tawfiq@jhah.com

12 Infectious Disease Division, Department of Medicine, Indiana University School of Medicine, Indianapolis, IN 46202, USA

13 Infectious Disease Division, Department of Medicine, Johns Hopkins University School of Medicine, Baltimore, MD 21287, USA

14 College of Medicine, Alfaisal University, Riyadh 11533, Saudi Arabia; awad.omari@drsulaimanalhabib.com

15 Research Center, Dr. Sulaiman Al Habib Medical Group, Riyadh 11372, Saudi Arabia

* Correspondence: saalhumaid@moh.gov.sa; Tel.: +966-561-522-581 
tests confirmed asymmetry ( $p$ values $<0.05$ ). Conclusion: Bacterial co-infection is relatively high in hospitalized patients with SARS-CoV-2, with little evidence of $S$. aureus playing a major role. Knowledge of the prevalence and type of co-infections in SARS-CoV-2 patients may have diagnostic and management implications.

Keywords: SARS-Cov-2; co-infection; coinfection; COVID-19; concurrent; bacterial; fungal; viral; meta-analysis

\section{Introduction}

Coronavirus disease 2019 (COVID-19) is caused by the severe acute respiratory syndrome coronavirus 2 (SARS-CoV-2) and was first described in Wuhan, China in 2019. Globally, as of 15 April 2021, there have been 137,866,311 confirmed cases of COVID-19, including 2,965,707 deaths, as reported by the World Health Organization [1]. Coinfection with SARS-CoV-2 and other bacterial, fungal, and respiratory viral pathogens [2-4], Grampositive and Gram-negative bacteria [5-7], Middle East respiratory syndrome coronavirus (MERS-CoV) [8], and influenza [9-13] has been described. However, the reported frequency is variable. Such coinfections in patients with SARS-CoV-2 may be a cause of increased morbidity and mortality $[2,6,7,14-22]$. Thus, timely diagnosis is important to initiate appropriate therapy and limit the overuse of antimicrobial agents. Previous studies, including case series $[2,5,8,11,14-16,19,20,23-50]$, cohort studies $[3,4,6,7,9,10,12,13,17,18,21,22,51-70]$, and meta-analyses [71-73], have shown variable results. In light of recent studies evaluating coinfections in SARS-CoV-2 patients, we aimed to re-evaluate the prevalence of bacterial, fungal, and respiratory viral coinfections in a comprehensive meta-analysis. Moreover, we aimed to identify the risk-factors, characteristics, and consequences associated with SARS-CoV-2 coinfection.

\section{Methods}

\subsection{Design}

This is a meta-analysis and was conducted per the Preferred Reporting Items for Systematic Reviews and Meta-Analyses [PRISMA] guidelines [74]. We searched PROQUEST, MEDLINE, EMBASE, PUBMED, CINAHL, WILEY ONLINE LIBRARY, and NATURE for full texts. Search keywords included Coronavirus infection OR SARS coronavirus OR severe acute respiratory syndrome OR COVID OR SARS AND mixed infection OR bacterial pneumonia OR bacteremia OR bacterial infection OR fungal infection OR viral infection OR respiratory infection OR mycosis OR coinfect OR co-infect OR concomitant infect OR concurrent infection OR mixed infect OR coinfection OR co-infection. The search included English language studies from 1 December 2019 to 31 March 2021. Then, articles were kept if the title and abstract contained discussion about bacterial, fungal, and/or respiratory viral co-infection in SARS-CoV-2 patients. In addition, we used manual backward snowballing of the bibliographies of retrieved articles to include additional relevant articles.

\subsection{Inclusion and Exclusion Criteria}

The included articles were pertinent if these articles included patients with a positive SARS-CoV-2 reverse-transcription polymerase chain reaction (RT-PCR) test of any age and a described co-infection on presentation or developed during the course of the disease or during hospital stay. These cases were retained if bacteria, fungi, and/or viruses were detected in the respiratory tract or blood culture samples and were excluded if they were identified from other samples. We aimed to include randomized controlled trials, cohort studies, and case series, and excluded other types of studies. 


\subsection{Data Extraction}

Three authors (S.A., A.A., and J.A.) reviewed the retrieved studies and chose relevant articles. Data were extracted using key headings as indicated in Table 1. The study designs were classified as well. The extracted information included: authors; study location; study design and setting; publication year; number of SARS-CoV-2 patients tested for co-pathogens; number of coinfected patients; age; proportion of male patients; percentage of patients requiring intensive care unit (ICU) and mechanical ventilation; mortality rates; proportion of patients with bacterial, fungal, and/or respiratory viral coinfections; total organisms identified; antimicrobials prescribed; laboratory techniques for co-pathogen detection; assessment of study risk of bias; and remarks on notable findings.

\subsection{Quality Assessment}

The Newcastle-Ottawa Scale [NOS] was the primary tool for examining the quality of included studies, as described previously [75]. The tool provides maximum scores of 4 for selection, 2 for comparability, and 3 for exposure/outcome. High-quality studies have a score of $>7$, and moderate-quality studies have a score of 5-7. Quality assessment was performed independently by four authors (A.M.A., S.A.A., G.Y.A., and A.R.) and a consensus was used to resolve any disagreement.

\subsection{Data Analysis}

We examined primarily the proportion of confirmed acute bacterial, fungal and/or respiratory viral infections in patients with SARS-CoV-2. This proportion was further classified based on initial presentation or during the course of the illness. Taking a conservative approach, a random effects with the DerSimoniane-Laird model was used [76], which produces wider confidence intervals [CIs] than a fixed effect model. Results were illustrated using forest plots. The Cochran's chi-square $\left(\chi^{2}\right)$ and the $I^{2}$ statistic provided the tools of examining statistical heterogeneity [77]. An $I^{2}$ value of $>50 \%$ suggested significant heterogeneity [78]. Examining the source of heterogeneity, a subgroup analysis was conducted based on ICU and non-ICU admission or only ICU admission. Funnel plots and Egger's correlation test estimate publication bias and $p$ value $<0.05$ indicates statistical significance [79]. $R$ version 4.1 .0 with the packages metafor and meta was used for all statistical analyses. 
Table 1. Summary of the characteristics of the included studies with evidence on SARS-CoV-2 and bacterial, fungal, and/or respiratory viral co-infections ( $\mathrm{n}=72$ ), 2020-2021.

\begin{tabular}{|c|c|c|c|c|c|c|c|c|c|c|c|c|c|c|c|c|}
\hline $\begin{array}{l}\text { Author, Year, } \\
\text { Study } \\
\text { Location }\end{array}$ & $\begin{array}{l}\text { Study } \\
\text { Design, } \\
\text { Setting }\end{array}$ & $\begin{array}{c}\text { Number of } \\
\text { SARS-Cov-2 } \\
\text { Patients Tested for } \\
\text { Co-Pathogens, } n\end{array}$ & $\begin{array}{l}\text { Co-Infected } \\
\text { Patients, } \mathbf{n} \\
(\%)\end{array}$ & $\begin{array}{c}\text { Age } \\
\text { (Years) }\end{array}$ & $\begin{array}{c}\text { Male, n } \\
(\%)\end{array}$ & $\begin{array}{c}\text { Admitted } \\
\text { to IU, } \mathrm{n} \\
(\%)\end{array}$ & $\begin{array}{c}\text { Mechanical } \\
\text { Ventilation, } \\
\text { n }(\%)\end{array}$ & $\begin{array}{c}\text { Deaths, n } \\
(\%)\end{array}$ & $\begin{array}{l}\text { Bacterial } \\
\text { Co-Infection, } \\
\text { n (\%) }\end{array}$ & $\begin{array}{l}\text { Fungal } \\
\text { Co-Infection, } \\
\mathbf{n}(\%)\end{array}$ & $\begin{array}{l}\text { Respiratory } \\
\text { Viral } \\
\text { Co-Infection, } \\
\text { n (\%) }\end{array}$ & Total Organisms, $\mathbf{n}$ & Antimicrobials Use, $\mathbf{n}$ & $\begin{array}{l}\text { Laboratory } \\
\text { Techniques for } \\
\text { Co-Pathogen } \\
\text { Detection }\end{array}$ & $\begin{array}{l}\text { Nos } \\
\text { Score }\end{array}$ & Key Findings \\
\hline $\begin{array}{l}\text { Alanio et al., } \\
\text { 2020 [23], } \\
\text { France }\end{array}$ & $\begin{array}{l}\text { Prospective } \\
\text { case series, } \\
\text { single center }\end{array}$ & 27 & $7(25.9)$ & $\begin{array}{l}\text { Median } \\
\text { (IQR), 63 } \\
(43-79)\end{array}$ & $5(71.4)$ & $7(100)$ & $7(100)$ & $4(75.1)$ & - & $7(25.9)$ & - & 7 Aspergillus fumigatus & $\begin{array}{l}3 \text { Macrolides } \\
2 \text { Antifungals }\end{array}$ & $\begin{array}{l}\text { Culture from } \\
\text { respiratory } \\
\text { specimens and GM } \\
\text { detection in the BAL } \\
\text { and serum }\end{array}$ & 7 & $\begin{array}{l}\text { Death was not related to } \\
\text { pulmonary aspergillosis but } \\
\text { to bacterial septic shock and } \\
\text { organ failure. }\end{array}$ \\
\hline $\begin{array}{l}\text { Allou et al., } \\
\text { 2021 [9], } \\
\text { France }\end{array}$ & $\begin{array}{c}\text { Prospective } \\
\text { cohort, single } \\
\text { center }\end{array}$ & 36 & $5(13.9)$ & $\begin{array}{l}\text { Median } \\
\text { (IIR), 68 } \\
\text { (57-82) }\end{array}$ & $4(80)$ & $10(27.8)$ & $2(5.5)$ & 0 & $2(5.5)$ & - & $3(8.3)$ & 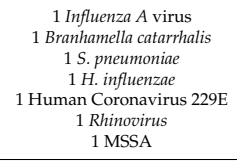 & Not reported & $\begin{array}{l}\text { RT-PCR for } \\
\text { naapharngeal } \\
\text { specimens lviruses] } \\
\text { AND sputum culture } \\
\text { [bacteria and fungi] }\end{array}$ & 7 & $\begin{array}{l}\text { Level of D-dimer was } \\
\text { siginificantly higher in } \\
\text { patients with co-infection } \\
\text { compared to patients } \\
\text { without co-infection } \\
(1.36 \mathrm{mg} / \mathrm{mL} \mathrm{vs} .0 .63 \\
\mathrm{mg} / \mathrm{mL}, p=0.05) .\end{array}$ \\
\hline $\begin{array}{l}\text { Amin et al., } \\
2021[141, \\
\text { United States }\end{array}$ & $\begin{array}{l}\text { Retrospective } \\
\text { case series, } \\
\text { single center }\end{array}$ & 140 & $79(56.4)$ & $\begin{array}{c}\text { Mean } \\
\text { (SD), } 62.3 \\
\text { (16.3) }\end{array}$ & $55(69.6)$ & $29(36.7)$ & $26(32.9)$ & $38(48.1)$ & $79(56.4)$ & - & - & 79 M. pneumoniae & $\begin{array}{l}\text { All patients received } \\
\text { antibiotics sorerage } \\
\text { against } M \text {. pheumoniae, } \\
\text { however, agents were } \\
\text { not reported }\end{array}$ & $\begin{array}{c}\text { Serum antibody test } \\
\text { (IgM) }\end{array}$ & 6 & 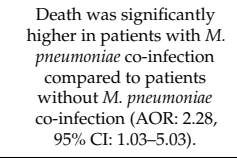 \\
\hline $\begin{array}{c}\text { Anton- } \\
\text { Vazquez } \\
\text { etal.,2021 } \\
\text { [24], Spain }\end{array}$ & $\begin{array}{l}\text { Retrospective } \\
\text { case series, } \\
\text { single center }\end{array}$ & 917 & $87(9.5)$ & $\begin{array}{l}\text { Median } \\
\text { (IIR), } 68 \\
(27-92)\end{array}$ & $37(42.5)$ & $8(9.2)$ & $\begin{array}{c}\text { Not } \\
\text { reported }\end{array}$ & $15(17.2)$ & $87(9.5)$ & - & - & 87 S. рпеитопіае & $\begin{array}{l}\text { Third Generation } \\
\text { Cephalosporins were } \\
\text { prescribed in the great } \\
\text { majority of cases }\end{array}$ & $\begin{array}{c}\text { Serum antibody test } \\
(\operatorname{lgM}, \mathrm{IgG})\end{array}$ & 6 & $\begin{array}{l}\text { Co-infected pneumococcal } \\
\text { pneumonia patients } \\
\text { compared with ConID-19 } \\
\text { patients without } \\
\text { pneumococal testing were } \\
\text { mostly female (57\% vs. } 34 \% \text {, } \\
p<0.001) \text {. } \\
\text { No differences in age, } \\
\text { length of stay, admission to } \\
\text { ICU, or mortality were } \\
\text { found between groups. }\end{array}$ \\
\hline $\begin{array}{l}\text { Arentze et al, } \\
2020 \text { [15], } \\
\text { United States }\end{array}$ & $\begin{array}{c}\text { Retrospective } \\
\text { case series, } \\
\text { single center }\end{array}$ & 21 & $4(19)$ & $\begin{array}{c}\text { Mean } \\
\text { (range), } \\
70(43-92)\end{array}$ & $11(52)$ & $21(100)$ & $15(71)$ & $11(52.4)$ & $1(4.8)$ & - & $3(14.3)$ & $\begin{array}{c}1 \text { Pseudomonas } \\
2 \text { Infuenzan A virus } \\
1 \text { Parainfluenza } 3 \text { virus }\end{array}$ & Not reported & Unspecified & 8 & $\begin{array}{l}\text { Study included } 21 \text { ICU } \\
\text { patients who had a high } \\
\text { rate of ARRS and a high } \\
\text { risk of death. }\end{array}$ \\
\hline $\begin{array}{c}\text { Bardi et al., } \\
2021[2], \\
\text { United States }\end{array}$ & $\begin{array}{c}\text { Retrospective } \\
\text { case series, } \\
\text { single center }\end{array}$ & 140 & $57(40.7)$ & $\begin{array}{l}\text { Median } \\
\text { (IRR), 63 } \\
\text { (60-68) }\end{array}$ & $47(82)$ & $57(100)$ & $56(98)$ & $31(54)$ & $51(36.4)$ & $6(4.3)$ & - & 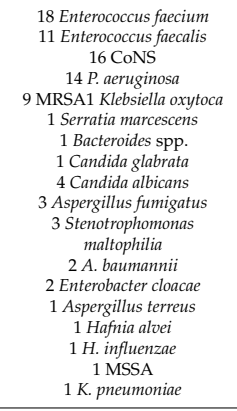 & $\begin{array}{l}53 \text { Third Generation } \\
\text { Cephalosporins } \\
53 \text { Macrolides } \\
47 \text { Other antibiotics }\end{array}$ & $\begin{array}{l}\text { Respiratory tracheal } \\
\text { aspirate and blood } \\
\text { cultures }\end{array}$ & 6 & 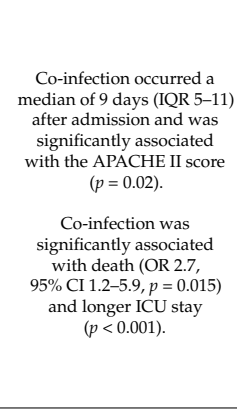 \\
\hline $\begin{array}{l}\text { Barrasa et al,, } \\
\text { 2020 [16], } \\
\text { Spain }\end{array}$ & $\begin{array}{c}\text { Retrospective } \\
\text { case series, } \\
\text { multi-center }\end{array}$ & 48 & $6(12.5)$ & $\begin{array}{l}\text { Median } \\
\text { (IIR), 63 } \\
\text { (51-75) }\end{array}$ & $27(56.2)$ & $48(100)$ & $45(93.7)$ & $12(25)$ & $5(10.4)$ & - & $1(2.1)$ & $\begin{array}{c}\text { 3. P. aeruginosa } \\
1 \text { Enterococcus faecium } \\
1 \text { H. influenzae } \\
1 \text { MRSA }\end{array}$ & $\begin{array}{l}17 \text { Fluoroquinolones } \\
22 \text { Third Generation } \\
\text { Cephalosporins } \\
10 \text { Macrolides } \\
\text { 9 Linezolid } \\
15 \text { Beta-Lactams }\end{array}$ & Unspecified & 7 & $\begin{array}{l}\text { Procalcitonin plasma above } \\
0.5 \mathrm{mg} / \mathrm{L} \text { was associated } \\
\text { with } 16 \% \text { vs. } 19 \%(p=0.78) \\
\text { risk of death after } 7 \text { days. }\end{array}$ \\
\hline
\end{tabular}


Table 1. Cont.

\begin{tabular}{|c|c|c|c|c|c|c|c|c|c|c|c|c|c|c|c|c|}
\hline $\begin{array}{l}\text { Author, Year, } \\
\text { Study } \\
\text { Location }\end{array}$ & $\begin{array}{l}\text { Study } \\
\text { Design, } \\
\text { Setting }\end{array}$ & $\begin{array}{c}\text { Number of } \\
\text { SARS--CoV-2 } \\
\text { Patients Tested for } \\
\text { Co-Pathogens, } \mathrm{n}\end{array}$ & $\begin{array}{c}\text { Co-IIffected } \\
\text { Patients, } n \\
(\%)\end{array}$ & $\begin{array}{c}\mathrm{Age} \\
\text { (Years) }\end{array}$ & 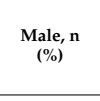 & $\begin{array}{l}\text { Admitted } \\
\text { to ICU, n } \\
(\%)\end{array}$ & $\begin{array}{l}\text { Mechanical } \\
\text { Ventilation, } \\
\mathrm{n}(\%)\end{array}$ & $\begin{array}{c}\text { Deaths, n } \\
(\%)\end{array}$ & $\begin{array}{l}\text { Bacterial } \\
\text { Co-Infection, } \\
\text { n (\%) }\end{array}$ & $\begin{array}{c}\text { Fungal } \\
\text { Co-Infection, } \\
\text { n (\%) }\end{array}$ & $\begin{array}{l}\text { Respiratory } \\
\text { Viral } \\
\text { Co-IIfection, } \\
\text { n (\%) }\end{array}$ & Total Organisms, $\mathrm{n}$ & Antimicrobials Use, n & $\begin{array}{l}\text { Laboratory } \\
\text { Techniques for } \\
\text { Co-Pathogen } \\
\text { Detection } \\
\end{array}$ & $\begin{array}{l}\text { NOS } \\
\text { Score }\end{array}$ & Key Findings \\
\hline $\begin{array}{l}\text { Bartoletti } \\
\text { et all, ,2020 } \\
\text { [17], Italy }\end{array}$ & $\begin{array}{c}\text { Prospective } \\
\text { cohort, } \\
\text { multi-center }\end{array}$ & 108 & $30(27.7)$ & $\begin{array}{l}\text { Median } \\
\text { (IIRR), 63 } \\
(57-70)\end{array}$ & $24(80)$ & $108(100)$ & $108(100)$ & $44(40.7)$ & - & $19(17.6)$ & - & $\begin{array}{c}15 \text { Aspergillus fumigatus } \\
3 \text { Aspergillun niger } \\
1 \text { Aspergillus flavus }\end{array}$ & $\begin{array}{l}9 \text { Macrolides } \\
16 \text { Antifungals }\end{array}$ & $\begin{array}{l}\text { Culture from } \\
\text { respiratory } \\
\text { specimens and GM } \\
\text { detection in the BAL } \\
\text { and serum }\end{array}$ & 7 & 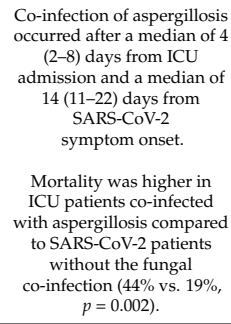 \\
\hline $\begin{array}{l}\text { Calcagno } \\
\text { et all, 2021 } \\
\text { [5], Italy }\end{array}$ & $\begin{array}{l}\text { Retrospective } \\
\text { case series, } \\
\text { single center }\end{array}$ & 56 & $10(17.8)$ & $\begin{array}{l}\text { Mean } \\
\text { (SD), } 63.3 \\
\text { (18) }\end{array}$ & $6(60)$ & $\begin{array}{l}\text { Not } \\
\text { reported }\end{array}$ & $\begin{array}{l}\text { Not } \\
\text { reported }\end{array}$ & $\begin{array}{l}\text { Not } \\
\text { reported }\end{array}$ & $10(17.8)$ & - & - & 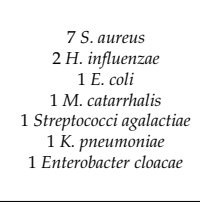 & Not reported & $\begin{array}{l}\text { RT-PCR of } \\
\text { respiratory tract } \\
\text { specimens } \\
\text { (nasopharyngeal, } \\
\text { BAL, BA, and } \\
\text { sputum) }\end{array}$ & 7 & 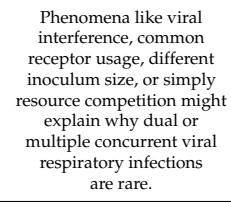 \\
\hline $\begin{array}{l}\text { Chen N et al., } \\
\text { 2020 [80], } \\
\text { China }\end{array}$ & $\begin{array}{l}\text { Retrospective } \\
\text { case series, } \\
\text { single center }\end{array}$ & 99 & $5(5)$ & $\begin{array}{l}\text { Mean } \\
\text { (SD), } 5.5 \\
\text { (13.1) }\end{array}$ & $67(67.7)$ & $23(23)$ & $17(17)$ & $11(11)$ & 1(1) & $4(4)$ & - & 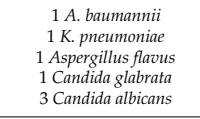 & $\begin{array}{c}70 \text { [cephalosporins, } \\
\text { quinolones, } \\
\text { carbapenems, } \\
\text { tigecycine, and } \\
\text { linezolid] } 15 \text { Antifitungals }\end{array}$ & $\begin{array}{l}\text { RT-PCR via throat } \\
\text { swab }\end{array}$ & 7 & $\begin{array}{l}\text { Six (6\%) of patients had } \\
\text { high procalcitonin levels. }\end{array}$ \\
\hline $\begin{array}{l}\text { Chen Tet al., } \\
\text { 2020 [25], } \\
\text { China }\end{array}$ & $\begin{array}{l}\text { Retrospective } \\
\text { case series, } \\
\text { single center }\end{array}$ & 203 & $17(8.4)$ & $\begin{array}{l}\text { Median } \\
\text { (IIR), } 54 \\
(20-91)\end{array}$ & $108(53.2)$ & $34(16.7)$ & $39(19.2)$ & $26(12.8)$ & $2(0.9)$ & - & $15(7.4)$ & 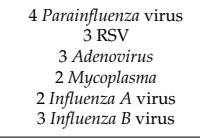 & Not reported & Unspecified & 7 & $\begin{array}{l}\text { Two mortality cases were } \\
\text { reported in co-inffected } \\
\text { patients. }\end{array}$ \\
\hline $\begin{array}{l}\text { Cheng L } \\
\text { etall, 2020 } \\
\text { [188), Hong } \\
\text { Kong }\end{array}$ & $\begin{array}{l}\text { Prospective } \\
\text { cohort, single } \\
\text { center }\end{array}$ & 147 & $12(8.2)$ & $\begin{array}{l}\text { Median } \\
\text { (IIRR), 49 } \\
(30-61)\end{array}$ & $9(75)$ & $1(8.3)$ & $\begin{array}{c}\text { Not } \\
\text { reported }\end{array}$ & 0 & $12(8.2)$ & - & - & $\begin{array}{l}\text { 3H. influenzae } \\
\text { 8 MSAA } \\
\text { 1 P. aeruginosa } \\
\text { 1 S. pneumoniae }\end{array}$ & $\begin{array}{c}46 \text { Penicillins \& } \\
\text { cephalosporins } \\
14 \text { Tetracycines } \\
3 \text { Fllorocyuninonones } \\
\text { 3 Macrolides }\end{array}$ & $\begin{array}{l}\text { RT-PCR of } \\
\text { respiratory tract } \\
\text { specimens AND } \\
\text { spuntumand blood } \\
\text { cultures }\end{array}$ & 6 & $\begin{array}{l}\text { Co-infected SARS-CoV-2-2 } \\
\text { patients had longer length } \\
\text { of hospitalization median: } \\
20 \text { tays vs.27 days, } \\
p=0.016) .\end{array}$ \\
\hline $\begin{array}{l}\text { Cheng Y } \\
\text { et al.,2021 } \\
{[10] \text {, China }}\end{array}$ & $\begin{array}{c}\text { Prospective } \\
\text { cohort, single } \\
\text { center }\end{array}$ & 213 & $97(45.5)$ & $\begin{array}{l}\text { Median } \\
\text { (IIRR), 61 } \\
(50-68)\end{array}$ & $47(48.5)$ & $\begin{array}{l}\text { Not } \\
\text { reported }\end{array}$ & $2(2.1)$ & $3(3.1)$ & - & - & $97(45.5)$ & 97 Influenza $A$ virus & Not reported & $\begin{array}{l}\text { Serum antibody test } \\
\text { (IgM) }\end{array}$ & 6 & $\begin{array}{l}\text { Similar symptoms and } \\
\text { clinical outcomes were seen } \\
\text { in the SARS-CoV-2 } \\
\text { co-infected group compared } \\
\text { to the SARS-Co-V-2 group } \\
\text { without co-infection. } \\
\text { Co-infection with Influenza } \\
A \text { virus had no effect on } \\
\text { disease outcome. } \\
\end{array}$ \\
\hline $\begin{array}{l}\text { Contou et al., } \\
\text { 2020 [51], } \\
\text { France }\end{array}$ & $\begin{array}{c}\begin{array}{c}\text { Prospective } \\
\text { cohort, single } \\
\text { center }\end{array} \\
\text { s. }\end{array}$ & 92 & $26(28)$ & $\begin{array}{l}\text { Median } \\
\text { (IIRR), 61 } \\
(55-70)\end{array}$ & $73(79)$ & $92(100)$ & $83(90)$ & $45(49)$ & $26(28)$ & - & - & 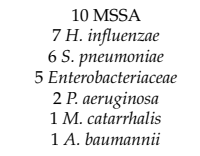 & $\begin{array}{l}14 \text { Third Generation } \\
\text { Cephalosporins } \\
14 \text { Beta-Lactam/Beta- } \\
\text { Lactamase Inhibitors } \\
6 \text { Beta-Lactams } \\
5 \text { Others antibiotics }\end{array}$ & $\begin{array}{c}\text { RT-PCR for } \\
\text { respiratory } \\
\text { specimens [viruses] } \\
\text { AND respiratory and } \\
\text { blood cultures } \\
\text { [bacteria and fungi] }\end{array}$ & 7 & $\begin{array}{l}\text { Resistance by co-pathogens } \\
\text { to 3rd generation } \\
\text { cephalosporin and to } \\
\text { amoxicilin-clavulanate } \\
\text { combination was observed } \\
\text { in } 8 \% \text { and } 21 \% \text {, respectively. }\end{array}$ \\
\hline
\end{tabular}


Table 1. Cont.

\begin{tabular}{|c|c|c|c|c|c|c|c|c|c|c|c|c|c|c|c|c|}
\hline $\begin{array}{l}\text { Author, Year, } \\
\text { Study } \\
\text { Location }\end{array}$ & $\begin{array}{l}\text { Study } \\
\text { Design, } \\
\text { Setting }\end{array}$ & $\begin{array}{c}\text { Number of } \\
\text { SARS-CVV-2 } \\
\text { Patients Tested for } \\
\text { Co-Pathogens, } \mathrm{n}\end{array}$ & $\begin{array}{c}\text { Co-Infected } \\
\text { Patients, n } \\
(\%)\end{array}$ & $\begin{array}{c}\text { Age } \\
\text { (Years) }\end{array}$ & $\underset{\substack{\text { Male, }, \mathrm{n} \\
(\%)}}{ }$ & $\begin{array}{l}\text { Admitted } \\
\text { to }[\mathrm{CU}, \mathrm{n} \\
(\%)\end{array}$ & $\begin{array}{l}\text { Mechanical } \\
\text { Ventilation, } \\
\text { n (\%) }\end{array}$ & $\begin{array}{l}\text { Deaths, } \mathrm{n} \\
(\%)\end{array}$ & $\begin{array}{l}\text { Bacterial } \\
\text { Co-Innection, } \\
\text { n }(\%)\end{array}$ & $\begin{array}{l}\text { Fungal } \\
\text { Co-Infection, } \\
\text { n (\%) }\end{array}$ & $\begin{array}{l}\text { Respiratory } \\
\text { Viral } \\
\text { Co-Infection, } \\
\mathbf{n}(\%)\end{array}$ & Total Organisms, $\mathbf{n}$ & Antimicrobials Use, $\mathbf{n}$ & $\begin{array}{l}\text { Laboratory } \\
\text { Techniques for } \\
\text { Co-Pathogen } \\
\text { Detection }\end{array}$ & $\begin{array}{l}\text { NOS } \\
\text { Score }\end{array}$ & Key Findings \\
\hline $\begin{array}{l}\text { Cuadrado- } \\
\text { Payán et al. } \\
\text { [111]. 2020, } \\
\text { Spain }\end{array}$ & $\begin{array}{l}\text { Retrospective } \\
\text { cass series, } \\
\text { single center }\end{array}$ & 4 & $4(100)$ & $\begin{array}{l}\text { Mean } \\
(\text { SDD, } 67 \\
(14.5)\end{array}$ & $3(75)$ & $3(75)$ & $3(75)$ & 0 & - & - & $4(100)$ & $\begin{array}{l}3 \text { Influenza } A \text { virus } \\
2 \text { Infuenza B virus }\end{array}$ & None & $\begin{array}{l}\text { RT-PCR for } \\
\text { respiratory } \\
\text { specimens }\end{array}$ & 7 & $\begin{array}{c}\text { Clinical courses in } \\
\text { co-infected SARS-CoV-2 } \\
\text { patients did not differ from } \\
\text { those previously reported. }\end{array}$ \\
\hline $\begin{array}{l}\text { De Francesco } \\
\text { et al, 2021 } \\
{[\text { [ब], Italy }}\end{array}$ & $\begin{array}{c}\text { Retrospective } \\
\text { cohort, } \\
\text { multi-center }\end{array}$ & 443 & 242 (54.6) & $\begin{array}{l}\text { Mean } \\
\text { (SD), 71 } \\
(19)\end{array}$ & $173(71.4)$ & $\begin{array}{l}\text { Not } \\
\text { reported }\end{array}$ & $16(6.8)$ & $\begin{array}{c}\text { Not } \\
\text { reported }\end{array}$ & $242(54.6)$ & & - & $\begin{array}{l}242 \text { C. pneumoniae } \\
63 \text { M. pnummoniae }\end{array}$ & 138 Macrolides & $\begin{array}{l}\text { Serum antibody test } \\
\text { (IgM, IgG) }\end{array}$ & 6 & 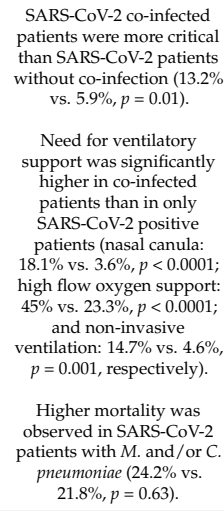 \\
\hline $\begin{array}{l}\text { Ding et al., } \\
2020[19], \\
\text { China }\end{array}$ & $\begin{array}{l}\text { Retrospective } \\
\text { case series, } \\
\text { single center }\end{array}$ & 115 & $5(4.3)$ & $\begin{array}{l}\text { Mean } \\
\text { (SD), } \\
50.20 \\
(9.83)\end{array}$ & $2(40)$ & 0 & 0 & 0 & - & - & $5(4.3)$ & $\begin{array}{l}\text { 3nfluenza } A \text { virus } \\
2 \text { Influenza B virus }\end{array}$ & $\begin{array}{l}\text { Five patients received } \\
\text { antibiotics; however, } \\
\text { agents were not } \\
\text { reported. }\end{array}$ & Influenza serology & 7 & $\begin{array}{l}\text { SARS-CoV-2 co-infected } \\
\text { patients did not show } \\
\text { severe disease compared to } \\
\text { SARS-Co-V-2 without } \\
\text { influenza co-infection } \\
\text { (similar laboratory results, } \\
\text { imaging, and prognosis). } \\
\text { Nasal blockade and } \\
\text { pharyngeal pain were more } \\
\text { in the SARS-Cov-2 } \\
\text { con-infected group. }\end{array}$ \\
\hline $\begin{array}{l}\text { Elhazmi } \\
\text { et al.,2021 } \\
\text { [8], Saudi } \\
\text { Arabia }\end{array}$ & $\begin{array}{l}\text { Retrospective } \\
\text { case series, } \\
\text { multi-center }\end{array}$ & 67 & $8(11.9)$ & $\begin{array}{l}\text { Mean } \\
\text { (SD), } 44.4 \\
\text { (11.8) }\end{array}$ & $6(75)$ & $67(100)$ & $7(87.5)$ & $3(37.5)$ & - & - & $8(11.9)$ & 8MERS-CoV & None & $\begin{array}{l}\text { RT-PCR for } \\
\text { respiratory } \\
\text { specimens }\end{array}$ & 7 & $\begin{array}{l}\text { Seven }(87.5 \%) \text { patients } \\
\text { were obese. }\end{array}$ \\
\hline $\begin{array}{l}\text { Garcia-Vidal } \\
\text { et al., 2021 } \\
{[7] \text {,Spain }}\end{array}$ & $\begin{array}{l}\text { Retrospective } \\
\text { cohort, single } \\
\text { center }\end{array}$ & 989 & $31(3.1)$ & $\begin{array}{l}\text { Median } \\
\text { (IVR), } 63 \\
(54.5-74)\end{array}$ & $18(58.1)$ & $8(25.8)$ & $\begin{array}{c}\text { Not } \\
\text { reported }\end{array}$ & $5(16.1)$ & $25(2.5)$ & & $7(0.7)$ & 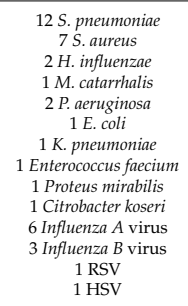 & $\begin{array}{l}26 \text { Macrolides } \\
24 \text { Third Generation } \\
\text { Cephalosporins } \\
2 \text { Fifth Generation } \\
\text { Cephalosporins }\end{array}$ & $\begin{array}{c}\text { RT-PCR for } \\
\text { respiratory } \\
\text { specimens [viruses] } \\
\text { AND blood, pleural } \\
\text { fluidss, pputum } \\
\text { cultures [bacteria and } \\
\text { fungi] }\end{array}$ & 7 & $\begin{array}{c}\text { Co-infection at COVID-19 } \\
\text { diagnosis is uncommon. } \\
\text { Worse clinical outcomes } \\
\text { were seen in SARS-CoV-2 } \\
\text { co-infected patients. }\end{array}$ \\
\hline $\begin{array}{l}\text { Gayam et al., } \\
2020[52], \\
\text { United States }\end{array}$ & $\begin{array}{l}\text { Retrospective } \\
\text { cohort, single } \\
\text { center }\end{array}$ & 350 & $6(1.7)$ & $\begin{array}{l}\text { Mean } \\
\text { (SD), } 57 \\
(10.6)\end{array}$ & $2(33.3)$ & $1(16.7)$ & $1(16.7)$ & $1(16.7)$ & $6(1.7)$ & - & & 6 M. pпеитопіiаe & $\begin{array}{l}\text { 6 Third Generation } \\
\text { Cephalosporins } \\
\text { 3 Macrolides } \\
\text { 3 Tetracyclines }\end{array}$ & $\begin{array}{l}\text { Serum antibody test } \\
(\mathrm{IgM}, \mathrm{IgG})\end{array}$ & 6 & $\begin{array}{l}\text { Only one patient }(16.7 \%) \\
\text { required IIU admission } \\
\text { and experienced organ } \\
\text { failure and death. }\end{array}$ \\
\hline
\end{tabular}


Table 1. Cont.

\begin{tabular}{|c|c|c|c|c|c|c|c|c|c|c|c|c|c|c|c|c|}
\hline $\begin{array}{l}\text { Author, Year, } \\
\text { Study } \\
\text { Location }\end{array}$ & $\begin{array}{l}\text { Study } \\
\text { Design, } \\
\text { Setting }\end{array}$ & $\begin{array}{c}\text { Number of } \\
\text { SARS-CVV-2 } \\
\text { Patients Tested for } \\
\text { Co-Pathogens, } \mathrm{n}\end{array}$ & $\begin{array}{l}\text { Co-Infected } \\
\text { Patients, } \\
(\%)\end{array}$ & $\begin{array}{c}\text { Age } \\
\text { (Years) }\end{array}$ & $\begin{array}{c}\text { Male, } \mathrm{n} \\
(\%)\end{array}$ & $\begin{array}{l}\text { Admitted } \\
\text { to } 1 C U, n, n \\
(\%)\end{array}$ & $\begin{array}{l}\text { Mechanical } \\
\text { Ventilation, } \\
\text { n (\%) }\end{array}$ & $\begin{array}{l}\text { Deaths, n } \\
(\%)\end{array}$ & $\begin{array}{l}\text { Bacterial } \\
\text { Co-Infection, } \\
\text { n }(\%)\end{array}$ & $\begin{array}{l}\begin{array}{c}\text { Fungal } \\
\text { Co-Infection, } \\
\mathrm{n}(\%)\end{array} \\
\text { n }\end{array}$ & $\begin{array}{l}\text { Respiratory } \\
\text { Viral } \\
\text { Co-Infection, } \\
\mathbf{n}(\%)\end{array}$ & Total Organisms, $\mathbf{n}$ & Antimicrobials Use, $\mathbf{n}$ & $\begin{array}{l}\text { Laboratory } \\
\text { Techniques for } \\
\text { Co-Pathogen } \\
\text { Detection }\end{array}$ & $\begin{array}{l}\text { NOS } \\
\text { Score }\end{array}$ & Key Findings \\
\hline $\begin{array}{l}\text { Hashemi } \\
\text { et al., } 2021 \\
\text { [121, Iran }\end{array}$ & $\begin{array}{c}\text { Retrospective } \\
\text { cohort, } \\
\text { multi-center }\end{array}$ & 105 dead patients & Not reported & $\begin{array}{l}\text { Range }(0) \\
\text { to }>60)\end{array}$ & $\begin{array}{c}\text { Males } \\
\text { were } \\
\text { females }\end{array}$ & $\begin{array}{c}\text { Not } \\
\text { reported }\end{array}$ & $\begin{array}{c}\text { Not } \\
\text { reported }\end{array}$ & $105(100)$ & - & - & $\begin{array}{l}\text { Not } \\
\text { reported }\end{array}$ & 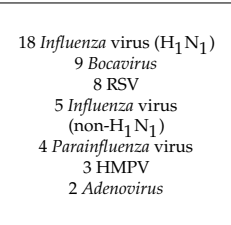 & Not reported & $\begin{array}{l}\text { RT-PCR for } \\
\text { respiratory } \\
\text { specimens }\end{array}$ & 5 & $\begin{array}{l}\text { Most of the co-infected } \\
\text { cases were men aged }>60 \\
\text { years, and had history of } \\
\text { obesity, cancer, hepatitis, } \\
\text { and kidney diseases. } \\
\text { Prevalence of SARS-CoV-2 } \\
\text { and inffunzzza } A \text { virus } \\
\text { co-infection in dead } \\
\text { patients was high. }\end{array}$ \\
\hline $\begin{array}{l}\text { Hazra et al., } \\
2020[53], \\
\text { United States }\end{array}$ & $\begin{array}{l}\text { Retrospective } \\
\text { cohort, single } \\
\text { center }\end{array}$ & 459 & $15(3.3)$ & $\begin{array}{l}\text { Median, } \\
39\end{array}$ & $\begin{array}{l}\text { Not } \\
\text { reported }\end{array}$ & $\begin{array}{l}\text { Not } \\
\text { reported }\end{array}$ & $\begin{array}{l}\text { Not } \\
\text { reported }\end{array}$ & $\begin{array}{l}\text { Not } \\
\text { reported }\end{array}$ & - & & $15(3.3)$ & $\begin{array}{c}2 \text { Adenovirus } \\
\text { 1 Coronavirus NL63 } \\
\text { 2 HMPV No3 } \\
\text { 3Ifluenza A virus } \\
\text { 1 Parainfluenza 2 virus } \\
\text { 8 Rhinovirus/Enterovirus }\end{array}$ & Not reported & $\begin{array}{l}\text { RT-PCR for } \\
\text { respiratory } \\
\text { specimens }\end{array}$ & 5 & $\begin{array}{c}\text { Co-infected patients were } \\
\text { youngere than those only } \\
\text { infected with SARS-CoV-2 } \\
\text { (age: } 39 \text { vs. } 58 \text { years, } \\
p=0.02) \text {. }\end{array}$ \\
\hline $\begin{array}{l}\text { Hughes et al., } \\
2020[26], \\
\text { United } \\
\text { Kingdom }\end{array}$ & $\begin{array}{l}\text { Retrospective } \\
\text { case series, } \\
\text { multi-center }\end{array}$ & 836 & $51(6.1)$ & $\begin{array}{l}\text { Median } \\
\text { (IIR), } 69 \\
(55-81)\end{array}$ & $519(62)$ & $3(5.9)$ & $\begin{array}{l}\text { Not } \\
\text { reported }\end{array}$ & $\begin{array}{c}\text { Not } \\
\text { reported }\end{array}$ & $51(6.1)$ & $30(3.6)$ & - & 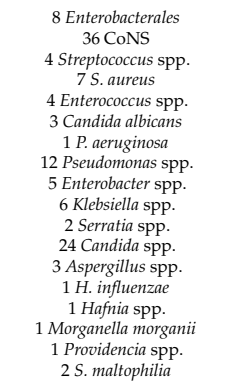 & Not reported & $\begin{array}{c}\text { RT-PCR for } \\
\text { respiratory } \\
\text { specimens [viruses] } \\
\text { AND blood, sputum, } \\
\text { and BAL cultures } \\
\text { [bacteria and fungi] }\end{array}$ & 6 & $\begin{array}{l}\text { Rate of bacterial } \\
\text { co-infection in ARRS-CoV-2 } \\
\text { patients in the early phase } \\
\text { of hospital admission } \\
\text { was low. }\end{array}$ \\
\hline $\begin{array}{l}\text { Karami et al., } \\
\text { 2020 [54], } \\
\text { The } \\
\text { Netherlands }\end{array}$ & $\begin{array}{c}\text { Retrospective } \\
\text { cohort, } \\
\text { multi-center }\end{array}$ & 925 & $12(1.2)$ & $\begin{array}{l}\text { Median } \\
\text { (IIR), 70 } \\
(59-77)\end{array}$ & $591(64)$ & $166(21.9)$ & $\begin{array}{c}\text { Not } \\
\text { reported }\end{array}$ & $214(23.3)$ & $12(1.2)$ & & $2(0.2)$ & 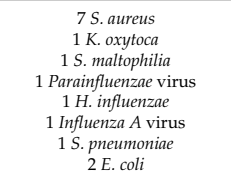 & No extractable data & $\begin{array}{l}\text { Blood and sputum } \\
\text { cultures [bacteria and } \\
\text { viruses] }\end{array}$ & 6 & $\begin{array}{l}\text { On presentation to the } \\
\text { hospital, bacterial } \\
\text { co-infections are rare. }\end{array}$ \\
\hline $\begin{array}{c}\text { Kim et al., } \\
2020 \text { (5l]! } \\
\text { United States }\end{array}$ & $\begin{array}{l}\text { Retrospective } \\
\text { cohort, single } \\
\text { center }\end{array}$ & 116 & $23(19.8)$ & $\begin{array}{c}\text { Median } \\
\text { (IQR), } \\
46.9 \\
(14-74)\end{array}$ & $12(52.2)$ & 0 & 0 & 0 & - & & $23(19.8)$ & 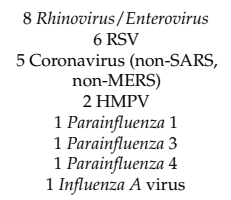 & Not reported & $\begin{array}{c}\text { RT-PCR via } \\
\text { nasopharyngeal } \\
\text { swab }\end{array}$ & 8 & $\begin{array}{l}\text { Patients with co-infections } \\
\text { did not differ significantly } \\
\text { in age (mean, } 46.9 \text { years) } \\
\text { from those infected with } \\
\text { SARS-Cov-2only (mean, } \\
\text { 51.1 years). }\end{array}$ \\
\hline $\begin{array}{l}\text { Koehler et al., } \\
2020[20], \\
\text { Germany }\end{array}$ & $\begin{array}{l}\text { Retrospective } \\
\text { case series, } \\
\text { single center }\end{array}$ & 19 & $5(26.3)$ & $\begin{array}{l}\text { Mean } \\
\text { (SD), } 62.6 \\
(8.8)\end{array}$ & $3(60)$ & $5(100)$ & $\begin{array}{c}\text { Not } \\
\text { reported }\end{array}$ & $3(60)$ & & $5(26.3)$ & $2(10.5)$ & $\begin{array}{c}2 \text { HMPV } \\
5 \text { Aspergillus fumigatus }\end{array}$ & 5 Antifungals & $\begin{array}{c}\text { RT-PCR for } \\
\text { respiratory } \\
\text { specimens [viruses] } \\
\text { AND GM detection } \\
\text { in the BAL and } \\
\text { tracheal aspirates }\end{array}$ & 6 & $\begin{array}{l}\text { Critical cases of } \\
\text { SARS-CoV-2 patients were } \\
\text { at risk of developing } \\
\text { aspergillosis co-infection } \\
\text { and had higher mortality. }\end{array}$ \\
\hline $\begin{array}{l}\text { Kreitmann } \\
\text { et al, 2020 } \\
{[56] \text {, France }}\end{array}$ & $\begin{array}{l}\text { Prospectivecohort, } \\
\text { single center }\end{array}$ & 47 & $13(27.6)$ & $\begin{array}{l}\text { Median } \\
\text { (IIR), } 61 \\
(56-74)\end{array}$ & $25(73.5)$ & $47(100)$ & $\begin{array}{l}\text { Not } \\
\text { reported }\end{array}$ & $5(35.8)$ & $13(27.6)$ & & - & $\begin{array}{c}\text { 9S. aureus } \\
\text { 5H. influenzae } \\
\text { 3S. phenumoniae } \\
\text { 1 M. catartralis } \\
\text { 1 Streptococus agalactiae }\end{array}$ & $\begin{array}{l}4 \text { Third Generation } \\
\text { Cephalosporins } \\
\text { 2 Macrolides } \\
\text { 30ther antibiotitics }\end{array}$ & $\begin{array}{c}\text { RT-PCR for } \\
\text { respiratory } \\
\text { specimens and/or } \\
\text { cultures }\end{array}$ & 6 & $\begin{array}{l}\text { Authors argue for initial } \\
\text { empirical antibiotic } \\
\text { coverage in } \\
\text { SARS-CoV-2 patients. }\end{array}$ \\
\hline
\end{tabular}


Table 1. Cont.

\begin{tabular}{|c|c|c|c|c|c|c|c|c|c|c|c|c|c|c|c|c|}
\hline $\begin{array}{l}\text { Author, Year, } \\
\text { Study , } \\
\text { Location }\end{array}$ & $\begin{array}{l}\text { Study } \\
\text { Design, } \\
\text { Setting }\end{array}$ & $\begin{array}{c}\text { Number of } \\
\text { SARS-CoV-2 } \\
\text { PAatients Tested for } \\
\text { Co-Pathogens, } \mathrm{n} \\
\end{array}$ & $\begin{array}{l}\text { Co-Infected } \\
\text { Patients, n } \\
(\%)\end{array}$ & $\begin{array}{c}\text { Age } \\
\text { (Years) }\end{array}$ & $\underset{(\%)}{\text { Male, } \mathrm{n}}$ & $\begin{array}{c}\text { Admitted } \\
\text { to mICU, } \\
(\%)\end{array}$ & $\begin{array}{c}\text { Mechanical } \\
\text { Ventilation, } \\
\mathrm{n}(\%)\end{array}$ & $\begin{array}{c}\text { Deaths, } \mathrm{n} \\
(\%)\end{array}$ & $\begin{array}{l}\text { Bacterial } \\
\text { Co-Infection, } \\
\text { n (\%) }\end{array}$ & $\begin{array}{l}\text { Fungal } \\
\text { Co-Infection, } \\
\text { n (\%) }\end{array}$ & $\begin{array}{l}\text { Respiratory } \\
\text { Viral } \\
\text { Co-Infection, } \\
\text { n (\%) } \\
\end{array}$ & Total Organisms, $\mathbf{n}$ & Antimicrobials Use, $\mathrm{n}$ & $\begin{array}{c}\text { Laboratory } \\
\text { Techniques for } \\
\text { Co-Pathogen } \\
\text { Detection } \\
\end{array}$ & $\begin{array}{l}\text { NOS } \\
\text { Score }\end{array}$ & Key Findings \\
\hline $\begin{array}{c}\text { Lehmann } \\
\text { etal, 2020 } \\
{[5] \text {, Unitited }} \\
\text { States }\end{array}$ & $\begin{array}{l}\text { Retrospective } \\
\text { cohort, single } \\
\text { center }\end{array}$ & 321 & $12(3.7)$ & $\begin{array}{c}\text { Mean } \\
\text { (SD), } 60 \\
(17)\end{array}$ & $155(48)$ & $17(5)$ & $\begin{array}{c}\text { Not } \\
\text { reported }\end{array}$ & $22(7)$ & $7(2.2)$ & - & $5(1.5)$ & 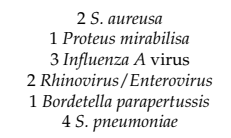 & $\begin{array}{l}\text { Antibiotic use was high } \\
(222[69 \%]) ; \text { however, } \\
\text { agents were not } \\
\text { reported. }\end{array}$ & $\begin{array}{c}\text { RT-PCR for } \\
\text { respiratory } \\
\text { specimens and } \\
\text { cultures }\end{array}$ & 7 & $\begin{array}{l}\text { Community-acquired } \\
\text { co-infection in COVIID-19i } \mathrm{i} \\
\text { infrequent and often viral } \\
\text { Co-infection was more } \\
\text { common among } \\
\text { ICU patients. }\end{array}$ \\
\hline $\begin{array}{l}\text { Li Y et al., } \\
2021 \text { [27], } \\
\text { China }\end{array}$ & $\begin{array}{c}\text { Retrospective } \\
\text { case series, } \\
\text { single center }\end{array}$ & 81 & $27(33.3)$ & $\begin{array}{l}\text { Mean } \\
\text { (SD), } \\
76.55 \\
(9.64)\end{array}$ & $15(55.6)$ & $1(3.7)$ & $1(3.7)$ & 0 & $27(33.3)$ & - & $6(7.4)$ & 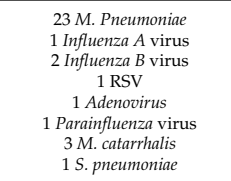 & No extractable data & $\begin{array}{c}\text { Direct } \\
\text { immunofluorescence } \\
\text { test AND serum } \\
\text { antibody test (IgM) }\end{array}$ & 7 & $\begin{array}{l}\text { Almost } 1 / 3(33.3 \%) \text { had } \\
\text { co-infection. } \\
\text { Coinfection did not cause } \\
\text { significant exacerbation in } \\
\text { clinical symptoms. }\end{array}$ \\
\hline $\begin{array}{l}\text { Li Z et al., } \\
\text { 2020 [28], } \\
\text { China }\end{array}$ & $\begin{array}{l}\text { Retrospective } \\
\text { case series, } \\
\text { multi- center }\end{array}$ & 32 & $14(43.7)$ & $\begin{array}{l}\text { Median } \\
\text { (IRR), } 57 \\
(47-69)\end{array}$ & $11(78.6)$ & $11(78.6)$ & $4(28.6)$ & $\begin{array}{c}\text { Not } \\
\text { reported }\end{array}$ & $10(31.2)$ & $7(21.9)$ & $5(15.6)$ & 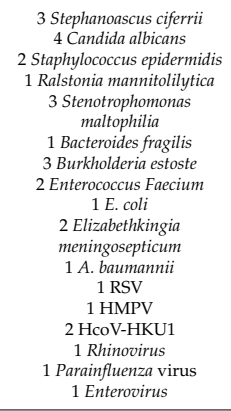 & Not reported & RT-PCR AND cultres & 6 & 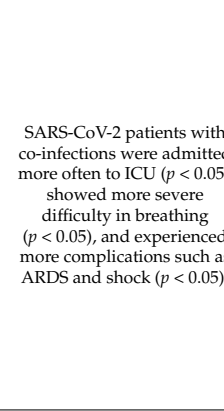 \\
\hline $\begin{array}{l}\text { Lin et al., } \\
\text { 2020 [29], } \\
\text { China }\end{array}$ & $\begin{array}{c}\text { Retrospective } \\
\text { case series, } \\
\text { single center }\end{array}$ & 92 & $6(6.5)$ & $\begin{array}{l}\text { Majority } \\
\approx 78 \% \text { ) } \\
\text { were in } \\
\text { the range } \\
(18-65)\end{array}$ & 1:1 ratio & $\begin{array}{c}\text { Not } \\
\text { reported }\end{array}$ & $\begin{array}{c}\text { Not } \\
\text { reported }\end{array}$ & $\begin{array}{c}\text { Not } \\
\text { reported }\end{array}$ & - & - & $6(6.5)$ & $\begin{array}{c}\text { 3RSV } \\
2 \text { Rhinovirus } \\
2 \text { HMP } \\
1 \text { Parainffluenza 2 virus } \\
2 \text { HcoV-HKU1 }\end{array}$ & Not reported & $\begin{array}{c}\text { RT-PCR of } \\
\text { respiratory tract } \\
\text { specimens (nas-o-vs. } \\
\text { oropharngeal } \\
\text { source not specified) }\end{array}$ & 7 & $\begin{array}{l}\text { Limitation of the sensitivit } \\
\text { of method for the differen } \\
\text { respiratory viruses and lon } \\
\text { load of virus in specimens } \\
\text { might have contributed to } \\
\text { negative results. }\end{array}$ \\
\hline $\begin{array}{l}\text { Liu Het al., } \\
2020 \text { [300], } \\
\text { China }\end{array}$ & $\begin{array}{c}\text { Retrospective } \\
\text { case series, } \\
\text { multi-center }\end{array}$ & 4 & $2(50)$ & $\begin{array}{l}\text { Range ( } 2 \\
\text { months to } \\
9 \text { years) }\end{array}$ & 1:1 ratio & 0 & 0 & 0 & $1(25)$ & - & $1(25)$ & $\begin{array}{l}\text { 1.M. pneumoniae } \\
1 \mathrm{RSV}\end{array}$ & Not reported & Unspecified & 6 & $\begin{array}{l}\text { Pulmonary involvement } \\
\text { was more severe, as } \\
\text { simultaneous infection of } \\
\text { RSV and SARSS-COV-2 in } \\
\text { one child was detected. }\end{array}$ \\
\hline $\begin{array}{l}\text { Liu Let al, } \\
2020[31], \\
\text { China }\end{array}$ & $\begin{array}{l}\text { Retrospective } \\
\text { case series, } \\
\text { single center }\end{array}$ & 53 & $31(58.5)$ & $\begin{array}{l}\text { Median } \\
\text { (IRR), 38 } \\
(28-47)\end{array}$ & $26(49)$ & $1(1.9)$ & $1(1.9)$ & 0 & $25(47.2)$ & - & $6(11.3)$ & $\begin{array}{c}25 \text { M. pneumoniae } \\
2 \text { Influenza A virus } \\
2 \text { Influenza B } \operatorname{Birus} \\
2 \mathrm{RSV}\end{array}$ & 25 Fluoroquinolones & $\begin{array}{c}\text { Serum antibody test } \\
\text { (IgM, IgG) }\end{array}$ & 6 & $\begin{array}{c}\text { COVID-19 patients } \\
\text { co-infected with } M \text {. } \\
\text { preummoniah had a higher } \\
\text { percentage of monocytes }( \\
<0.0044) \text { and a lower } \\
\text { neutrophils percentage } \\
(p<0.0264) .\end{array}$ \\
\hline $\begin{array}{l}\text { Ma et al., } \\
2020[32], \\
\text { China }\end{array}$ & $\begin{array}{c}\text { Retrospective } \\
\text { case series, } \\
\text { single center }\end{array}$ & 93 & $46(49.5)$ & $\begin{array}{l}\text { Median } \\
\text { (IRR), 67 } \\
(54-72)\end{array}$ & $51(54.8)$ & $\begin{array}{l}\text { Not } \\
\text { reported }\end{array}$ & $\begin{array}{c}\text { Not } \\
\text { reported }\end{array}$ & $44(47.3)$ & - & - & $46(49.5)$ & $\begin{array}{l}44 \text { Influenza } A \text { virus } \\
2 \text { Influenza B virus } \\
\text { Aderovirus } \\
1 \text { Parainfluenza virus }\end{array}$ & Not reported & $\begin{array}{c}\text { Serum antibody test } \\
(\lg ) \text { (g) }\end{array}$ & 6 & $\begin{array}{l}\text { Critically ill COVID-19 } \\
\text { patients with influenza wer } \\
\text { more prone to cardiac } \\
\text { injury than those without } \\
\text { influenzan.Critically ill } \\
\text { COVVID-19 patients with } \\
\text { influenza exhibited more } \\
\text { severe inflammation and } \\
\text { organ injury. }\end{array}$ \\
\hline
\end{tabular}


Table 1. Cont.

\begin{tabular}{|c|c|c|c|c|c|c|c|c|c|c|c|c|c|c|c|c|}
\hline $\begin{array}{l}\text { Author, Year, } \\
\text { Study } \\
\text { Location }\end{array}$ & $\begin{array}{l}\text { Study } \\
\text { Design, } \\
\text { Setting }\end{array}$ & $\begin{array}{c}\text { Number of } \\
\text { SARS-Cov-2 } \\
\text { Patients Tested for } \\
\text { Co-Pathogens, } \mathrm{n}\end{array}$ & $\begin{array}{l}\text { Co-Infected } \\
\text { Patients, } \\
(\%)\end{array}$ & $\begin{array}{c}\text { Age } \\
\text { (Years) }\end{array}$ & $\underset{(\%)}{\text { Male, },}$ & $\begin{array}{l}\text { Admitted } \\
\text { to ICU, n } \\
(\%)\end{array}$ & $\begin{array}{l}\text { Mechanical } \\
\text { Ventitation, } \\
\text { n } \% \text { ) }\end{array}$ & $\begin{array}{l}\text { Deaths, } n \\
(\%)\end{array}$ & $\begin{array}{l}\text { Bacterial } \\
\text { Co-Innection, } \\
\text { n (\%) }\end{array}$ & $\begin{array}{l}\text { Fungal } \\
\text { Co-Infection, } \\
\text { n }(\%)\end{array}$ & $\begin{array}{l}\text { Respiratory } \\
\text { Viral } \\
\text { Co-Infection, } \\
\mathbf{n}(\%)\end{array}$ & Total Organisms, $\mathbf{n}$ & Antimicrobials Use, $\mathbf{n}$ & $\begin{array}{l}\text { Laboratory } \\
\text { Techniques for } \\
\text { Co-Pathogen } \\
\text { Detection }\end{array}$ & $\begin{array}{l}\text { NOS } \\
\text { Score }\end{array}$ & Key Findings \\
\hline $\begin{array}{l}\text { Mannheim } \\
\text { et al, 2020 } \\
\text { [33], United } \\
\text { States }\end{array}$ & $\begin{array}{l}\text { Retrospective } \\
\text { cases series, } \\
\text { multi-center }\end{array}$ & 10 & $4(40)$ & $\begin{array}{l}\text { Median } \\
\text { (IQR), 11 } \\
(7-16)\end{array}$ & $\begin{array}{c}\text { Males } \\
\text { were } \\
\text { females }\end{array}$ & $7(70)$ & $\begin{array}{l}\text { Not } \\
\text { reported }\end{array}$ & 0 & $2(20)$ & - & $3(30)$ & 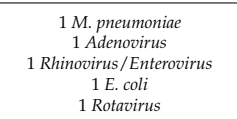 & Not reported & $\begin{array}{l}\text { RT-PCR for } \\
\text { respiratory } \\
\text { specimens }\end{array}$ & 6 & $\begin{array}{l}\text { Underlying co-infection } \\
\text { might have contributed to } \\
\text { severe disease. }\end{array}$ \\
\hline $\begin{array}{l}\text { Massey et al., } \\
2020[58], \\
\text { United States }\end{array}$ & $\begin{array}{c}\text { Retrospective } \\
\text { cohort, } \\
\text { multi-center }\end{array}$ & 1456 & Not reported & $\begin{array}{l}\text { Mean } \\
\text { (SD), } 72.4 \\
\text { (20.9) }\end{array}$ & $\begin{array}{l}\text { Not } \\
\text { reported }\end{array}$ & $\begin{array}{l}\text { Not } \\
\text { reported }\end{array}$ & $\begin{array}{l}\text { Not } \\
\text { reported }\end{array}$ & $\begin{array}{l}\text { Not } \\
\text { reported }\end{array}$ & $\begin{array}{l}\text { Not } \\
\text { reported }\end{array}$ & - & $\begin{array}{l}\text { Not } \\
\text { reported }\end{array}$ & $\begin{array}{c}937 \text { S. aureus } \\
576 \text { EBV } \\
577 \mathrm{HHV} 6 \\
328 \mathrm{M} \text {. catarhalis } \\
64 \mathrm{~K} \text {. pneumoniae } \\
305 \mathrm{HMPV} 109 \text { Adenovirus }\end{array}$ & Not reported & $\begin{array}{l}\text { RT-PCR for } \\
\text { respiratory } \\
\text { specimens }\end{array}$ & 6 & $\begin{array}{l}\text { Advanced age and nursing } \\
\text { home status were } \\
\text { associated with higher } \\
\text { co-infection rates in } \\
\text { SARS-CoV-2 patients. } \\
\text { In SARS-CoV-2 patients, } \\
86.3 \% \text { had at least one } \\
\text { co-infection compared to } \\
75.7 \% \text { in the negatitive } \\
\text { SARS-CoV-2 group } \\
(p<0.0001) \text {. }\end{array}$ \\
\hline $\begin{array}{l}\text { May et al., } \\
2021[3], \\
\text { United } \\
\text { Kingdom }\end{array}$ & $\begin{array}{l}\text { Retrospective } \\
\text { cohort, single } \\
\text { center }\end{array}$ & 77 & $39(50.6)$ & $\begin{array}{l}\text { Not } \\
\text { reported }\end{array}$ & $\begin{array}{l}\text { Not } \\
\text { reported }\end{array}$ & $39(100)$ & $\begin{array}{l}\text { Not } \\
\text { reported }\end{array}$ & $\begin{array}{l}\text { Not } \\
\text { reported }\end{array}$ & $28(36.4)$ & $11(14.3)$ & - & 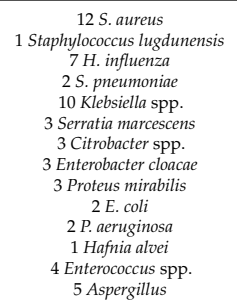 & Not reported & Unspecified & 5 & $\begin{array}{l}\text { There was no significicant } \\
\text { correlation between } \\
\text { hospitial mortality and } \\
\text { isolation of a pathogen in } \\
\text { early or any respiritatory } \\
\text { sample }(p=0.512 \text { and } \\
p=1.0, \text { respectively). }\end{array}$ \\
\hline $\begin{array}{l}\text { Mo et al,, } \\
2020 \text { [81], } \\
\text { China }\end{array}$ & $\begin{array}{l}\text { Retrospective } \\
\text { cohort, single } \\
\text { center }\end{array}$ & 155 & $12(7.7)$ & $\begin{array}{l}\text { Median } \\
\text { (IIR), } 54 \\
(42-66)\end{array}$ & $86(55.5)$ & $37(23.9)$ & $36(23.2)$ & $22(14.2)$ & $2(1.3)$ & - & $13(8.4)$ & 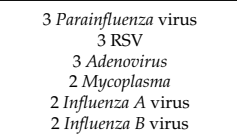 & Not reported & Unspecified & 5 & $\begin{array}{l}\text { COVID-19 patients were } \\
\text { divided into general and } \\
\text { refractory groups. }\end{array}$ \\
\hline $\begin{array}{l}\text { Nasir et al., } \\
2020 \text { [34], } \\
\text { Pakitstan }\end{array}$ & $\begin{array}{l}\text { Retrospective } \\
\text { case series, } \\
\text { single center }\end{array}$ & 23 & $9(39.1)$ & $\begin{array}{l}\text { Median } \\
\text { (IOR), } 71 \\
(51-85)\end{array}$ & $7(77.8)$ & $23(100)$ & $2(22.2)$ & $4(17.4)$ & $9(39.1)$ & $5(21.7)$ & - & 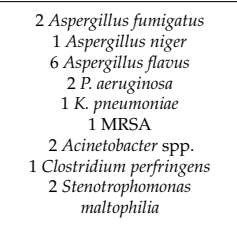 & $\begin{array}{l}7 \text { Macrolides } 5 \\
\text { Antifungals }\end{array}$ & $\begin{array}{l}\text { Culture from } \\
\text { respiratory } \\
\text { specimens and GM } \\
\text { detection in the BAL, } \\
\text { tracheal aspirates } \\
\text { and serum }\end{array}$ & 6 & $\begin{array}{l}\text { Invasive aspergillosis is a } \\
\text { complication in moderate to to } \\
\text { severe COVID-19 patients. }\end{array}$ \\
\hline $\begin{array}{l}\text { Nowak et al., } \\
2020 \text { [59], } \\
\text { United States }\end{array}$ & $\begin{array}{c}\text { Retrospective } \\
\text { cohort, } \\
\text { multi-center }\end{array}$ & $\begin{array}{l}1204 \\
1270 \\
1103 \\
1103 \\
1103 \\
1103\end{array}$ & $\begin{array}{l}1(0.1) \\
4(0.3) \\
17(1.5) \\
8(0.7) \\
4(0.4) \\
2(0.2)\end{array}$ & $\begin{array}{l}\text { Mean, } \\
60.1\end{array}$ & $16(44)$ & $\begin{array}{l}\text { Not } \\
\text { reported }\end{array}$ & $\begin{array}{l}\text { Not } \\
\text { reported }\end{array}$ & $\begin{array}{l}\text { Not } \\
\text { reported }\end{array}$ & - & - & $36(2.8)$ & 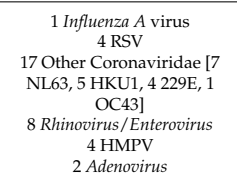 & Not reported & $\begin{array}{l}\text { RT-PCR for } \\
\text { respiratory } \\
\text { specimens }\end{array}$ & 6 & $\begin{array}{l}\text { Study hypothesized that } \\
\text { competitive advantage may } \\
\text { play arole in the } \\
\text { SARS-Co-V-2 interaction } \\
\text { with other respiratory } \\
\text { viruses during co-infection. }\end{array}$ \\
\hline
\end{tabular}


Table 1. Cont.

\begin{tabular}{|c|c|c|c|c|c|c|c|c|c|c|c|c|c|c|c|c|}
\hline $\begin{array}{l}\text { Author, Year, } \\
\text { Study } \\
\text { Location }\end{array}$ & $\begin{array}{c}\text { Study } \\
\text { Design, } \\
\text { Setting }\end{array}$ & $\begin{array}{c}\text { Number of } \\
\text { SARSS-CoV-2 } \\
\text { Patients Tested for } \\
\text { Co-Pathogens, } n\end{array}$ & $\begin{array}{l}\text { Co-Infected } \\
\text { Patients, } \\
(\%)\end{array}$ & $\begin{array}{c}\text { Age } \\
\text { (Years) }\end{array}$ & $\underset{\substack{\text { Male, }, \mathrm{n} \\
(\%)}}{ }$ & $\begin{array}{l}\text { Admitted } \\
\text { to ICU, n } \\
(\%)\end{array}$ & $\begin{array}{l}\text { Mechanical } \\
\text { Ventilation, } \\
\text { n }(\%)\end{array}$ & $\begin{array}{l}\text { Deaths, n } \\
(\%)\end{array}$ & $\begin{array}{l}\text { Bacterial } \\
\text { Co-Infection, } \\
\text { n ( } \%)\end{array}$ & $\begin{array}{c}\text { Fungal } \\
\text { Co-Infection, } \\
\text { n }(\%)\end{array}$ & $\begin{array}{l}\text { Respiratory } \\
\text { Viral } \\
\text { Co-Infection, } \\
\text { n (\%) }\end{array}$ & Total Organisms, $\mathbf{n}$ & Antimicrobials Use, $\mathbf{n}$ & $\begin{array}{l}\text { Laboratory } \\
\text { Techniques for } \\
\text { Co-Pathogen } \\
\text { Detection } \\
\end{array}$ & $\begin{array}{l}\text { NOS } \\
\text { Score }\end{array}$ & Key Findings \\
\hline $\begin{array}{l}\text { Oliva et al., } \\
2020 \text { [35], } \\
\text { Italy }\end{array}$ & $\begin{array}{l}\text { Retrospective } \\
\text { case series, } \\
\text { single center }\end{array}$ & 182 & $7(3.8)$ & $\begin{array}{l}\text { Median } \\
\text { (IIR) } 73 \\
(45-79)\end{array}$ & $4(57.1)$ & $1(14.3)$ & $\begin{array}{l}\text { Not } \\
\text { reported }\end{array}$ & 0 & $7(3.8)$ & - & - & $\begin{array}{l}5 \text { C. pneumoniae } \\
2 \mathrm{M} \text {. pneumoniae }\end{array}$ & $\begin{array}{c}7 \text { Macrolides } \\
1 \text { Teicoplanin } \\
1 \text { Beta-Lactam/Beta- } \\
\text { Lactamase Inhibitors } \\
1 \text { Third Generation } \\
\text { Cephalosporins }\end{array}$ & $\begin{array}{l}\text { Serum antibody test } \\
\text { (IgM) }\end{array}$ & 6 & 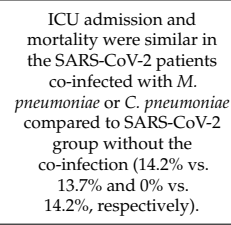 \\
\hline $\begin{array}{l}\text { Ozaras et al., } \\
\text { 2020 } 0 \text { 660], } \\
\text { Turkey }\end{array}$ & $\begin{array}{c}\text { Retrospective } \\
\text { cohort } \\
\text { multi-center }\end{array}$ & 1103 & $6(0.54)$ & $\begin{array}{c}\text { Mean } \\
\text { (SD), } 40.5 \\
(14) \\
\end{array}$ & $3(50)$ & 0 & 0 & 0 & - & - & $6(0.5)$ & $\begin{array}{l}2 \text { Influenza } A \text { virus } \\
4 \operatorname{Influenza} B \text { virus }\end{array}$ & 6 Macrolides & $\begin{array}{l}\text { Direct immunofluo- } \\
\text { rescence test }\end{array}$ & 6 & $\begin{array}{l}\text { Cases reported in this study } \\
\text { were mild to moderate } \\
\text { in severity. }\end{array}$ \\
\hline $\begin{array}{l}\text { Peng et al., } \\
\text { 2020 [36], } \\
\text { China }\end{array}$ & $\begin{array}{l}\text { Retrospective } \\
\text { case series, } \\
\text { single center }\end{array}$ & 75 & $42(56)$ & $\begin{array}{c}\text { Mean } \\
\text { (range), } \\
6.06 \text { years } \\
\text { (1 month- } \\
15 \text { years) }\end{array}$ & $44(58.67)$ & $\begin{array}{c}\text { Not } \\
\text { reported }\end{array}$ & $\begin{array}{c}\text { Not } \\
\text { reported }\end{array}$ & 0 & $31(41.3)$ & & $8(10.7)$ & 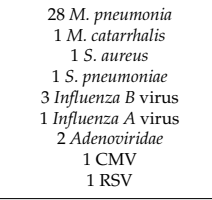 & $\begin{array}{l}30 \text { Macrolides } \\
\text { Thirty-seven patients } \\
\text { received antibiotics; } \\
\text { however, agents were } \\
\text { not reported. }\end{array}$ & $\begin{array}{c}\text { Serum antibody test } \\
(\operatorname{IgM})\end{array}$ & 6 & $\begin{array}{l}\text { Co-infection never } \\
\text { increased patients' length of of } \\
\text { stay or decreased time of } \\
\text { SARS-Cov-2 of } \\
\text { virological clearance. }\end{array}$ \\
\hline $\begin{array}{l}\text { Pongpirul } \\
\text { et al, 2020 } \\
{[37],} \\
\text { Thailand }\end{array}$ & $\begin{array}{l}\text { Retrospective } \\
\text { case series, } \\
\text { multi-center }\end{array}$ & 11 & $11(100)$ & $\begin{array}{l}\text { Median } \\
\text { (IIR), 61 } \\
(28-74)\end{array}$ & $6(54.5)$ & 0 & 0 & 0 & $5(45.4)$ & - & $2(18.2)$ & $\begin{array}{l}\text { 4H. influenzae } \\
1 \text { Adenovirus } \\
1 \text { Influezza A virus } \\
1 \text { K. pneumoniae }\end{array}$ & $\begin{array}{c}5 \text { Third Generation } \\
\text { Cephalosporins } \\
2 \text { Beta-Lactam/Beta- } \\
\text { Lactamase } \\
\text { Inhibitors } \\
\end{array}$ & $\begin{array}{c}\text { RT-PCR via } \\
\text { nasopharyngeal and } \\
\text { oropharyngeal swabs } \\
\text { and sputum } \\
\text { specimens } \\
\end{array}$ & 8 & $\begin{array}{l}\text { Nasopharyngeal and } \\
\text { oropharnygeal swabs and } \\
\text { sputum specimens were } \\
\text { also tested for } 33 \\
\text { respiratory pathogens. }\end{array}$ \\
\hline $\begin{array}{l}\text { Ramadan } \\
\text { etal.,2020 } \\
\text { [21], Egypt }\end{array}$ & $\begin{array}{l}\text { Prospective } \\
\text { cohort, multi- } \\
\text { center }\end{array}$ & 260 & $28(10.8)$ & $\begin{array}{c}\text { Most } \\
\text { common } \\
\text { age range } \\
\text { was } \\
\text { between } \\
51 \text { and } 70 \\
\text { years } \\
(36.2 \%)\end{array}$ & $144(55.4)$ & $60(23)$ & $8(13.3)$ & $24(40)$ & $28(10.8)$ & $5(1.9)$ & - & 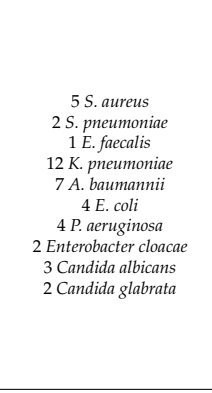 & 28 Macrolides & $\begin{array}{l}\text { Respiratory and } \\
\text { blood cultures }\end{array}$ & 7 & 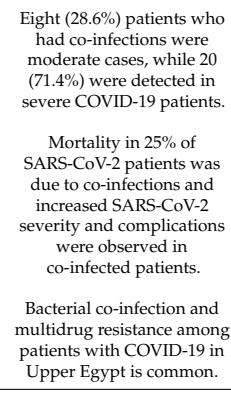 \\
\hline $\begin{array}{l}\text { Richardson } \\
\text { et al, 2020 } \\
\text { [38], United } \\
\text { States }\end{array}$ & $\begin{array}{l}\text { Retrospective } \\
\text { case series, } \\
\text { multi-center }\end{array}$ & 1996 & $42(2.1)$ & $\begin{array}{c}\text { Not } \\
\text { reported }\end{array}$ & $\begin{array}{l}\text { Not } \\
\text { reported }\end{array}$ & $\begin{array}{l}\text { Not } \\
\text { reported }\end{array}$ & $\begin{array}{c}\text { Not } \\
\text { reported }\end{array}$ & $\begin{array}{c}\text { Not } \\
\text { reported }\end{array}$ & $\begin{array}{l}\text { Not } \\
\text { reported }\end{array}$ & - & $\begin{array}{c}\text { Not } \\
\text { reported }\end{array}$ & $\begin{array}{c}22 \text { Enteroovirus/Rhinovirus } \\
7 \text { Coronavirus } \\
\text { (non-COVID-19) } \\
4 \text { RSV } \\
3 \text { Parainfluenza } 3 \\
\text { 2. preumoniae } \\
2 \mathrm{HMPV} \\
1 \text { Inffuenza A virus } \\
1 \text { M. pneumoniae } \\
\end{array}$ & Not reported & $\begin{array}{c}\text { Respiratory viral } \\
\text { panel }\end{array}$ & 8 & $\begin{array}{l}\text { Most patients were obese } \\
\text { (60.7\% had a BMI } 303) \text { and } \\
\text { old (median (IIQR): } 63 \\
(52-75)) .\end{array}$ \\
\hline $\begin{array}{c}\text { Rutsaert } \\
\text { et al, 2020 } \\
\text { [39], Belgium }\end{array}$ & $\begin{array}{l}\text { Retrospective } \\
\text { case series, } \\
\text { single center }\end{array}$ & 34 & $6(17.6)$ & $\begin{array}{l}\text { Median } \\
\text { (IIR), } 74 \\
\text { (38-86) }\end{array}$ & $6(100)$ & $6(100)$ & $6(100)$ & $4(66.7)$ & - & $6(17.6)$ & - & $\begin{array}{l}5 \text { Aspergillus fumigatus } \\
1 \text { Aspergillus flavus }\end{array}$ & 5 Antifungals & $\begin{array}{c}\text { Culture from } \\
\text { respiratory } \\
\text { specimens and GM } \\
\text { detection in the BAL } \\
\text { and serum }\end{array}$ & 6 & $\begin{array}{l}\text { Patients were old and had } \\
\text { deteriorating outcomes due } \\
\text { to many medical conditions } \\
\text { and risc factors. }\end{array}$ \\
\hline
\end{tabular}


Table 1. Cont.

\begin{tabular}{|c|c|c|c|c|c|c|c|c|c|c|c|c|c|c|c|c|}
\hline $\begin{array}{l}\text { Author, Year, } \\
\text { Study } \\
\text { Location }\end{array}$ & $\begin{array}{l}\text { Study } \\
\text { Design, } \\
\text { Setting }\end{array}$ & $\begin{array}{c}\text { Number of } \\
\text { SARS-Cov-2 } \\
\text { Patients Tested for } \\
\text { Co-Pathogens, } \mathrm{n}\end{array}$ & $\begin{array}{c}\text { Co-Infected } \\
\text { Patients, n } \\
(\%)\end{array}$ & $\begin{array}{c}\mathrm{Age} \\
\text { (Years) }\end{array}$ & $\underset{(\%)}{\text { Male, }}$ & $\begin{array}{l}\text { Admitted } \\
\text { to IIU, } \mathrm{n} \\
(\%)\end{array}$ & $\begin{array}{l}\text { Mechanical } \\
\text { Ventilation, } \\
n(\%)\end{array}$ & 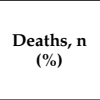 & $\begin{array}{l}\text { Bacterial } \\
\text { Co-rnfection, } \\
\mathrm{n}(\%)\end{array}$ & $\begin{array}{l}\text { Fungal } \\
\text { Co-Infection, } \\
\text { n ( } \%)\end{array}$ & $\begin{array}{l}\text { Respiratory } \\
\text { Viral } \\
\text { Co-Infection, } \\
\mathrm{n}(\%)\end{array}$ & Total Organisms, $\mathrm{n}$ & Antimicrobials Use, $\mathbf{n}$ & $\begin{array}{l}\text { Laboratory } \\
\text { Techniques for } \\
\text { Co-Pathogen } \\
\text { Detection }\end{array}$ & $\begin{array}{l}\text { NOS } \\
\text { Score }\end{array}$ & Key Findings \\
\hline $\begin{array}{c}\text { Schirmer } \\
\text { et al, } 2021 \\
\text { [13], United } \\
\text { States }\end{array}$ & $\begin{array}{c}\text { Retrospective } \\
\text { cohort, } \\
\text { multi-center }\end{array}$ & 3757 & $56(1.5)$ & $\begin{array}{l}\text { Median } \\
\text { (IRR), } 68 \\
(56-74)\end{array}$ & $55(98)$ & $10(26)$ & $\begin{array}{c}\text { Not } \\
\text { reported }\end{array}$ & $10(18)$ & $1(0.03)$ & - & $55(1.5)$ & 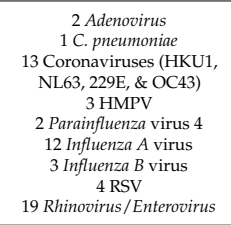 & Not reported & $\begin{array}{l}\text { Molecular and/or } \\
\text { viral culture } \\
\text { respiratory assays } \\
\text { [multiplex } \\
\text { respiratory pathogen } \\
\text { panels] }\end{array}$ & 6 & $\begin{array}{l}\text { Individuals with COVID-19 } \\
\text { co-infection had higher } \\
\text { odds of being male. }\end{array}$ \\
\hline $\begin{array}{l}\text { Sepulveda } \\
\text { et al., 2020 } \\
\text { [61], United } \\
\text { States }\end{array}$ & $\begin{array}{l}\text { Retrospective } \\
\text { cohort, multi- } \\
\text { center }\end{array}$ & 4185 & $159(3.8)$ & $\begin{array}{c}\text { Not } \\
\text { reported }\end{array}$ & $\begin{array}{c}\text { Not } \\
\text { reported }\end{array}$ & $\begin{array}{c}\text { Not } \\
\text { reported }\end{array}$ & $\begin{array}{c}\text { Not } \\
\text { reported }\end{array}$ & $\begin{array}{c}\text { Not } \\
\text { reported }\end{array}$ & $156(3.7)$ & $3(0.07)$ & - & 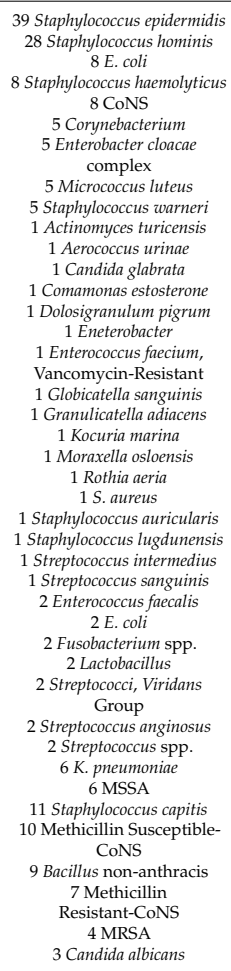 & Not reported & Blood cultures & 6 & 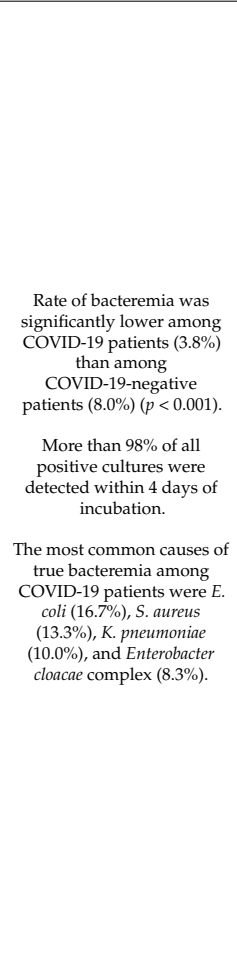 \\
\hline
\end{tabular}


Table 1. Cont.

\begin{tabular}{|c|c|c|c|c|c|c|c|c|c|c|c|c|c|c|c|c|}
\hline $\begin{array}{c}\text { Author, Year, } \\
\text { Study } \\
\text { Location }\end{array}$ & $\begin{array}{l}\text { Study } \\
\text { Design, } \\
\text { Setting }\end{array}$ & $\begin{array}{c}\text { Number of } \\
\text { SARS-Cov-2 } \\
\text { PAtients Tested for } \\
\text { Co-Pathogens, } n\end{array}$ & $\begin{array}{c}\text { Co-Infected } \\
\text { Patients, } n \\
(\%)\end{array}$ & $\begin{array}{c}\text { Age } \\
\text { (Years) }\end{array}$ & $\underset{(\%)}{\text { Male, n }}$ & $\begin{array}{l}\text { Admitted } \\
\text { to IIU, } \mathrm{n} \\
(\%)\end{array}$ & $\begin{array}{l}\text { Mechanical } \\
\text { ventilation, } \\
\mathrm{n}(\%)\end{array}$ & $\begin{array}{c}\text { Deaths, } \mathrm{n} \\
(\%)\end{array}$ & $\begin{array}{l}\text { Bacterial } \\
\text { Co-Infection, } \\
\text { n }(\%)\end{array}$ & $\begin{array}{l}\text { Fungal } \\
\text { Co-Infection, } \\
\text { n (\%) }\end{array}$ & $\begin{array}{l}\text { Respiratory } \\
\text { Viral } \\
\text { Co-Infection, } \\
\text { n (\%) }\end{array}$ & Total Organisms, $\mathrm{n}$ & Antimicrobials Use, $\mathbf{n}$ & $\begin{array}{l}\text { Laboratory } \\
\text { Techniques for } \\
\text { Co-Pathogen } \\
\text { Detection }\end{array}$ & $\begin{array}{l}\text { NOS } \\
\text { Score }\end{array}$ & Key Findings \\
\hline $\begin{array}{l}\text { Singh et al., } \\
2021[62], \\
\text { United States }\end{array}$ & $\begin{array}{c}\text { Retrospective } \\
\text { cohort, } \\
\text { multi-center }\end{array}$ & 4259 & $1,558(36.59)$ & $\begin{array}{l}\text { Mean } \\
\text { (SD), } \\
45.21 \\
(20.43)\end{array}$ & $692(44.4)$ & $\begin{array}{l}\text { Not } \\
\text { reported }\end{array}$ & $\begin{array}{l}\text { Not } \\
\text { reported }\end{array}$ & $\begin{array}{l}\text { Not } \\
\text { reported }\end{array}$ & $517(12.1)$ & - & $53(1.2)$ & 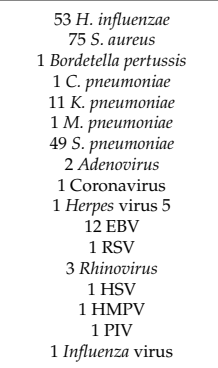 & Not reported & $\begin{array}{l}\text { RT-PCR for } \\
\text { respiratory } \\
\text { specimens }\end{array}$ & 6 & $\begin{array}{l}\text { Co-infections were } \\
\text { significantly higher in the } \\
\text { older age group ( } 60+\text { years). }\end{array}$ \\
\hline $\begin{array}{l}\text { Song et al., } \\
2020[63], \\
\text { China }\end{array}$ & $\begin{array}{l}\text { Retrospective } \\
\text { cohort, single } \\
\text { center }\end{array}$ & 89 & $18(20.2)$ & $\begin{array}{c}\text { Median } \\
\text { (IQR), } \\
35.5 \\
(15-76)\end{array}$ & $\begin{array}{c}\text { Not } \\
\text { reported }\end{array}$ & $2(11.1)$ & $\begin{array}{l}\text { Not } \\
\text { reported }\end{array}$ & $\begin{array}{c}\text { Not } \\
\text { reported }\end{array}$ & $18(20.2)$ & - & - & 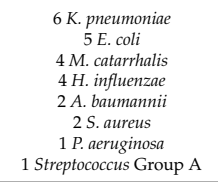 & Not reported & $\begin{array}{l}\text { RT-PCR for } \\
\text { respiratory } \\
\text { specimens }\end{array}$ & 6 & $\begin{array}{l}\text { Authors did not detect } \\
\text { co-infection of } S \text { SRSS-CoV-2 } \\
\text { with other viruses. }\end{array}$ \\
\hline $\begin{array}{l}\text { Sun et al., } \\
\text { 2020 [400], } \\
\text { China }\end{array}$ & $\begin{array}{l}\text { Retrospective } \\
\text { case series, } \\
\text { single center }\end{array}$ & 36 & $\approx 23(62.86)$ & $\begin{array}{c}\text { Mean } \\
\text { (range), } \\
6.43 \\
\text { months } \\
(2-12 \\
\text { months) }\end{array}$ & $22(61.11)$ & $1(2.78)$ & $1(2.78)$ & $1(2.78)$ & $1(2.8)$ & - & $1(2.8)$ & $\begin{array}{c}1 \mathrm{M} \text {. pneumonia } \\
1 \text { Influenza } A \text { virus }\end{array}$ & $\begin{array}{l}15 \text { Second Generation } \\
\text { Cephalosporins15 } \\
\text { Macrolides }\end{array}$ & Unspecified & 6 & $\begin{array}{c}\text { Co-infections were common no } \\
\text { in infants with COVID-19, } \\
\text { which were different from } \\
\text { adults with coVID-19; } \\
\text { however, authors never } \\
\text { provided details of all } \\
\text { co-pathogens. }\end{array}$ \\
\hline $\begin{array}{l}\text { Tagarro et al., } \\
\text { 2021 [41], } \\
\text { Spain }\end{array}$ & $\begin{array}{l}\text { Retrospective } \\
\text { case series, } \\
\text { multi-center }\end{array}$ & 41 & $2(4.8)$ & $\begin{array}{c}\text { Mean } \\
\text { (range), } 1 \\
(0-15)\end{array}$ & $\begin{array}{l}\text { Females } \\
\text { were> } \\
\text { males }\end{array}$ & $4(9.7)$ & $1(2)$ & 0 & - & - & $2(4.9)$ & 2 Influenza B virus & Not reported & Unspecified & 7 & $\begin{array}{r}\text { Most patients who tested } \\
\text { positive for SARS-CoV-2 } \\
\text { had no comorbiditites }(67 \%) \text {. }\end{array}$ \\
\hline $\begin{array}{l}\text { Tang et al., } \\
\text { 2021 [64], } \\
\text { China }\end{array}$ & $\begin{array}{l}\text { Retrospective } \\
\text { cohort, single } \\
\text { center }\end{array}$ & 78 & $11(14.1)$ & $\begin{array}{l}\text { Mean } \\
(\text { (SD), } 42.7 \\
(14.9)\end{array}$ & $41(52.6)$ & $2(18.2)$ & $2(18.2)$ & 0 & $6(7.7)$ & - & $6(7.7)$ & $\begin{array}{c}\text { 5M. pneumoniae } \\
4 \mathrm{RSV} \\
2 \mathrm{C} \text {. pneumoniae } \\
1 \text { Influenza B virus } \\
1 \text { Adenoviruses } \\
1 \text { Legionella pneumohhila }\end{array}$ & $\begin{array}{l}48 \text { Fluoroquinolones } \\
5 \text { Beta-Lactam/Beta- } \\
\text { Lactamase Inhibitors } \\
\text { 3 Linezolid } \\
\text { 1 Vancomycin } \\
\text { 3 Carbapenems }\end{array}$ & $\begin{array}{l}\text { Serum antibody test } \\
\text { (IgM) }\end{array}$ & 6 & $\begin{array}{l}\text { SARS-CoV-2 patients with } \\
\text { co-infections had } \\
\text { significantly higher levels of } \\
\text { procalationin compared to } \\
\text { SARS-CoV-2 patients with } \\
\text { no co-infections }(p=0.002)\end{array}$ \\
\hline $\begin{array}{l}\text { Thelen et al,, } \\
\text { 2021 [65], } \\
\text { The } \\
\text { Netherlands }\end{array}$ & $\begin{array}{c}\text { Retrospective } \\
\text { cohort, } \\
\text { multi-center }\end{array}$ & 678 & $61(9)$ & $\begin{array}{l}\text { Median } \\
\text { (IQR), } 70 \\
(58-78)\end{array}$ & $443(65.1)$ & $6(0.9)$ & $\begin{array}{l}\text { Not } \\
\text { reported }\end{array}$ & $\begin{array}{c}\text { Not } \\
\text { reported }\end{array}$ & $61(9)$ & - & - & 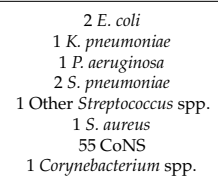 & Not reported & $\begin{array}{l}\text { RT-PCR for } \\
\text { respiratory } \\
\text { specimens AND } \\
\text { blood cultures }\end{array}$ & 6 & $\begin{array}{l}\text { Prevalence of co-infection in } \\
\text { SARS-CoV-2 patients was } \\
\text { very low compared to } \\
\text { influenzza patient group. }\end{array}$ \\
\hline $\begin{array}{l}\text { Van Arkel } \\
\text { et al, 2020 } \\
\text { [24], The } \\
\text { Netherlands }\end{array}$ & $\begin{array}{l}\text { Retrospective } \\
\text { case series, } \\
\text { single center }\end{array}$ & 31 & $6(19.3)$ & $\begin{array}{c}\text { Median } \\
\text { (IQR), } \\
62.5 \\
(43-83)\end{array}$ & $6(100)$ & $6(100)$ & $6(100)$ & $4(66.7)$ & - & & - & 5 Aspergillus fumigatus & 6 Antifungals & $\begin{array}{l}\text { Culture from } \\
\text { respiratory } \\
\text { specimens and GM } \\
\text { detection in the BAL, } \\
\text { tracheal aspirates, } \\
\text { and serum. }\end{array}$ & 6 & $\begin{array}{l}\text { Pulmonary aspergillosis } \\
\text { co-infections occurred after } \\
\text { a median of } 11.5 \text { days }(8-42) \\
\text { after COVID-19 symptom } \\
\text { onset and at a mediain of } \\
5 \text { days }(3-28) \text { after ICU } \\
\text { admission. }\end{array}$ \\
\hline
\end{tabular}


Table 1. Cont.

\begin{tabular}{|c|c|c|c|c|c|c|c|c|c|c|c|c|c|c|c|c|}
\hline $\begin{array}{l}\text { Author, Year, } \\
\text { Study } \\
\text { Location }\end{array}$ & $\begin{array}{l}\text { Study } \\
\text { Design, } \\
\text { Setting }\end{array}$ & $\begin{array}{c}\text { Number of } \\
\text { SARS-CVV-2 } \\
\text { Patients Tested for } \\
\text { Co-Pathogens, } \mathrm{n}\end{array}$ & $\begin{array}{l}\text { Co-Infected } \\
\text { Patients, n } \\
(\%)\end{array}$ & $\begin{array}{c}\text { Age } \\
\text { (Years) }\end{array}$ & $\begin{array}{c}\text { Male, } \mathrm{n} \\
(\%)\end{array}$ & $\begin{array}{l}\text { Admitted } \\
\text { to }[\mathrm{CU}, \mathrm{n} \\
(\%)\end{array}$ & $\begin{array}{l}\text { Mechanical } \\
\text { Ventilation, } \\
\text { n (\%) }\end{array}$ & $\begin{array}{l}\text { Deaths, } \mathrm{n} \\
(\%)\end{array}$ & $\begin{array}{l}\text { Bacterial } \\
\text { Co-Infection, } \\
\text { n }(\%)\end{array}$ & $\begin{array}{l}\text { Fungal } \\
\text { Co-Infection, } \\
\mathrm{n}(\%)\end{array}$ & $\begin{array}{l}\text { Respiratory } \\
\text { Viral } \\
\text { Co-Infection, } \\
\mathbf{n}(\%)\end{array}$ & Total Organisms, $\mathbf{n}$ & Antimicrobials Use, $\mathbf{n}$ & $\begin{array}{l}\text { Laboratory } \\
\text { Techniques for } \\
\text { Co-Pathogen } \\
\text { Detection }\end{array}$ & $\begin{array}{l}\text { NOS } \\
\text { Score }\end{array}$ & Key Findings \\
\hline $\begin{array}{l}\text { Wang L et al., } \\
2021 \text { [22], } \\
\text { United } \\
\text { Kingdom }\end{array}$ & $\begin{array}{l}\text { Retrospective } \\
\text { cohort, multi- } \\
\text { center }\end{array}$ & 1396 & $37(2.7)$ & $\begin{array}{l}\text { Median } \\
\text { (IIR), } 76 \\
\text { (64-82) }\end{array}$ & $28(75.7)$ & $11(29.7)$ & $\begin{array}{c}\text { Not } \\
\text { reported }\end{array}$ & $10(27)$ & $37(2.7)$ & $4(0.3)$ & - & 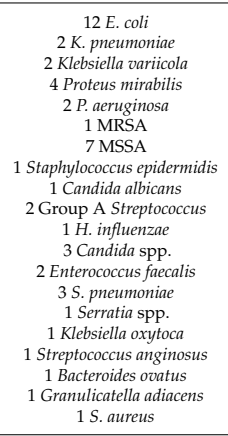 & Not reported & Unspecified & 7 & 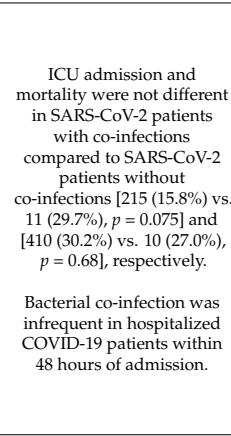 \\
\hline $\begin{array}{l}\text { Wang R et al., } \\
2020[43], \\
\text { China }\end{array}$ & $\begin{array}{l}\text { Retrospective } \\
\text { case series, } \\
\text { single center }\end{array}$ & 118 & $35(29.7)$ & $\begin{array}{l}\text { Mean } \\
\text { (SD), } \\
38.76 \\
(13.79) \\
\end{array}$ & $(56.8)$ & $19(16.1)$ & $4(3.4)$ & 0 & $35(29.7)$ & - & $1(0.8)$ & $\begin{array}{l}\text { 40 M. pneumoniae } \\
1 \text { Adenovirus } \\
1 \text { Influenza B Birus } \\
1 \text { Influenza A virus }\end{array}$ & $\begin{array}{l}\text { Seventy-nine patients } \\
\text { received antibioicicss } \\
\text { however agents were } \\
\text { not reported. }\end{array}$ & $\begin{array}{l}\text { Serum Antibody test } \\
\text { (IgM) }\end{array}$ & 6 & $\begin{array}{l}\text { Old age, chronic underlying } \\
\text { diseases, and smoking } \\
\text { history may be risk factors } \\
\text { that worsen } \\
\text { SARS-CoV-2 disease. }\end{array}$ \\
\hline $\begin{array}{l}\text { Wang Y et al., } \\
2020[44], \\
\text { China }\end{array}$ & $\begin{array}{l}\text { Retrospective } \\
\text { case series, } \\
\text { single center }\end{array}$ & 55 & $4(7.3)$ & $\begin{array}{c}\text { Median } \\
\text { (IQR), 49 } \\
(2-69)\end{array}$ & $22(40)$ & 0 & 0 & 0 & $3(12.7)$ & - & $1(1.8)$ & $\begin{array}{c}1 \mathrm{EBV} \\
\text { 3м. pneumoniae }\end{array}$ & Not reported & Serologically & 7 & $\begin{array}{l}\text { All patients included in this } \\
\text { study had } \\
\text { laboradty-confirmed } \\
\text { positive results for } \\
\text { SARS-CoV-2 and } \\
\text { were asymptomatic. }\end{array}$ \\
\hline $\begin{array}{l}\text { Wang } Z \text { et al., } \\
2020[45], \\
\text { China }\end{array}$ & $\begin{array}{l}\text { Retrospective } \\
\text { case series, } \\
\text { single center }\end{array}$ & $\begin{array}{l}29 \text { sputum } \\
28 \text { blood }\end{array}$ & $\begin{array}{l}5(17.2) \\
4(14.3)\end{array}$ & $\begin{array}{l}\text { Majority } \\
(51 \%) \\
\text { were in } \\
\text { the range } \\
(30-49)\end{array}$ & $\begin{array}{l}\text { Females } \\
\text { were } \\
\text { males }\end{array}$ & $\begin{array}{c}\text { Not } \\
\text { reported }\end{array}$ & $\begin{array}{l}\text { Not } \\
\text { reported }\end{array}$ & $5(7.5)$ & $5(\approx 17.2)$ & $2(6.9)$ & $2(7.1)$ & $\begin{array}{l}2 \text { Candida albicans } \\
\text { 2 Enterobacter cloacae } \\
\text { 1A buamannii } \\
\text { 2 Chlamydia } \\
1 \text { RSV } \\
1 \text { Adenovirus }\end{array}$ & $\begin{array}{l}39 \text { Fluoroquinolones } \\
8 \text { Antifungals }\end{array}$ & $\begin{array}{l}\text { Serum Antibody test } \\
\text { (IgM, IgG) }\end{array}$ & 7 & $\begin{array}{l}\text { Source of patients' samples } \\
\text { tested for co-pathogens } \\
\text { were sputum and blood. }\end{array}$ \\
\hline $\begin{array}{l}\text { Wee et al., } \\
2020[66], \\
\text { Singapore }\end{array}$ & $\begin{array}{l}\text { Prospective } \\
\text { cohort, single } \\
\text { center }\end{array}$ & 431 & $6(1.4)$ & $\begin{array}{l}\text { Mean } \\
\text { (SD), } 29.2 \\
(1.7)\end{array}$ & $6(100)$ & 0 & 0 & 0 & 0 & - & $6(1.4)$ & $\begin{array}{c}\text { 3Rhinovirus } \\
\text { 2 Parainfluenza } \\
\text { 1Other coronavirus } \\
\text { (229E/NL63/OC43) }\end{array}$ & Not reported & $\begin{array}{l}\text { RT-PCR for } \\
\text { respiratory } \\
\text { specimens }\end{array}$ & 6 & $\begin{array}{l}\text { Co-infections in patients } \\
\text { with } \mathrm{s} \text { ARS-CoV-2 shown no } \\
\text { increase in morbidity or } \\
\text { mortality. } \\
\text { All cases of COVID-19 } \\
\text { co-infections were young, } \\
\text { healthy, and had no } \\
\text { medical comorbidities. }\end{array}$ \\
\hline $\begin{array}{l}\text { Wu C et al., } \\
2020 \text { [67], } \\
\text { China }\end{array}$ & $\begin{array}{l}\text { Retrospective } \\
\text { cohort, single } \\
\text { center }\end{array}$ & 173 & $1(0.6)$ & $\begin{array}{l}\text { Majority } \\
\text { (80.1.\%) } \\
\text { hada } \\
\text { median } \\
\text { age }<65\end{array}$ & $\begin{array}{c}\text { Males } \\
\text { were } \\
\text { females }\end{array}$ & $53(26.4)$ & $67(33.3)$ & $44(21.9)$ & - & - & $1(0.6)$ & 1 Influenza $A$ virus & Not reported & $\begin{array}{c}\text { RT-PCR for } \\
\text { respiratory } \\
\text { specimens [viruses] } \\
\text { AND sputum culture } \\
\text { [bacteria and fungi] }\end{array}$ & 8 & $\begin{array}{c}\text { Most }(\mathrm{n}=173[86.1 \%]) \\
\text { patients were tested for } 9 \\
\text { additional respiratory } \\
\text { pathogens. Bacteria and } \\
\text { fungi cultures were } \\
\text { collected from } 148 \\
(73.6 \%) \text { patients. }\end{array}$ \\
\hline $\begin{array}{l}\text { Wu Q et al., } \\
2020 \text { [46], } \\
\text { China }\end{array}$ & $\begin{array}{l}\text { Retrospective } \\
\text { case series, } \\
\text { multi-center }\end{array}$ & 34 & $19(55.9)$ & 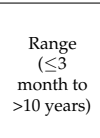 & $\begin{array}{c}\text { Males } \\
\text { weres } \\
\text { females }\end{array}$ & 0 & $1(2.9)$ & 0 & $16(47)$ & - & $10(29.4)$ & $\begin{array}{c}16 \text { M. pneumoniae } \\
2 \mathrm{RSV} \\
2 \mathrm{EBV} \\
3 \mathrm{CMV} \\
1 \text { Influezza } A \text { virus } \\
1 \text { Influenza } B \text { virus }\end{array}$ & 15 Macrolides & Unspecified & 7 & $\begin{array}{l}\text { Nearly one-half of the } \\
\text { infected children had } \\
\text { co-infection with other } \\
\text { common } \\
\text { respiratory pathogens. }\end{array}$ \\
\hline
\end{tabular}


Table 1. Cont.

\begin{tabular}{|c|c|c|c|c|c|c|c|c|c|c|c|c|c|c|c|c|}
\hline $\begin{array}{l}\text { Author, Year, } \\
\text { Study } \\
\text { Location }\end{array}$ & $\begin{array}{l}\text { Study } \\
\text { Design, } \\
\text { Setting }\end{array}$ & $\begin{array}{c}\text { Number of } \\
\text { SARS-CVV-2 } \\
\text { Patients Tested for } \\
\text { Co-Pathogens, } \mathrm{n}\end{array}$ & $\begin{array}{l}\text { Co-Infected } \\
\text { Patients, n } \\
(\%)\end{array}$ & $\begin{array}{c}\text { Age } \\
\text { (Years) }\end{array}$ & $\underset{(\%)}{\text { Male, }}$ & $\begin{array}{l}\text { Admitted } \\
\text { to ICU, } n \\
(\%)\end{array}$ & $\begin{array}{l}\text { Mechanical } \\
\text { Ventilation, } \\
\text { n } \% \text { ) }\end{array}$ & $\begin{array}{l}\text { Deaths, } n \\
(\%)\end{array}$ & $\begin{array}{l}\text { Bacterial } \\
\text { Co-rnfection, } \\
\text { n } \% \text { (\%) }\end{array}$ & $\begin{array}{l}\text { Fungal } \\
\text { Co-Infection, } \\
\text { n (\%) }\end{array}$ & $\begin{array}{l}\text { Respiratory } \\
\text { Viral } \\
\text { Co-Infection, } \\
\mathbf{n}(\%)\end{array}$ & Total Organisms, $\mathbf{n}$ & Antimicrobials Use, $\mathbf{n}$ & $\begin{array}{l}\text { Laboratory } \\
\text { Techniques for } \\
\text { Co-Pathogen } \\
\text { Detection }\end{array}$ & $\begin{array}{l}\text { NOS } \\
\text { Score }\end{array}$ & Key Findings \\
\hline $\begin{array}{l}\text { Xia et al,, } \\
2020[47], \\
\text { China }\end{array}$ & $\begin{array}{l}\text { Retrospective } \\
\text { cases series, } \\
\text { single center }\end{array}$ & 20 & $8(40)$ & $\begin{array}{l}\text { Range }(<1 \\
\text { month to } \\
>6 \text { years })\end{array}$ & $\begin{array}{c}\text { Males } \\
\text { were> } \\
\text { females }\end{array}$ & 0 & 0 & 0 & $4(20)$ & - & $5(25)$ & $\begin{array}{c}1 \text { CMV } \\
\text { 2 Inffuzzan B Birus } \\
1 \text { Influenza A virus } \\
4 \text { Mycolpssma } \\
1 \text { RSV }\end{array}$ & Not reported & Unspecified & 5 & $\begin{array}{l}\text { Procalcitonin increased in } \\
\text { most of the cases }(80 \%) \text {. }\end{array}$ \\
\hline $\begin{array}{l}\text { Yang et al., } \\
2020[48], \\
\text { China }\end{array}$ & $\begin{array}{l}\text { Retrospective } \\
\text { case series, } \\
\text { single center }\end{array}$ & 52 & $7(13.5)$ & $\begin{array}{c}\text { Majority } \\
(73 \%) \\
\text { were in } \\
\text { the range } \\
(50-79)\end{array}$ & $\begin{array}{c}\text { Males } \\
\text { were> } \\
\text { females }\end{array}$ & $52(100)$ & $37(71)$ & $32(61.5)$ & $4(7.7)$ & $3(5.8)$ & - & $\begin{array}{c}2 \text { K. pneumoniae } \\
1 \text { Aspergillus flavus } \\
1 \text { Aspergillus fumigatus } \\
1 \text { P. aeruginosa } \\
1 \text { Serratia marcescens } \\
1 \text { Candida albicans }\end{array}$ & $\begin{array}{l}\text { Forty-nine patients } \\
\text { received antibioticics; } \\
\text { however, agents were } \\
\text { not reported. }\end{array}$ & $\begin{array}{l}\text { Respiratory and } \\
\text { blood cultures }\end{array}$ & 8 & $\begin{array}{l}\text { Those isolated pathogens } \\
\text { caused hospital-acquired } \\
\text { infections. }\end{array}$ \\
\hline $\begin{array}{l}\text { Yue et al, } \\
2020 \text { [688, } \\
\text { China }\end{array}$ & $\begin{array}{l}\text { Retrospective } \\
\text { cohort, single } \\
\text { center }\end{array}$ & 307 & $176(57.3)$ & $\begin{array}{c}\text { Mean } \\
\text { (SD), 60.3 } \\
(16.5)\end{array}$ & $75(42.6)$ & $\begin{array}{l}\text { Not } \\
\text { reported }\end{array}$ & $\begin{array}{c}\text { Not } \\
\text { reported }\end{array}$ & $\begin{array}{c}\text { Not } \\
\text { reported }\end{array}$ & - & - & $176(57.3)$ & $\begin{array}{l}153 \text { Influenza } A \text { virus } \\
23 \text { Influenza } B \text { virus }\end{array}$ & None & $\begin{array}{l}\text { Serum antibody test } \\
(\operatorname{IgM})\end{array}$ & 6 & 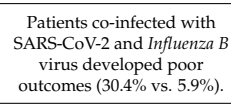 \\
\hline $\begin{array}{l}\text { Zha et al., } \\
2020[82], \\
\text { China }\end{array}$ & $\begin{array}{l}\text { Retrospective } \\
\text { cases series, } \\
\text { single center }\end{array}$ & 874 & $22(2.5)$ & $\begin{array}{c}\text { Median } \\
\text { (IQR), } \\
56.5(52.5- \\
66.5)\end{array}$ & $11(50)$ & $\begin{array}{c}\text { Not } \\
\text { reported }\end{array}$ & $\begin{array}{l}\text { Not } \\
\text { reported }\end{array}$ & $1(4.5)$ & $22(2.5)$ & - & - & 22 M. pneumoniae & $\begin{array}{l}18 \text { Fluoroquinolones } \\
1 \text { Cephalosporins } \\
3 \text { Beta-Lactam Beta- } \\
\text { Lactamase } \\
\text { Inhibitors }\end{array}$ & $\begin{array}{c}\text { RT-PCR for } \\
\text { respiratory } \\
\text { specimens OR serum } \\
\text { antibody test (IgM) }\end{array}$ & 6 & 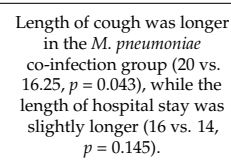 \\
\hline $\begin{array}{l}\text { Zhang et al., } \\
2020 \text { [50], } \\
\text { China }\end{array}$ & $\begin{array}{l}\text { Retrospective } \\
\text { case series, } \\
\text { single center }\end{array}$ & 140 & $7(5)$ & $\begin{array}{c}\text { Majority } \\
(70 \%) \\
\text { were }>50\end{array}$ & 1:1 ratio & $\begin{array}{l}\text { Not } \\
\text { reported }\end{array}$ & $\begin{array}{l}\text { Not } \\
\text { reported }\end{array}$ & $\begin{array}{c}\text { Not } \\
\text { reported }\end{array}$ & $5(3.6)$ & - & $2(1.4)$ & $\begin{array}{l}\text { 5M. pneumonia } \\
1 \mathrm{RSV} \\
1 \mathrm{EBV}\end{array}$ & Not reported & $\begin{array}{c}\text { Serum antibody test } \\
(\mathrm{IgN}, \mathrm{IgG})\end{array}$ & 5 & $\begin{array}{l}\text { No clinical and radiological } \\
\text { signs of co-infection caused } \\
\text { by these pathogens were } \\
\text { identified. } \\
\text { Increased procalititonin } \\
(p=0.004) \text { was more } \\
\text { commonnly observed in } \\
\text { severe patients. }\end{array}$ \\
\hline $\begin{array}{l}\text { Zhao et al,, } \\
2020[699, \\
\text { China }\end{array}$ & $\begin{array}{l}\text { Prospective } \\
\text { cohort, } \\
\text { multi-center }\end{array}$ & 19 & $2(10.5)$ & $\begin{array}{l}\text { Median } \\
\text { (IRR), } 48 \\
(27-56)\end{array}$ & $\begin{array}{c}\text { Males } \\
\text { were> } \\
\text { females }\end{array}$ & 0 & 0 & 0 & $1(5.3)$ & - & $1(5.3)$ & $\begin{array}{c}1 \text { Coxsackie virus } \\
1 \text { Mycoplasma }\end{array}$ & None & $\begin{array}{c}\text { RT-PCR for } \\
\text { respiratory } \\
\text { specimens AND } \\
\text { serum antibody test } \\
\text { (IgM) }\end{array}$ & 6 & Sample size was very small. \\
\hline $\begin{array}{l}\text { Zheng F } \\
\text { etal, 2020 } \\
{[49] \text {, China }}\end{array}$ & $\begin{array}{l}\text { Retrosppective } \\
\text { case series, } \\
\text { multi-center }\end{array}$ & 25 & $6(24)$ & $\begin{array}{l}\text { Range (1 } \\
\text { month to } \\
\geq 6 \text { years) }\end{array}$ & $\begin{array}{c}\text { Males } \\
\text { were> } \\
\text { females }\end{array}$ & $2(8)$ & $2(8)$ & 0 & $4(16)$ & - & $2(8)$ & 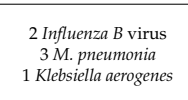 & $\begin{array}{l}1 \text { Beta-Lactam/Beta- } \\
\text { Lactamases Inhibitors } \\
1 \text { Carbapenems } \\
1 \text { Linezolid }\end{array}$ & Unspecified & 5 & $\begin{array}{c}\text { Highest incidence of } \\
\text { infection occurred in } \\
\text { children aged }<3 \text { years. }\end{array}$ \\
\hline $\begin{array}{l}\text { Zheng X } \\
\text { et al, 2020 } \\
{[770] \text {, China }}\end{array}$ & $\begin{array}{l}\text { Retrospective } \\
\text { cohort, single } \\
\text { center }\end{array}$ & 1001 & $4(0.4)$ & $\begin{array}{c}\text { Mean } \\
\text { (SD),35 } \\
(19.6)\end{array}$ & 1:1 & 0 & 0 & 0 & - & - & $4(0.4)$ & $\begin{array}{l}\text { 3Influenza } A \text { virus } \\
3 \text { Influenza } B \text { virus }\end{array}$ & $\begin{array}{l}\text { Three patients received } \\
\text { antibiotics; however, } \\
\text { agents were not } \\
\text { reported. }\end{array}$ & $\begin{array}{l}\text { RT-PCR for } \\
\text { respiratory } \\
\text { specimens }\end{array}$ & 7 & $\begin{array}{l}\text { Patients with both } \\
\text { SARS-CoV-2 and influenza } \\
\text { virus infection showed } \\
\text { similar clincal } \\
\text { characteristics tot those } \\
\text { patients with SARS-Cov-2 } \\
\text { infection only. }\end{array}$ \\
\hline & & & & & & & & & & & & & & & & $\begin{array}{l}\text { Co-infection of SARS-CoV-2 } \\
\text { and influenza viruses } \\
\text { was low. }\end{array}$ \\
\hline
\end{tabular}


Table 1. Cont.

\begin{tabular}{|c|c|c|c|c|c|c|c|c|c|c|c|c|c|c|c|c|}
\hline $\begin{array}{l}\text { Author, Year, } \\
\text { Study } \\
\text { Location }\end{array}$ & $\begin{array}{l}\text { Study } \\
\text { Design, } \\
\text { Setting }\end{array}$ & $\begin{array}{c}\text { Number of } \\
\text { SARS-Cov-2 } \\
\text { Patients Tested for } \\
\text { Co-Pathogens, } n\end{array}$ & $\begin{array}{c}\text { Co-Infected } \\
\text { Patients, n } \\
(\%)\end{array}$ & $\begin{array}{c}\text { Age } \\
\text { (Years) }\end{array}$ & $\underset{\substack{\text { Male, }, n \\
(\%)}}{ }$ & $\begin{array}{l}\text { Admitted } \\
\text { to ICU, n } \\
(\%)\end{array}$ & $\begin{array}{l}\text { Mechanical } \\
\text { Ventilation, } \\
n(\%)\end{array}$ & $\begin{array}{c}\text { Deaths, n } \\
(\%)\end{array}$ & $\begin{array}{l}\text { Bacterial } \\
\text { Co-Infection, } \\
\text { n (\%) }\end{array}$ & $\begin{array}{c}\text { Fungal } \\
\text { Co-Infection, } \\
\text { n ( } \%)\end{array}$ & $\begin{array}{l}\text { Respiratory } \\
\text { Viral } \\
\text { Co-Infection, } \\
\text { n (\%) } \\
\end{array}$ & Total Organisms, $\mathbf{n}$ & Antimicrobials Use, $\mathbf{n}$ & $\begin{array}{l}\text { Laboratory } \\
\text { Techniques for } \\
\text { Co-Pathogen } \\
\text { Detection }\end{array}$ & $\begin{array}{l}\text { NOS } \\
\text { Score }\end{array}$ & Key Findings \\
\hline $\begin{array}{l}\text { Zhu et al., } \\
\text { 2020 [4], } \\
\text { China }\end{array}$ & $\begin{array}{c}\text { Retrospective } \\
\text { cohort, single } \\
\text { center }\end{array}$ & 257 & $243(94.5)$ & $\begin{array}{l}\text { Median } \\
\text { (IIR), } 51 \\
(2-99)\end{array}$ & $138(53.7)$ & $3(1.2)$ & 0 & 0 & $236(91.8)$ & $60(23.3)$ & $81(31.5)$ & 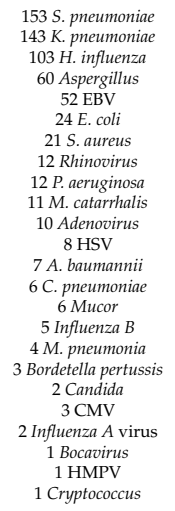 & Not reported & $\begin{array}{l}\text { RT-PCR for } \\
\text { respiratory } \\
\text { specimens }\end{array}$ & 7 & $\begin{array}{l}\text { Highest and lowest rates of } \\
\text { co-infections were found in } \\
\text { patients aged 15-44 and } \\
\text { below 15, respectively. } \\
\text { Most co-infections occurred } \\
\text { within } 1-4 \text { days of onsef of } \\
\text { COVID-19 disease. } \\
\text { Proportion of viral, fungal } \\
\text { and bacterial co-infections } \\
\text { were the highest in severe } \\
\text { COVID-19 cases. }\end{array}$ \\
\hline
\end{tabular}

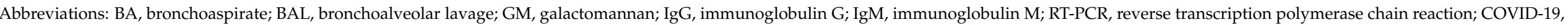

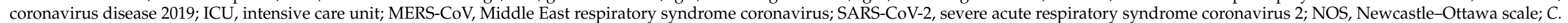

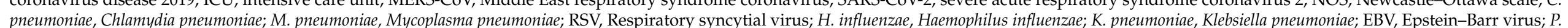

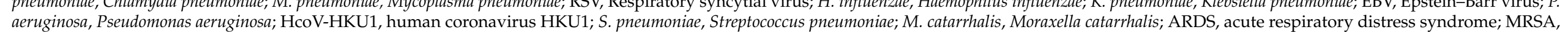

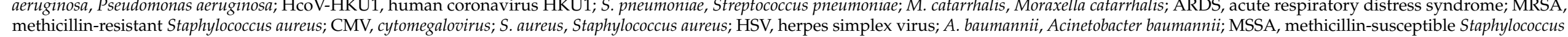
aureus; CoNS, coagulase-negative staphylococci; AOR, adjusted odds ratio; CI, confidence interval; HHV6, human herpes virus 6; E. coli, Escherichia coli; spp., species; HMPV, human metapneumovirus. 


\section{Results}

\subsection{Characteristics and Quality of Included Studies}

Of the initial 7317 retrieved publications, there were 4609 duplicate articles, and 2080 articles were found to be irrelevant based on their titles and abstracts and were excluded. An additional 1065 articles were excluded after review, meaning that we included 72 articles in the systematic review [2-70,80-82], while 68 articles were included in the meta-analysis [2-11,13-37,39-41,43-57,59-70,80-82] (Figure 1).
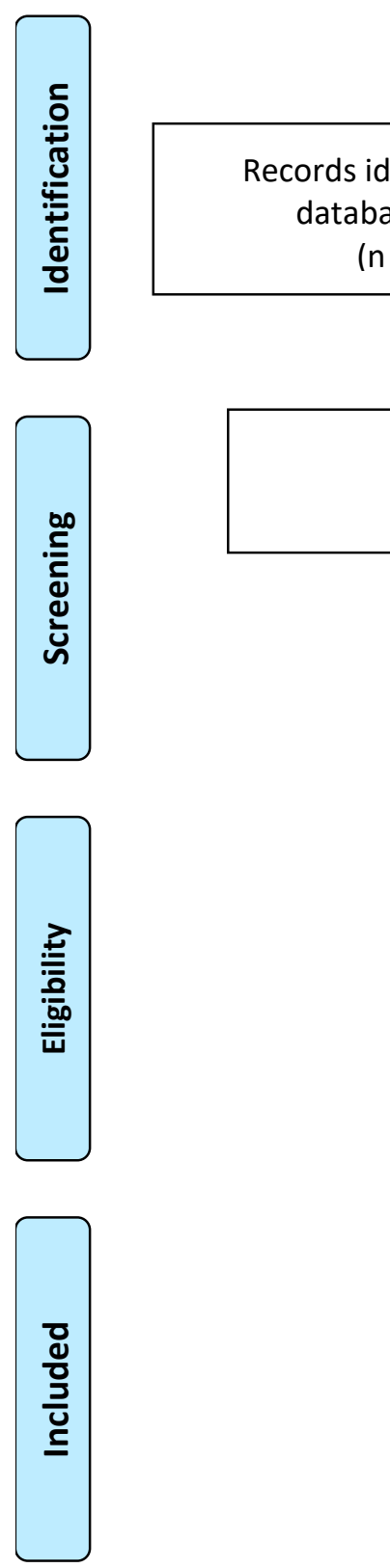

Records after duplicates removed $(n=4,609)$

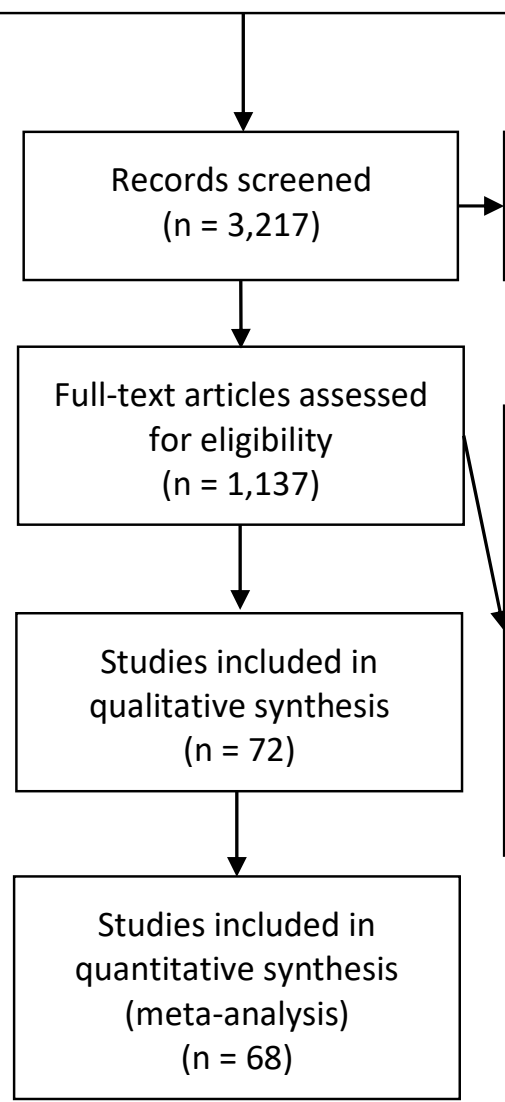

Records excluded $(n=2,080)$

Full-text articles excluded, with reasons $(n=1,065)$

Review articles: 413

Case reports: 138

Study with no details on copathogens: 64 Study with no relevant data: 171 Overlapping dataset: 224 No extractable data: 55

Figure 1. Flow diagram of literature search and data extraction from studies included in the systematic review and meta-analysis.

The included studies had a total of 31,953 SARS-CoV-2 infected patients as detailed in Table 1. Of those patients, 25,302 (79.2\%) were from 32 cohort studies and $20.8 \%$ were from 40 case series. The geographical distribution of these studies was as follows: Asia $(n=36)$, Europe $(n=22)$, and North America $(n=14)$. The majority of the studies were single center and only 24 studies were multi-center. Laboratory techniques for co-pathogen detection within studies included 19 that used respiratory samples and RT- 
PCR tests $[4,5,8,11-13,29,33,37,38,53,55,58,59,62,63,66,70,80], 17$ that used serologic tests (antibodies) $[6,10,14,19,24,31,32,35,36,43-45,50,52,60,64,68], 15$ that used RT-PCR tests with respiratory and/or blood cultures $[7,9,17,18,23,26,28,34,39,42,51,56,57,65,67], 12$ that did not specify their testing methods $[3,15,16,22,25,30,40,41,46,47,49,81]$, five that only used respiratory and/or blood cultures $[2,21,48,54,61]$, and three that tested both serology and RT-PCR $[27,69,82]$ (Table 1). Seven studies examined patients for influenza $A$ and $B$ only $[10,11,19,41,60,68,70]$; while five studies evaluated patients for the presence of Chlamydia or Mycoplasma [6,24,35,52,82]; and four studies only evaluated for the presence of fungi $[17,23,39,42]$. The proportion of patients receiving antibiotic agents was reported in 34 studies $[2,6,7,14,16-21,23,24,31,34-37,39,40,42,43,45,46,48,49,51,52,56,57,60,64,70,80,82]$. The most commonly used antimicrobials were macrolides $(n=355)$, 2nd/3rd/5th generation cephalosporins $(n=157)$, fluoroquinolones, $(n=150)$, antifungals $(n=62)$, betalactams/beta-lactam inhibitors $(n=26)$, beta-lactams $(n=21)$, tetracyclines $(n=17)$, linezolid $(n=13)$, carbapenems $(n=4)$, and glycopeptides $(n=2)$. The median NOS score was 6 with a range from 5 to 8 . The NOS quality was moderate for 66 studies, and high quality for 6 studies. The majority $(60 / 72,83.3 \%)$ of the studies included only adult patients. The proportion of male patients had a median of $55.9 \%$ [interquartile range (IQR) $48.9-71.9 \%$ ]. The majority $(n=58)$ of the studies included any hospitalized patient, and 14 studies included only critically ill. Sixteen, thirteen, and four studies exclusively reported on respiratory viral, bacterial, and fungal co-infections, respectively; and the remaining 39 studies reported on bacterial, fungal, and respiratory viral co-infections; Table 1.

\subsection{Meta-Analysis of Bacterial, Fungal, and Respiratory Viral Co-Infections in Patients with SARS-CoV-2}

The overall pooled proportions of SARS-CoV-2 patients who had laboratory-confirmed bacterial, fungal, and respiratory viral coinfections were $15.9 \%(95 \%$ CI 13.6 to $18.2, n=1940$, 49 studies, $I^{2} 99 \%, p<0.00001$ ), 3.7\% (95\% CI 2.6 to $4.8, \mathrm{n}=177,16$ studies, $I^{2} 93 \%$, $p<0.00001$ ), and $6.6 \%$ (95\% CI 5.5 to $7.6, \mathrm{n}=737,44$ studies, $I^{2} 96 \%, p<0.00001$ ), respectively; (Figures 2-4).

In bacterial coinfected SARS-CoV-2 patients, subgroup analysis showed some difference in the rates between all patients (ICU and non-ICU group); and the ICU only group (14.8\% (95\% CI 12.4 to $17.3, \mathrm{n}=1802,41$ studies, $\left.I^{2}=99 \%\right)$; and $22.2 \%$ (95\% CI 16.1 to 28.4 , $\mathrm{n}=137,8$ studies, $I^{2}=88 \%$ ), respectively); Figure 2. In the fungal co-infected SARS-CoV-2 patients, subgroup analysis showed a significant difference in the rates between all patients (ICU and non-ICU); and ICU only patients [2.7\% (95\% CI 0.0 to $3.8, \mathrm{n}=155,8$ studies, $\left.I^{2}=95 \%\right)$; and 9.6\% (95\% CI 6.8 to $12.4, \mathrm{n}=62,8$ studies, $\left.I^{2}=74 \%\right)$, respectively]; Figure 3 .

However, in the respiratory viral co-infected SARS-CoV-2 patients, subgroup analysis showed an identical proportion between all patients (ICU and non-ICU) and the ICU only patients [6.6\% (95\% CI 5.5 to $7.7, \mathrm{n}=723,40$ studies, $\left.\mathrm{I}^{2}=96 \%\right)$; and $6.6 \%(95 \% \mathrm{CI} 0.0$ to 11.3 , $\mathrm{n}=14,4$ studies, $I^{2}=58 \%$ ), respectively]; Figure 4 .

Funnel plots for possible publication bias for the pooled effect size to determine the prevalence of coinfections in SARS-Cov-2 patients appeared asymmetrical on visual inspection, and Egger's tests confirmed asymmetry with $p$ values $<0.05$; Figures $5-7$. 


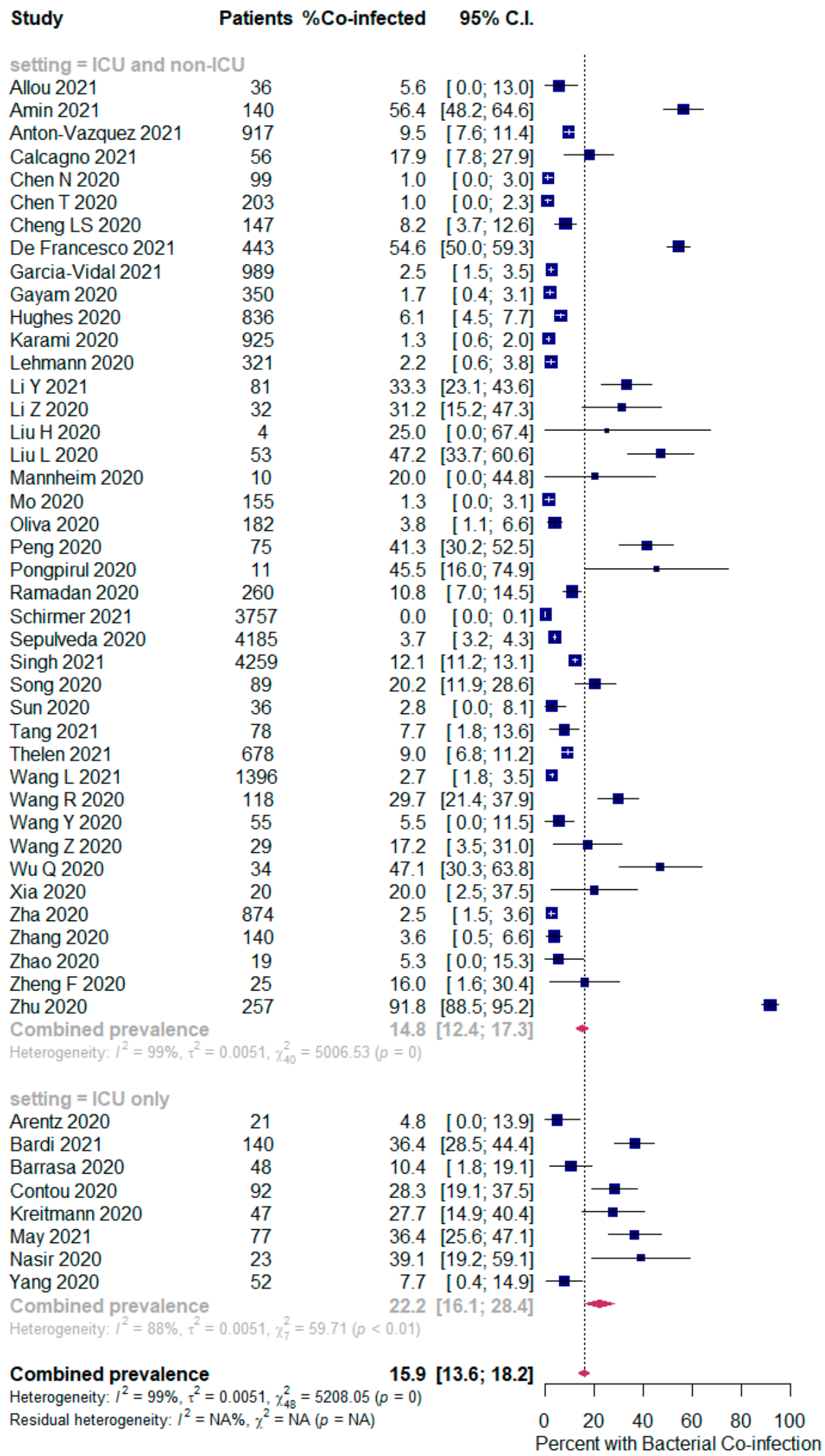

Figure 2. Forest plot of proportion of SARS-CoV-2 patients with bacterial co-infections (all patients in the upper panel and only ICU patients in the lower panel). 


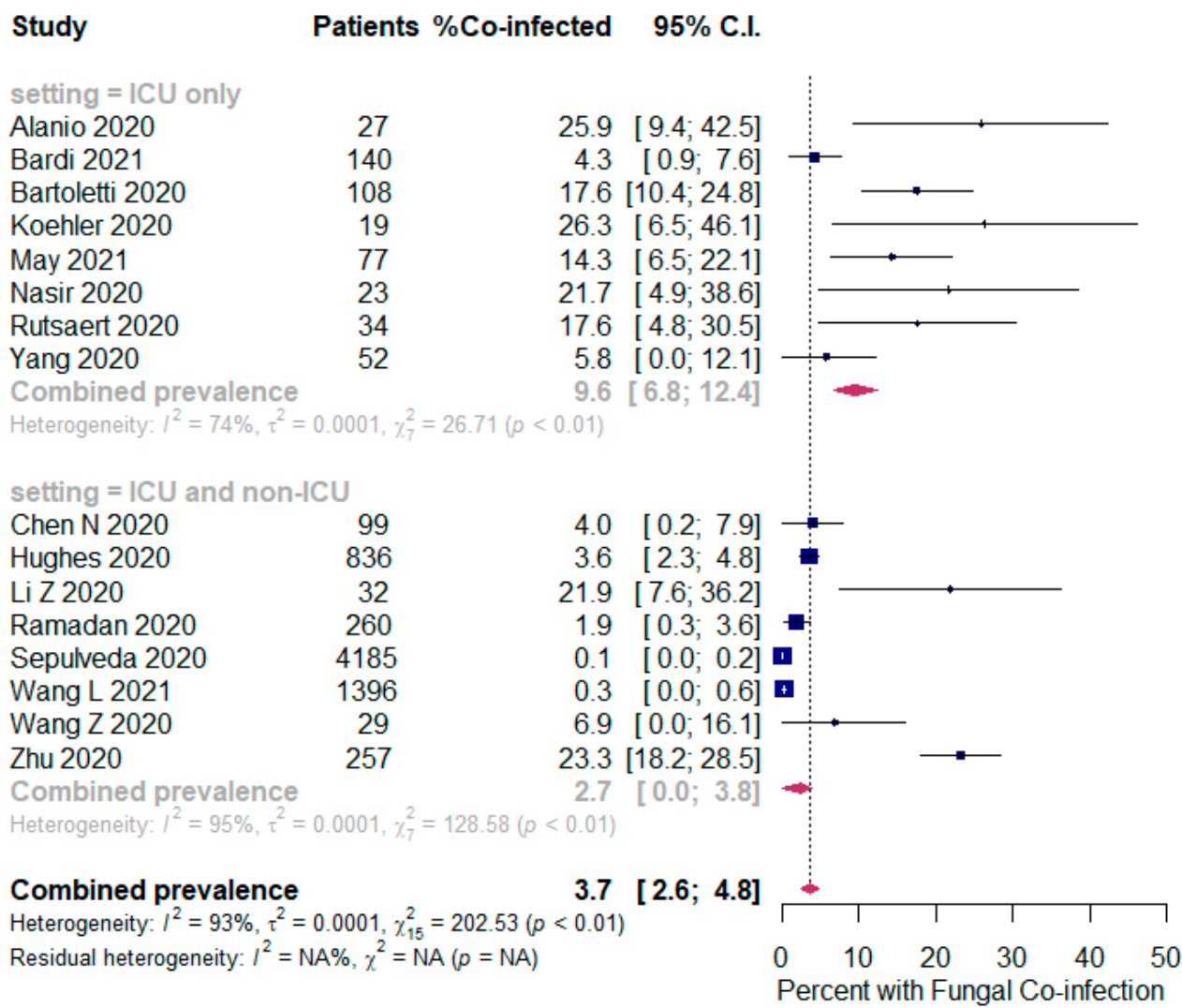

Figure 3. Forest plot of proportion of SARS-CoV-2 patients with fungal co-infections (all patients in the upper panel and only ICU patients in the lower panel).

\subsection{Bacterial, Fungal and Respiratory Viral Co-Pathogens}

Specific bacterial co-pathogens were reported in 49/72 (68\%) studies, which is about $57.3 \%$ of the reported co-infections. The most common bacteria were $S$. aureus $(\mathrm{n}=1095)$, M. catarrhalis $(\mathrm{n}=352)$, M. pneumoniae $(\mathrm{n}=338)$, S. pneumoniae $(\mathrm{n}=316)$, C. pneumoniae $(\mathrm{n}=261)$, K. pneumoniae $(\mathrm{n}=259)$, and H. influenzae $(\mathrm{n}=197)($ Table 2$)$.

Fungal co-pathogens were reported in $16 / 72(22.2 \%)$ studies, which is equal to only $3.2 \%$ of the reported co-infections. The most common fungal organisms were Aspergillus spp. $(\mathrm{n}=68)$, Aspergillus fumigatus $(\mathrm{n}=43)$, Other Candida spp. $(\mathrm{n}=29)$, Candida albicans $(\mathrm{n}=25)$ and Aspergillus flavus $(\mathrm{n}=10)$ (Table 3).

Respiratory viral co-pathogens were reported in 44/72 (61.1\%) studies, representing about $39.5 \%$ of the reported co-infections. The most common respiratory viruses were EBV ( $\mathrm{n}=644)$, HHV6 $(\mathrm{n}=574)$, Influenza A virus $(\mathrm{n}=355), \mathrm{HMPV}(\mathrm{n}=328)$, and Adenovirus $(\mathrm{n}=144)$ (Table 4). 
Study

setting $=\mathrm{ICU}$ and non-ICU

Allou 2021

Chen T 2020

Cheng Y 2020

Cuadrado-Payán 2020

Garcia-Vidal 2021

Hazra 2020

Karami 2020

Kim 2020

Lehmann 2020

Li Y 2021

Li Z 2020

Lin 2020

Liu $\mathrm{H} 2020$

Liu L 2020

Ma 2020

Mannheim 2020

Mo 2020

Nowak 2020

Ozaras 2020

Peng 2020

Pongpirul 2020

Schirmer 2021

Singh 2021

Sun 2020

Tagarro 2021

Tang 2021

Wang R 2020

Wang Y 2020

Wang Z 2020

Wee 2020

Wu C 2020

Wu Q 2020

Xia 2020

Yue 2020

Zhang 2020

Zhao 2020

Zheng F 2020

Zheng X 2020

Zhu 2020

Combined prevalence

setting = ICU only

Arentz 2020

Barrasa 2020

Elhazmi 2021

Koehler 2020

Combined prevalence

Heterogeneity: $I^{2}=58 \%, \tau^{2}=0.0006, x_{3}^{2}=7.16(p=0.07)$

Combined prevalence

Heterogeneity: $I^{2}=96 \%, \tau^{2}=0.0006, \gamma_{43}^{2}=1027.24(p<0.01)$

Residual heterogeneity: $I^{2}=\mathrm{NA} \%, \chi^{2}=\mathrm{NA}(p=\mathrm{NA})$

$<0.01)$
Ding 2020

95\% C.I.

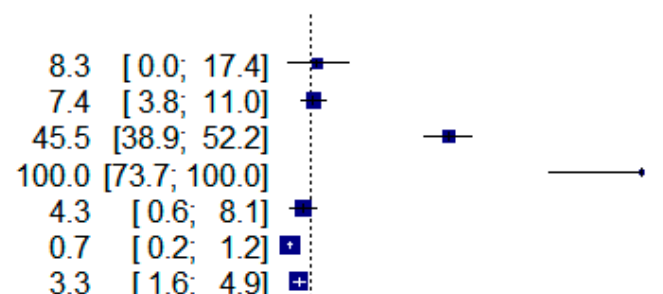

$0.2 \quad[0.0 ; 0.5]$ ㅁ

$19.8[12.6 ; 27.1]$

$1.6 \quad[0.2 ; 2.9]$

$7.4 \quad[1.7 ; 13.1]$

$15.6 \quad[3.0 ; 28.2]$

$6.5 \quad[1.5 ; 11.6]$

$25.0 \quad[0.0 ; 67.4]$

11.3 [2.8; 19.9]

49.5 [39.3; 59.6]

$30.0 \quad[1.6 ; 58.4]$

$8.4 \quad[4.0 ; 12.8]$

$2.8 \quad[1.9 ; 3.7]$

$0.5 \quad[0.1 ; 1.0] \mathbf{~}$

$10.7[3.7 ; 17.7]=$

$18.2 \quad[0.0 ; 41.0]$

$1.5 \quad[1.1 ; 1.8]$

$1.2[0.9 ; 1.6] \mathbf{t}$

$2.8 \quad[0.0 ; 8.1]$

$4.9 \quad[0.0 ; 11.5]$

$7.7[1.8 ; 13.6]-$

$0.8 \quad[0.0 ; 2.5]+$

$1.8 \quad[0.0 ; 5.3]$

$6.9 \quad[0.0 ; 16.1]$

$1.4 \quad[0.3 ; 2.5] \boldsymbol{+}$

$0.6[0.0 ; 1.7] \boldsymbol{t}$

$29.4[14.1 ; 44.7]$

$25.0 \quad[6.0 ; 44.0]$

$57.3[51.8 ; 62.9]$

$1.4[0.0 ; 3.4]$

$5.3 \quad[0.0 ; 15.3]$

$8.0[0.0 ; 18.6]=$

$0.4 \quad[0.0 ; 0.8] \mathbf{E}$

$31.5[25.8 ; 37.2]$

$6.6 \quad[5.5 ; 7.7]$

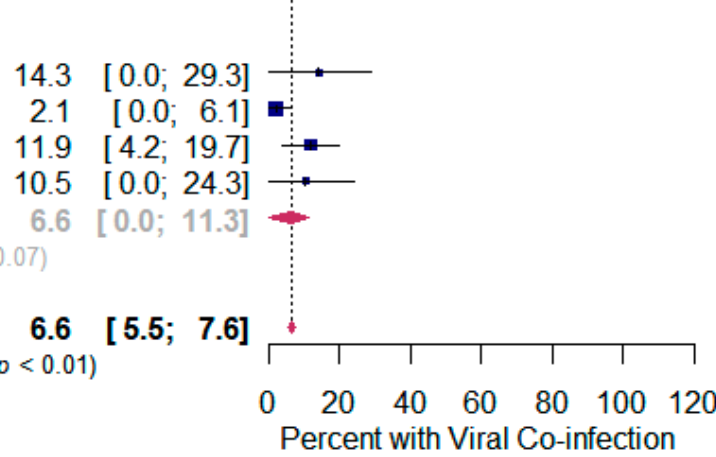

Figure 4. Forest plot of proportion of SARS-CoV-2 patients with respiratory viral co-infections (all patients in the upper panel and only ICU patients in the lower panel). 


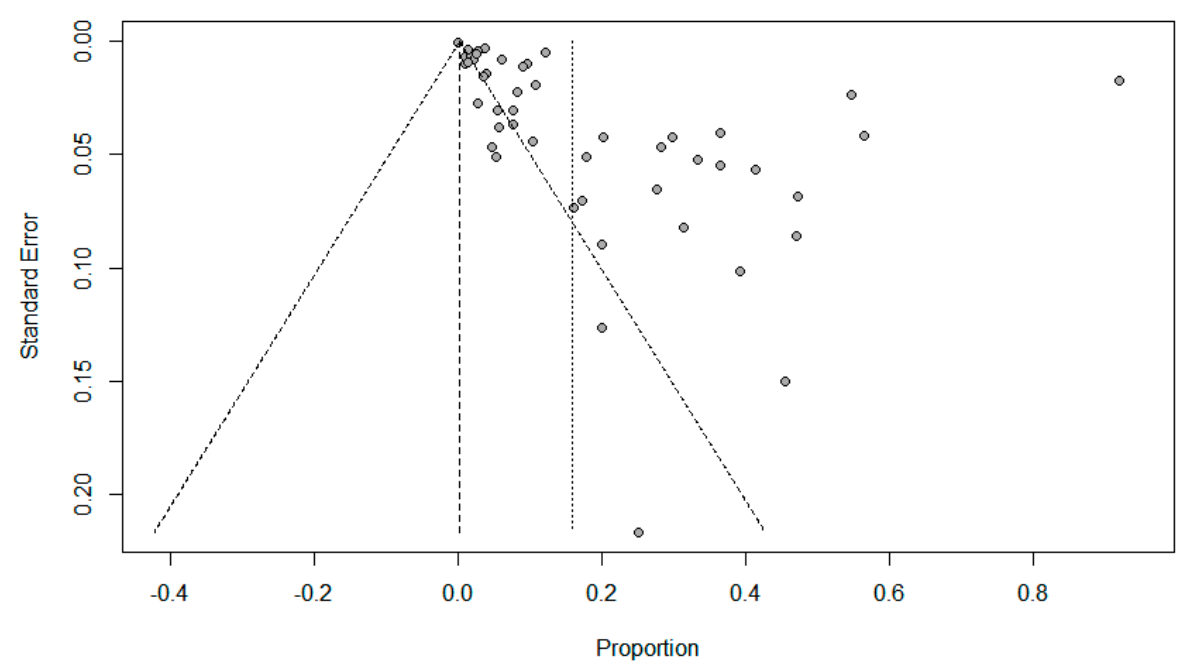

Figure 5. Funnel plots evaluating publication bias for the pooled effect size determining the prevalence of bacterial co-infections in SARS-Cov-2 patients.

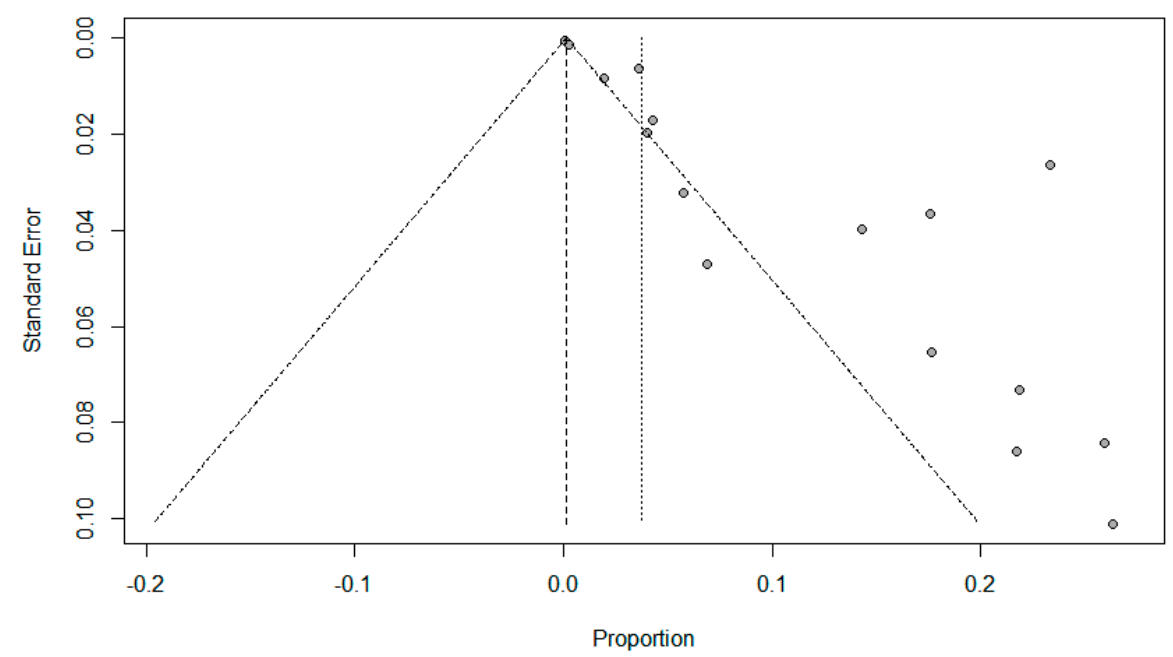

Figure 6. Funnel plots evaluating publication bias for the pooled effect size to determine the prevalence of fungal co-infections in SARS-Cov-2 patients.

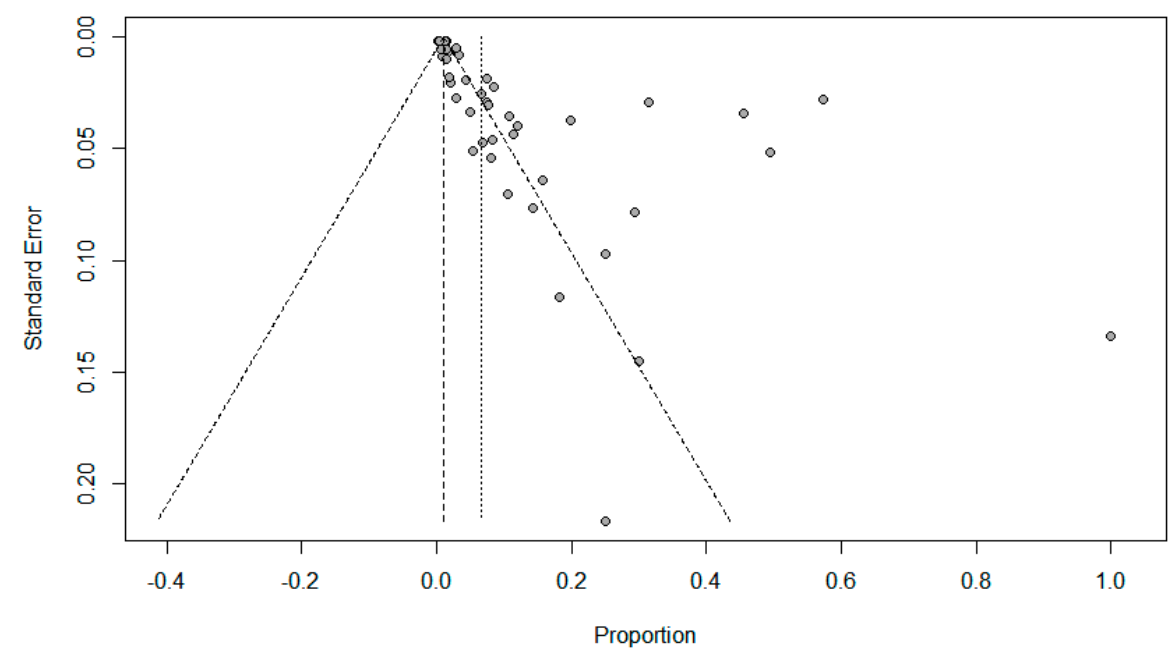

Figure 7. Funnel plots to evaluate publication bias for the pooled effect size to determine the prevalence of other respiratory viral co-infections in SARS-Cov-2 patients. 
Table 2. Proportion of all identified SARS-CoV-2 bacterial co-infections $(\mathrm{N}=3468)$.

\begin{tabular}{|c|c|c|c|}
\hline Bacterial Pathogen Type & Identified Number (\%) & Bacterial Pathogen Type & Identified Number (\%) \\
\hline S. aureus & $1,095(31.6)$ & Corynebacterium spp. & $6(0.2)$ \\
\hline M. catarrhalis & $352(10.1)$ & Bordetella pertussis & $5(0.1)$ \\
\hline M. pneumoniae & $338(9.7)$ & Micrococcus luteus & $5(0.1)$ \\
\hline S. pneumoniae & $316(9.1)$ & Citrobacter koseri & $4(0.1)$ \\
\hline C. pneumoniae & $261(7.5)$ & Hafnia alvei & $3(0.1)$ \\
\hline K. pneumoniae & $259(7.5)$ & S. maltophilia & $3(0.1)$ \\
\hline H. influenzae & $197(5.7)$ & Streptococcus anginosus & $3(0.1)$ \\
\hline CoNS & 115 (3.3) & Streptococcus Group A & $3(0.1)$ \\
\hline E. coli & $65(1.9)$ & Burkholderia cepacia & $3(0.1)$ \\
\hline P. aeruginosa & $48(1.4)$ & Bacteroides spp. & $3(0.1)$ \\
\hline Staphylococcus epidermidis & $42(1.2)$ & Stephanoascus ciferrii & $3(0.1)$ \\
\hline MSSA & $31(0.9)$ & $\begin{array}{c}\text { Elizabethkingia } \\
\text { meningosepticum }\end{array}$ & $2(0.1)$ \\
\hline Other Enterococcus spp. & $31(0.9)$ & Granulicatella adiacens & $2(0.1)$ \\
\hline Staphylococcus hominis & $28(0.8)$ & Lactobacillus & $2(0.1)$ \\
\hline A. baumannii & $24(0.7)$ & Streptococci agalactiae & $2(0.1)$ \\
\hline Enterococcus faecium & $23(0.7)$ & Fusobacterium spp. & $2(0.1)$ \\
\hline MRSA & $18(0.5)$ & Aerococcus urinae & $1(0.03)$ \\
\hline Enterococcus faecalis & $17(0.5)$ & Streptococcus intermedius & $1(0.03)$ \\
\hline Other Klebsiella spp. & $15(0.4)$ & Streptococcus sanguinis & $1(0.03)$ \\
\hline Enterobacter cloacae & $15(0.4)$ & Actinomyces turicensis & $1(0.03)$ \\
\hline Pseudomonas spp. & $13(0.4)$ & Providencia spp. & $1(0.03)$ \\
\hline Streptococcus pneumoniae & $12(0.3)$ & Ralstonia mannitolilytica & $1(0.03)$ \\
\hline Staphylococcus capitis & $11(0.3)$ & Rothia aeria & $1(0.03)$ \\
\hline Methicillin Susceptible- CoNS & $10(0.3)$ & Legionella pneumophila & $1(0.03)$ \\
\hline Other Streptococcus spp. & $9(0.3)$ & Clostridium perfringens & $1(0.03)$ \\
\hline Proteus mirabilis & $9(0.3)$ & Comamonas testosteroni & $1(0.03)$ \\
\hline Bacillus non-anthracis & $9(0.3)$ & Dolosigranulum pigrum & $1(0.03)$ \\
\hline Other Staphylococcus spp. & $8(0.2)$ & Globicatella sanguinis & $1(0.03)$ \\
\hline Serratia marcescens & $8(0.2)$ & Kocuria marina & $1(0.03)$ \\
\hline Staphylococcus haemolyticus & $8(0.2)$ & Morganella morganii & $1(0.03)$ \\
\hline Stenotrophomonas maltophilia & $8(0.2)$ & Moraxella osloensis & $1(0.03)$ \\
\hline Methicillin Resistant- CoNS & $7(0.2)$ & & \\
\hline
\end{tabular}

Abbreviations: SARS-CoV-2, severe acute respiratory syndrome coronavirus 2; C. pneumoniae, Chlamydia pneumoniae; M. pneumoniae, Mycoplasma pneumoniae; H. influenzae, Haemophilus influenzae; K. pneumoniae, Klebsiella pneumoniae; P. aeruginosa, Pseudomonas aeruginosa; S. pneumoniae, Streptococcus pneumoniae; M. catarrhalis, Moraxella catarrhalis; MRSA, methicillin-resistant Staphylococcus aureus; S. aureus, Staphylococcus aureus; A. baumannii, Acinetobacter baumannii; MSSA, methicillin-susceptible Staphylococcus aureus; CoNS, coagulase-negative staphylococci; E. coli, Escherichia coli; spp., species. 
Table 3. Proportion of all identified SARS-CoV-2 fungal co-infections ( $\mathrm{N}=192)$.

\begin{tabular}{cc}
\hline Fungal Pathogen Type & Identified Number (\%) \\
\hline Aspergillus spp. & $68(35.4)$ \\
\hline Aspergillus fumigatus & $43(22.4)$ \\
\hline Other Candida spp. & $29(15.1)$ \\
\hline Candida albicans & $25(13)$ \\
\hline Aspergillus flavus & $10(5.2)$ \\
\hline Mucor & $6(3.1)$ \\
\hline Candida glabrata & $5(2.6)$ \\
\hline Aspergillus niger & $4(2.1)$ \\
\hline Aspergillus terreus & $1(0.5)$ \\
\hline Cryptococcus & $1(0.5)$ \\
\hline
\end{tabular}

Abbreviations: SARS-CoV-2, severe acute respiratory syndrome coronavirus 2; spp., species.

Table 4. Proportion of all identified SARS-CoV-2 respiratory viral co-infections ( $=2392)$.

\begin{tabular}{|c|c|}
\hline Respiratory Viral Pathogen Type & Identified Number (\%) \\
\hline EBV & $644(26.9)$ \\
\hline HHV6 & $574(24)$ \\
\hline Influenza $A$ virus & $355(14.8)$ \\
\hline HMPV & $328(13.7)$ \\
\hline Adenovirus & $144(6)$ \\
\hline Influenza $B$ virus & $68(2.8)$ \\
\hline Rhinovirus/Enterovirus & $68(2.8)$ \\
\hline RSV & $52(2.2)$ \\
\hline Parainfluenza $[1,2,3$ and 4$]$ virus & $29(1.2)$ \\
\hline HcoV-OC43 & $11(0.5)$ \\
\hline Rhinovirus & $22(0.9)$ \\
\hline Influenza virus $\left(\mathrm{H}_{1} \mathrm{~N}_{1}\right)$ & $18(0.8)$ \\
\hline HcoV-HKU1 & $16(0.7)$ \\
\hline HcoV-NL63 & $13(0.5)$ \\
\hline Bocavirus & $10(0.4)$ \\
\hline HSV & $10(0.4)$ \\
\hline HcoV-229E & $9(0.4)$ \\
\hline CMV & $8(0.3)$ \\
\hline MERS-CoV & $8(0.3)$ \\
\hline Enterovirus & $1(0.04)$ \\
\hline Rotavirus & $1(0.04)$ \\
\hline Coxsackie virus & $1(0.04)$ \\
\hline Human Coronavirus 229E & $1(0.04)$ \\
\hline Herpes virus 5 & $1(0.04)$ \\
\hline
\end{tabular}

Abbreviations: SARS-CoV-2, severe acute respiratory syndrome coronavirus 2; RSV, respiratory syncytial virus; EBV, Epstein-Barr virus; HcoV-HKU1, human coronavirus HKU1; CMV, cytomegalovirus; HSV, herpes simplex virus; HHV6, human herpes virus 6; HMPV, human metapneumovirus. 


\section{Discussion}

In this large systematic review and meta-analysis, we included 31,953 patients with laboratory-confirmed SARS-CoV-2 from 72 observational studies in order to estimate the prevalence of coinfections with bacterial, fungal, and respiratory viral pathogens. This study showed the following microbial coinfection prevalences: bacterial $(15.9 \%, 95 \% \mathrm{CI}$ 13.6-18.2); fungal (3.7\%, 95\% CI 2.6-4.8); and respiratory viral (6.6\%, 95\% CI 5.5-7.6) coinfections. Bacterial and fungal coinfections were more common in ICU patients $((22.2 \% \%$, 95\% CI 16.1-28.4) and (9.6\%, 95\% CI 6.8-12.4), respectively) than mixed ICU and nonICU patients, as expected. However, respiratory viral co-infection rate in SARS-CoV-2 patients was identical in both groups $(6.6 \%, 95 \%$ CI $0.0-11.3)$. Nevertheless, the included studies in this meta-analysis are case series and cohort studies and we did not identify any randomized controlled trials addressing this issue. In addition, the included studies comprised only admitted patients, which may skew the findings and should not be generalized to all SARS-COV-2 patients. Non-admitted COVID-19 patients were not represented in these studies and thus the exact prevalence of coinfections could not be calculated for all SARS-CoV-2 infected patients [83-85]. The findings in this meta-analysis showed different results from previous systematic meta-analyses that evaluated coinfections among COVID-19 patients [71-73]. We reported a higher prevalence of coinfections in hospitalized SARS-CoV-2 patients. The current meta-analysis is more comprehensive and included a total of 71 studies [2,4-70,80] and one abstract [3], including a total of 31,953 patients. The inclusion of 18 recently published studies $[2,3,5-10,12-14,22,24,27,41,62,64,65]$ contributed to the refinement of the estimate of the pooled prevalence of pathogens contributing to coinfections in SARS-CoV-2 patients.

In this meta-analysis, bacterial coinfection was more prevalent than fungal and other respiratory viruses. This finding may reflect high rates of antimicrobial use for admitted patients with SARS-CoV-2 infection to treat documented or presumed bacterial co-infections. Thus, it is important to study the occurrence, type, and intended antimicrobial agent use in SARS-COV-2 patients in order to develop additional strategies for the optimal use of antimicrobial agents in this population. As expected, bacterial, fungal, and other respiratory viral co-infections in SARS-CoV-2 patients were more frequent in ICUs compared with non-ICU locations $[2,20,28,57]$, a finding which has previously been described in systematic reviews [71,72] and may reflect the epicenter role of ICUs in both infections and antimicrobial resistance. One of the reasons for the increase in infection rate in ICUs could be due to the simultaneous infection of the virus and bacterium. Viruses can facilitate the attachment and colonization of the bacteria in the respiratory tract, which is certainly no exception for SARS-CoV-2 [86]. Nevertheless, other factors such as ICU type, used equipment rate, admission or discharge criteria, high workload or nurse ratio, etc. can also affect the quality of care and the rate of ICU-acquired, healthcare-associated infections $[87,88]$. With observed strains currently being placed on healthcare systems during the upstroke of the SARS-CoV-2 pandemic, guidelines must focus on the maintenance of good knowledge and compliance of infection prevention and control [89], antimicrobial stewardship [90], and robust surveillance for healthcare-associated infections and antimicrobial resistance [91,92].

The most common method used to detect co-infections in the studies included in this review was RT-PCR tests for respiratory samples. The choice of diagnostic test for pathogens depends in part upon test availability and how soon the results are needed. If available, molecular assays (RT-PCR or, alternatively, a rapid molecular assay) are preferred over antigen detection tests (e.g., direct and indirect immunofluorescence assays) because molecular tests are the most sensitive [93]. Nevertheless, positive RT-PCR tests might indicate recently resolved infection or colonization [94,95]. In addition, many studies evaluated serological (antibodies) tests with this method detecting co-infections in SARS$\mathrm{CoV}-2$ patients. Application of serologic laboratory technique for co-pathogens detection across all studies was likely to reveal an even higher overall co-infection proportion than found in our study. Consecutively, it is possible that positive serology indicated recent and not acute infection in included patients [96]. Serologic testing is useful primarily for 
research purposes and antibody-based tests might produce false negative results during the window period. It is worthwhile to mention that administration of broad-spectrum antimicrobials to a large percentage of the patients included in this review might relatively have lowered the sensitivity of microbial culture methods, which could have resulted in underestimation of the true numbers of co-infections.

Specific co-infecting pathogens in SARS-CoV-2 patients were identified in this study from the 72 included studies. In line with the previous systematic reviews and metaanalyses [71,72], M. pneumoniae, K. pneumoniae, and H. influenzae were among the predominant co-pathogens. However, in this meta-analysis, S. aureus was the most common bacterial pathogens co-infecting SARS-CoV-2 patients. However, this finding needs to be carefully interpreted, as $85.6 \%$ of all $S$. aureus co-pathogens in our review were reported by one study [58]. S. aureus infections are a known complication of other viral pandemics, such as the Spanish flu and the $\mathrm{H}_{1} \mathrm{~N}_{1}$ influenza pandemic $[97,98]$. S. aureus is known to act synergistically in SARS-CoV-2 patients, increasing mortality and severity of disease [38,99]. The proposed mechanisms of viral-induced $S$. aureus co-infections include viral modification of airway structures and increased adherence of the organism to respiratory mucosa, as well as initiation of immune-suppressive responses [22,100,101]. Further investigations are necessary to confirm an association between SARS-CoV-2 infection and susceptibility to $S$. aureus coinfections.

It was noted that male patients with SARS-CoV-2 were more likely to have coinfections than female [13]. However, patients with pneumococcal pneumoniae and SARS-CoV-2 were mostly females [24]. Older age appears to be the major risk factor associated with coinfections with bacteria and respiratory viruses [12,38,43,58,62] and fungi [39]. This might be attributed mainly to the differences in the inclusion criteria and the population age groups included in the studies, or it could be explained by the gender-based biological differences in the host immune response to COVID-19 infection [102]. The age-dependent defects in T-cell and B-cell function and the excess production of type 2 cytokines could lead to a deficiency in control of viral replication and more prolonged proinflammatory responses, potentially leading to poorer outcomes [103]. Yet, SARS-CoV-2 patients of any age may develop such coinfections and experience severe disease, especially in those with comorbidities, even in young people [4,53], children [27,49], and infants [40].

A few underlying comorbidities were associated with increased risk of coinfections, and these included obesity $[8,12,38]$, cancer, hepatitis, and kidney disease [12,43]. Laboratory abnormalities that have been described in SARS-CoV-2 patients with bacterial and respiratory viral coinfections were high procalcitonin [47,50,64,80], d-dimer [9], and monocytes [31]; and low neutrophils [31]. Some conclusions could be drawn from available data as to whether patients who have a concurrent bacterial, fungal, and/or respiratory viral infection have a worse prognosis than those in whom SARS-CoV-2 is the only detected pathogen. Mortality in SARS-CoV-2 patients was increased due to bacterial $[2,6,14,21]$, fungal $[2,17,20,21]$, or respiratory viral [20] co-infections compared to SARS-CoV-2 patients with no co-infections. Few studies observed no increase in mortality in COVID-19 patients compared to those who did not have bacterial [3,22,24,35,66], fungal [3,22], or other respiratory viral [66] coinfections. Clinical presentation, laboratory results, radiological findings, and outcome are likely to differ between SARS-CoV-2 positive patients with and without co-infections. Bacterial coinfection increased SARS-CoV-2 patients' hospital length of stay [18,50], need for ventilatory support [6,28], ARDS [28], shock [28], multi-organ injury [23,32], and caused more severe COVID-19 disease [2,21,28,33,34,53,68]. Two studies reported conflicting results on the role of bacterial [24,36] or respiratory viral [36] coinfection in relation to increasing length of hospital stay or ICU admission [22,24,35]. It was shown that the patterns of SARS-CoV-2 symptoms and clinical outcomes were not different in the bacterial [27] and respiratory viral $[10,11,27,66,70]$ co-infected patients. The severity and time of SARS-CoV-2 disease clearance were not different in patients with respiratory viral co-infections $[19,36]$. 
The data on the timing of the occurrence of co-infection was variable. The occurrence of co-infections has a median time of 4-11.5 days (IQR 2-42) of ICU admission [2,17,42]. Bacterial co-infection was infrequent within $2-4$ days of hospital admission $[22,26]$. Nonetheless, considering the high number and severity of bacterial co-infections previously reported in patients with SARS-CoV-2, initiation of antibiotic therapy for all hospitalized patients with COVID-19 is recommended [7]. The approach of administering empiric antibiotic therapy solely to patients who were admitted for SARS-CoV-2 and who presented with a chest X-ray suggestive of bacterial infection, have a need for direct ICU admission, or are severely immunocompromised should be reconsidered. When bacterial co-infection in SARS-CoV-2 patients is suspected, an antibiotic approach with optimal S. aureus coverage, such as ceftaroline, ceftriaxone, or cefazolin plus levofloxacin, is recommended in areas with methicillin-sensitive $S$. aureus prevalence [104].

\section{Limitations}

The main limitation of this meta-analysis is that included studies were observational with no randomized controlled trials; and there was no standardized microbiologic testing at specified intervals. In interpreting funnel plots, the different possible reasons for funnel plot asymmetry should be distinguished. Possible sources of asymmetry in funnel plots might be the wide differences between the included populations in the different studies, publication bias and selective outcome and/or analysis reporting, poor methodological design and inadequate analysis, or asymmetry might have occurred by chance. Furthermore, the analysis was limited to the English literature and thus may miss other studies published in other languages.

\section{Conclusions}

Bacterial co-infection is relatively high in hospitalized patients with SARS-CoV-2, with little evidence of $S$. aureus having a major role. Empiric antibiotic therapy should be considered in SARS-CoV-2 patients who present with a chest X-ray suggestive of bacterial infection, the need for direct ICU admission, or a severely immunocompromised condition. Knowledge of the prevalence and type of co-infections in SARS-CoV-2 patients may have diagnostic and management implications.

Author Contributions: S.A., A.A.M., A.A.R., Z.A.A. and J.A.A.-T. contributed equally to this study. S.A., A.A.M., Z.A.A., and A.A.R. were the core team leading the systematic review. S.A., A.A.M., and J.A.A.-T. identified and selected the studies. A.M.A. (Abeer M. Alshawi), S.A.A., G.Y.A., and A.A.R. did the quality assessment of the studies. S.A., A.A.M., M.S.A., and A.A.A. collected the data. S.A., A.H.B.S., A.M.A. (Abdullah M. Alotaibi), and A.A.-O. analyzed the data. S.A., A.A.M., Z.A.A., A.A.R., and J.A.A.-T. drafted the manuscript. The corresponding author attests that all listed authors meet authorship criteria and that no others meeting the criteria have been omitted. All authors have read and agreed to the published version of the manuscript.

Funding: This research received no external funding.

Institutional Review Board Statement: Not applicable.

Informed Consent Statement: Not applicable.

Data Availability Statement: Data are available upon request. Please contact author for data requests.

Acknowledgments: We would like to thank Hani N. Mufti for precious guidance and support to create the forest and funnel plots using RStudio. We would also like to thank the reviewers for very helpful and valuable comments and suggestions for improving the paper.

Conflicts of Interest: The authors declare that they have no competing interests. 


\section{References}

1. World Health Organization. WHO Coronavirus (COVID-19) Dashboard. 2021. Available online: https://covid19.who.int (accessed on 5 April 2021).

2. Bardi, T.; Pintado, V.; Gomez-Rojo, M.; Escudero-Sanchez, R.; Lopez, A.A.; Diez-Remesal, Y.; Castro, N.M.; Ruiz-Garbajosa, P.; Pestaña, D. Nosocomial infections associated to COVID-19 in the intensive care unit: Clinical characteristics and outcome. Eur. J. Clin. Microbiol. Infect. Dis. 2021, 40, 495-502. [CrossRef]

3. May, A.; Swetenham, N.; Pandey, M.; Taylor, V.; Hughes, H.; Underwood, J. P197 Bacterial and fungal respiratory co-infection among patients admitted to ICU with COVID-19: A retrospective cohort study in a UK hospital. BMJ 2021, 76, A196-A197.

4. Zhu, X.; Ge, Y.; Wu, T.; Zhao, K.; Chen, Y.; Wu, B.; Zhu, F.; Zhu, B.; Cui, L. Co-infection with respiratory pathogens among COVID-2019 cases. Virus Res. 2020, 285, 198005. [CrossRef]

5. Calcagno, A.; Ghisetti, V.; Burdino, E.; Trunfio, M.; Allice, T.; Boglione, L.; Bonora, S.; Di Perri, G. Co-infection with other respiratory pathogens in COVID-19 patients. Clin. Microbiol. Infect. 2021, 27, 297-298. [CrossRef]

6. De Francesco, M.A.; Poiesi, C.; Gargiulo, F.; Bonfanti, C.; Pollara, P.; Fiorentini, S.; Caccuri, F.; Carta, V.; Mangeri, L.; Pellizzeri, S. Co-infection of Chlamydia pneumoniae and Mycoplasma pneumoniae with SARS-CoV-2 is associated with more severe features. J. Infect. 2021, 8. [CrossRef]

7. Garcia-Vidal, C.; Sanjuan, G.; Moreno-García, E.; Puerta-Alcalde, P.; Garcia-Pouton, N.; Chumbita, M.; Fernandez-Pittol, M.; Pitart, C.; Inciarte, A.; Bodro, M. Incidence of co-infections and superinfections in hospitalized patients with COVID-19: A retrospective cohort study. Clin. Microbiol. Infect. 2021, 27, 83-88. [CrossRef] [PubMed]

8. Elhazmi, A.; Al-Tawfiq, J.A.; Sallam, H.; Al-Omari, A.; Alhumaid, S.; Mady, A.; Al Mutair, A. Severe respiratory syndrome Coronavirus 2 (SARS-CoV-2) and middle east respiratory syndrome Coronavirus (MERS-CoV) coinfection: A unique case series. Travel Med. Infect. Dis. 2021, 41, 102026. [CrossRef] [PubMed]

9. Allou, N.; Larsen, K.; Dubernet, A.; Traversier, N.; Masse, L.; Foch, E.; Bruneau, L.; Maillot, A.; André, M.; Lagrange-Xelot, M. Co-infection in patients with hypoxemic pneumonia due to COVID-19 in Reunion Island. Medicine 2021, 100, e24524. [CrossRef]

10. Cheng, Y.; Ma, J.; Wang, H.; Wang, X.; Hu, Z.; Li, H.; Zhang, H.; Liu, X. Co-infection of influenza A virus and SARS-CoV-2: A retrospective cohort study. J. Med. Virol. 2021, 93. [CrossRef]

11. Cuadrado-Payán, E.; Montagud-Marrahi, E.; Torres-Elorza, M.; Bodro, M.; Blasco, M.; Poch, E.; Soriano, A.; Piñeiro, G.J. SARS-CoV-2 and influenza virus co-infection. Lancet 2020, 395, e84. [CrossRef]

12. Hashemi, S.A.; Safamanesh, S.; Ghasemzadeh-Moghaddam, H.; Ghafouri, M.; Azimian, A. High prevalence of SARS-CoV-2 and influenza A virus (H1N1) coinfection in dead patients in northeastern Iran. J. Med. Virol. 2021, 93, 1008-1012. [CrossRef]

13. Schirmer, P.; Lucero-Obusan, C.; Sharma, A.; Sohoni, P.; Oda, G.; Holodniy, M. Respiratory co-infections with COVID-19 in the Veterans Health Administration, 2020. Diagn. Microbiol. Infect. Dis. 2021, 100, 115312. [CrossRef]

14. Amin, D.; McKitish, K.; Shah, P.S. Association of mortality and recent Mycoplasma pneumoniae infection in COVID-19 patients. J. Med. Virol. 2021, 93, 1180-1183. [CrossRef] [PubMed]

15. Arentz, M.; Yim, E.; Klaff, L.; Lokhandwala, S.; Riedo, F.X.; Chong, M.; Lee, M. Characteristics and outcomes of 21 critically ill patients with COVID-19 in Washington state. JAMA 2020, 323, 1612-1614. [CrossRef] [PubMed]

16. Barrasa, H.; Rello, J.; Tejada, S.; Martín, A.; Balziskueta, G.; Vinuesa, C.; Fernández-Miret, B.; Villagra, A.; Vallejo, A.; San Sebastián, A. SARS-CoV-2 in Spanish intensive care units: Early experience with 15-day survival in Vitoria. Anaesth. Crit. Care Pain Med. 2020, 39, 553-561. [CrossRef]

17. Bartoletti, M.; Pascale, R.; Cricca, M.; Rinaldi, M.; Maccaro, A.; Bussini, L.; Fornaro, G.; Tonetti, T.; Pizzilli, G.; Francalanci, E. Epidemiology of invasive pulmonary aspergillosis among COVID-19 intubated patients: A prospective study. Clin. Infect. Dis. 2020. [CrossRef] [PubMed]

18. Cheng, L.S.; Chau, S.K.; Tso, E.Y.; Tsang, S.W.; Li, I.Y.; Wong, B.K.; Fung, K.S. Bacterial co-infections and antibiotic prescribing practice in adults with COVID-19: Experience from a single hospital cluster. Ther. Adv. Infect. Dis. 2020, 7. [CrossRef]

19. Ding, Q.; Lu, P.; Fan, Y.; Xia, Y.; Liu, M. The clinical characteristics of pneumonia patients coinfected with 2019 novel coronavirus and influenza virus in Wuhan, China. J. Med. Virol. 2020, 92, 1549-1555. [CrossRef]

20. Koehler, P.; Cornely, O.A.; Böttiger, B.W.; Dusse, F.; Eichenauer, D.A.; Fuchs, F.; Hallek, M.; Jung, N.; Klein, F.; Persigehl, T. COVID-19 associated pulmonary aspergillosis. Mycoses 2020, 63, 528-534. [CrossRef]

21. Ramadan, H.K.-A.; Mahmoud, M.A.; Aburahma, M.Z.; Elkhawaga, A.A.; El-Mokhtar, M.A.; Sayed, I.M.; Hosni, A.; Hassany, S.M.; Medhat, M.A. Predictors of severity and co-infection resistance profile in COVID-19 patients: First report from upper Egypt. Infect. Drug Res. 2020, 13, 3409. [CrossRef]

22. Wang, L.; Amin, A.K.; Khanna, P.; Aali, A.; McGregor, A.; Bassett, P.; Gopal Rao, G. An observational cohort study of bacterial co-infection and implications for empirical antibiotic therapy in patients presenting with COVID-19 to hospitals in north west London. J. Antimicrob. Chemother. 2021, 76, 796-803. [CrossRef]

23. Alanio, A.; Dellière, S.; Fodil, S.; Bretagne, S.; Mégarbane, B. Prevalence of putative invasive pulmonary aspergillosis in critically ill patients with COVID-19. Lancet Respir. Med. 2020, 8, e48-e49. [CrossRef]

24. Anton-Vazquez, V.; Clivillé, R. Streptococcus pneumoniae coinfection in hospitalised patients with COVID-19. Eur. J. Clin. Microbiol. Infect. Dis. 2021, 40, 1353-1355. [CrossRef] [PubMed] 
25. Chen, T.; Dai, Z.; Mo, P.; Li, X.; Ma, Z.; Song, S.; Chen, X.; Luo, M.; Liang, K.; Gao, S. Clinical characteristics and outcomes of older patients with coronavirus disease 2019 (COVID-19) in Wuhan, China: A single-centered, retrospective study. J. Gerontol. Ser. A 2020, 75, 1788-1795. [CrossRef]

26. Hughes, S.; Troise, O.; Donaldson, H.; Mughal, N.; Moore, L.S. Bacterial and fungal coinfection among hospitalized patients with COVID-19: A retrospective cohort study in a UK secondary-care setting. Clin. Microbiol. Infect. 2020, 26, 1395-1399. [CrossRef] [PubMed]

27. Li, Y.; Wang, H.; Wang, F.; Lu, X.; Du, H.; Xu, J.; Han, F.; Zhang, L.; Zhang, M. Co-infections of SARS-CoV-2 with multiple common respiratory pathogens in infected children: A retrospective study. Medicine 2021, 100. [CrossRef]

28. Li, Z.; Chen, Z.; Chen, L.D.; Zhan, Y.Q.; Li, S.Q.; Cheng, J.; Zhu, A.; Chen, L.Y.; Zhong, N.S.; Li, S.Y. Coinfection with SARS-CoV-2 and other respiratory pathogens in patients with COVID-19 in Guangzhou, China. J. Med. Virol. 2020, 92, 2381-2383. [CrossRef] [PubMed]

29. Lin, D.; Liu, L.; Zhang, M.; Hu, Y.; Yang, Q.; Guo, J.; Guo, Y.; Dai, Y.; Xu, Y.; Cai, Y. Co-infections of SARS-CoV-2 with multiple common respiratory pathogens in infected patients. Sci. China Life Sci. 2020, 63, 606-609. [CrossRef] [PubMed]

30. Liu, H.; Liu, F.; Li, J.; Zhang, T.; Wang, D.; Lan, W. Clinical and CT imaging features of the COVID-19 pneumonia: Focus on pregnant women and children. J. Infect. 2020,80, e7-e13. [CrossRef]

31. Liu, L.; Lei, X.; Xiao, X.; Yang, J.; Li, J.; Ji, M.; Du, W.; Tan, H.; Zhu, J.; Li, B. Epidemiological and clinical characteristics of patients with coronavirus disease-2019 in Shiyan City, China. Front. Cell. Infect. Microbiol. 2020, 10. [CrossRef] [PubMed]

32. Ma, S.; Lai, X.; Chen, Z.; Tu, S.; Qin, K. Clinical characteristics of critically ill patients co-infected with SARS-CoV-2 and the influenza virus in Wuhan, China. Int. J. Infect. Dis. 2020, 96, 683-687. [CrossRef]

33. Mannheim, J.; Gretsch, S.; Layden, J.E.; Fricchione, M.J. Characteristics of hospitalized pediatric coronavirus disease 2019 cases in Chicago, Illinois, March-April 2020. J. Pediatr. Infect. Dis. Soc. 2020, 9, 519-522. [CrossRef] [PubMed]

34. Nasir, N.; Farooqi, J.; Mahmood, S.F.; Jabeen, K. COVID-19-associated pulmonary aspergillosis (CAPA) in patients admitted with severe COVID-19 pneumonia: An observational study from Pakistan. Mycoses 2020, 63, 766-770. [CrossRef]

35. Oliva, A.; Siccardi, G.; Migliarini, A.; Cancelli, F.; Carnevalini, M.; D’Andria, M.; Attilia, I.; Danese, V.C.; Cecchetti, V.; Romiti, R. Co-infection of SARS-CoV-2 with Chlamydia or Mycoplasma pneumoniae: A case series and review of the literature. Infection 2020, 48, 871-877. [CrossRef]

36. Peng, H.; Gao, P.; Xu, Q.; Liu, M.; Peng, J.; Wang, Y.; Xu, H. Coronavirus disease 2019 in children: Characteristics, antimicrobial treatment, and outcomes. J. Med. Virol. 2020, 128, 104425. [CrossRef]

37. Pongpirul, W.A.; Mott, J.A.; Woodring, J.V.; Uyeki, T.M.; MacArthur, J.R.; Vachiraphan, A.; Suwanvattana, P.; Uttayamakul, S.; Chunsuttiwat, S.; Chotpitayasunondh, T. Clinical characteristics of patients hospitalized with coronavirus disease, Thailand. Emerg. Infect. Dis. 2020, 26, 1580-1585. [CrossRef]

38. Richardson, S.; Hirsch, J.S.; Narasimhan, M.; Crawford, J.M.; McGinn, T.; Davidson, K.W.; Barnaby, D.P.; Becker, L.B.; Chelico, J.D.; Cohen, S.L. Presenting characteristics, comorbidities, and outcomes among 5700 patients hospitalized with COVID-19 in the New York City area. JAMA 2020, 323, 2052-2059. [CrossRef] [PubMed]

39. Rutsaert, L.; Steinfort, N.; Van Hunsel, T.; Bomans, P.; Naesens, R.; Mertes, H.; Dits, H.; Van Regenmortel, N. COVID-19-associated invasive pulmonary aspergillosis. Ann. Intensiv. Care 2020, 10, 71. [CrossRef] [PubMed]

40. Sun, D.; Chen, X.; Li, H.; Lu, X.-X.; Xiao, H.; Zhang, F.-R.; Liu, Z.-S. SARS-CoV-2 infection in infants under 1 year of age in Wuhan City, China. World J. Pediatr. 2020, 16, 260-266. [CrossRef] [PubMed]

41. Tagarro, A.; Epalza, C.; Santos, M.; Sanz-Santaeufemia, F.J.; Otheo, E.; Moraleda, C.; Calvo, C. Screening and severity of coronavirus disease 2019 (COVID-19) in children in Madrid, Spain. JAMA Pediatr. 2021, 175, 316-317. [CrossRef]

42. Van Arkel, A.L.; Rijpstra, T.A.; Belderbos, H.N.; Van Wijngaarden, P.; Verweij, P.E.; Bentvelsen, R.G. COVID-19-associated pulmonary aspergillosis. Am. J. Respir. Crit. Care Med. 2020, 202, 132-135. [CrossRef]

43. Wang, R.; Pan, M.; Zhang, X.; Han, M.; Fan, X.; Zhao, F.; Miao, M.; Xu, J.; Guan, M.; Deng, X. Epidemiological and clinical features of 125 hospitalized patients with COVID-19 in Fuyang, Anhui, China. Int. J. Infect. Dis. 2020, 95, 421-428. [CrossRef] [PubMed]

44. Wang, Y.; Liu, Y.; Liu, L.; Wang, X.; Luo, N.; Li, L. Clinical outcomes in 55 patients with severe acute respiratory syndrome coronavirus 2 who were asymptomatic at hospital admission in Shenzhen, China. J. Infect. Dis. 2020, 221, 1770-1774. [CrossRef] [PubMed]

45. Wang, Z.; Yang, B.; Li, Q.; Wen, L.; Zhang, R. Clinical features of 69 cases with coronavirus disease 2019 in Wuhan, China. Clin. Infect. Dis. 2020, 71, 769-777. [CrossRef]

46. Wu, Q.; Xing, Y.; Shi, L.; Li, W.; Gao, Y.; Pan, S.; Wang, Y.; Wang, W.; Xing, Q. Coinfection and other clinical characteristics of COVID-19 in children. Pediatrics 2020, 146. [CrossRef] [PubMed]

47. Xia, W.; Shao, J.; Guo, Y.; Peng, X.; Li, Z.; Hu, D. Clinical and CT features in pediatric patients with COVID-19 infection: Different points from adults. Pediatr. Pulmonol. 2020, 55, 1169-1174. [CrossRef]

48. Yang, X.; Yu, Y.; Xu, J.; Shu, H.; Liu, H.; Wu, Y.; Zhang, L.; Yu, Z.; Fang, M.; Yu, T. Clinical course and outcomes of critically ill patients with SARS-CoV-2 pneumonia in Wuhan, China: A single-centered, retrospective, observational study. Lancet Respir. Med. 2020, 8, 475-481. [CrossRef]

49. Zheng, F.; Liao, C.; Fan, Q.-H.; Chen, H.; Zhao, X.; Xie, Z.; Li, X.; Chen, C.; Lu, X.; Liu, Z. Clinical characteristics of children with coronavirus disease 2019 in Hubei, China. Curr. Med. Sci. 2020, 275-280. [CrossRef] 
50. Zhang, J.; Dong, X.; Cao, Y.; Yuan, Y.; Yang, Y.; Yan, Y.; Akdis, C.A.; Gao, Y. Clinical characteristics of 140 patients infected with SARS-CoV-2 in Wuhan, China. Allergy 2020, 75, 1730-1741. [CrossRef] [PubMed]

51. Contou, D.; Claudinon, A.; Pajot, O.; Micaëlo, M.; Flandre, P.L.; Dubert, M.; Cally, R.; Logre, E.; Fraissé, M.; Mentec, H. Bacterial and viral co-infections in patients with severe SARS-CoV-2 pneumonia admitted to a French ICU. Ann. Intensive Care 2020, 10, 119. [CrossRef]

52. Gayam, V.; Konala, V.M.; Naramala, S.; Garlapati, P.R.; Merghani, M.A.; Regmi, N.; Balla, M.; Adapa, S. Presenting characteristics, comorbidities, and outcomes of patients coinfected with COVID-19 and Mycoplasma pneumoniae in the USA. J. Med. Virol. 2020, 92, 2181-2187. [CrossRef]

53. Hazra, A.; Collison, M.; Pisano, J.; Kumar, M.; Oehler, C.; Ridgway, J.P. Coinfections with SARS-CoV-2 and other respiratory pathogens. Infect. Control Hosp. Epidemiol. 2020, 41, 1228-1229. [CrossRef]

54. Karami, Z.; Knoop, B.T.; Dofferhoff, A.S.; Blaauw, M.J.; Janssen, N.A.; van Apeldoorn, M.; Kerckhoffs, A.P.; van de Maat, J.S.; Hoogerwerf, J.J.; Ten Oever, J. Few bacterial co-infections but frequent empiric antibiotic use in the early phase of hospitalized patients with COVID-19: Results from a multicentre retrospective cohort study in The Netherlands. Infect. Dis. 2020. [CrossRef] [PubMed]

55. Kim, D.; Quinn, J.; Pinsky, B.; Shah, N.H.; Brown, I. Rates of co-infection between SARS-CoV-2 and other respiratory pathogens. JAMA 2020, 323, 2085-2086. [CrossRef] [PubMed]

56. Kreitmann, L.; Monard, C.; Dauwalder, O.; Simon, M.; Argaud, L. Early bacterial co-infection in ARDS related to COVID-19. Intensive Care Med. 2020, 46, 1787-1789. [CrossRef] [PubMed]

57. Lehmann, C.J.; Pho, M.T.; Pitrak, D.; Ridgway, J.P.; Pettit, N.N. Community acquired co-infection in COVID-19: A retrospective observational experience. Clin. Infect. Dis. 2020. [CrossRef]

58. Massey, B.W.; Jayathilake, K.; Meltzer, H.Y. Respiratory microbial co-infection with SARS-CoV-2. Front. Microbiol. 2020, 11 [CrossRef] [PubMed]

59. Nowak, M.D.; Sordillo, E.M.; Gitman, M.R.; Paniz Mondolfi, A.E. Coinfection in SARS-CoV-2 infected patients: Where are influenza virus and rhinovirus/enterovirus? J. Med. Virol. 2020, 92, 1699-1700. [CrossRef]

60. Ozaras, R.; Cirpin, R.; Duran, A.; Duman, H.; Arslan, O.; Bakcan, Y.; Kaya, M.; Mutlu, H.; Isayeva, L.; Kebanl1, F. Influenza and COVID-19 coinfection: Report of six cases and review of the literature. J. Med. Virol. 2020, 92, 2657-2665. [CrossRef]

61. Sepulveda, J.; Westblade, L.F.; Whittier, S.; Satlin, M.J.; Greendyke, W.G.; Aaron, J.G.; Zucker, J.; Dietz, D.; Sobieszczyk, M.; Choi, J.J. Bacteremia and blood culture utilization during COVID-19 surge in New York City. J. Med. Virol. 2020, 58. [CrossRef]

62. Singh, V.; Upadhyay, P.; Reddy, J.; Granger, J. SARS-CoV-2 respiratory co-infections: Incidence of viral and bacterial co-pathogens. Int. J. Infect. Dis. 2021. [CrossRef] [PubMed]

63. Song, W.; Jia, X.; Zhang, X.; Ling, Y.; Yi, Z. Co-infection in COVID-19, a cohort study. J. Infect. 2020. [CrossRef] [PubMed]

64. Tang, M.-L.; Li, Y.-Q.; Chen, X.; Lin, H.; Jiang, Z.-C.; Gu, D.-L.; Chen, X.; Tang, C.-X.; Xie, Z.-Q. Co-infection with common respiratory pathogens and SARS-CoV-2 in patients with COVID-19 pneumonia and laboratory biochemistry findings: A retrospective cross-sectional study of 78 patients from a single center in China. Int. Med. J. Exp. Clin. Res. 2021, 27, e929783-1.

65. Thelen, J.M.; Buenen, A.N.; van Apeldoorn, M.; Wertheim, H.F.; Hermans, M.H.; Wever, P.C. Community-acquired bacteraemia in COVID-19 in comparison to influenza A and influenza B: A retrospective cohort study. BMC Infect. Dis. 2021, 21, 199. [CrossRef]

66. Wee, L.E.; Ko, K.K.K.; Ho, W.Q.; Kwek, G.T.C.; Tan, T.T.; Wijaya, L. Community-acquired viral respiratory infections amongst hospitalized inpatients during a COVID-19 outbreak in Singapore: Co-infection and clinical outcomes. J. Clin. Virol. 2020, 128, 104436. [CrossRef] [PubMed]

67. Wu, C.; Chen, X.; Cai, Y.; Zhou, X.; Xu, S.; Huang, H.; Zhang, L.; Zhou, X.; Du, C.; Zhang, Y. Risk factors associated with acute respiratory distress syndrome and death in patients with coronavirus disease 2019 pneumonia in Wuhan, China. JAMA Intern. Med. 2020, 180, 934-943. [CrossRef]

68. Yue, H.; Zhang, M.; Xing, L.; Wang, K.; Rao, X.; Liu, H.; Tian, J.; Zhou, P.; Deng, Y.; Shang, J. The epidemiology and clinical characteristics of co-infection of SARS-CoV-2 and influenza viruses in patients during COVID-19 outbreak. J. Med. Virol. 2020, 92, 2870-2873. [CrossRef] [PubMed]

69. Zhao, D.; Yao, F.; Wang, L.; Zheng, L.; Gao, Y.; Ye, J.; Guo, F.; Zhao, H.; Gao, R. A comparative study on the clinical features of coronavirus 2019 (COVID-19) pneumonia with other pneumonias. Clin. Infect. Dis. 2020, 71, 756-761. [CrossRef] [PubMed]

70. Zheng, X.; Wang, H.; Su, Z.; Li, W.; Yang, D.; Deng, F.; Chen, J. Co-infection of SARS-CoV-2 and Influenza virus in Early Stage of the COVID-19 Epidemic in Wuhan, China. J. Infect. 2020. [CrossRef]

71. Lansbury, L.; Lim, B.; Baskaran, V.; Lim, W.S. Co-infections in people with COVID-19: A systematic review and meta-analysis. J. Infect. 2020, 81, 266-275. [CrossRef]

72. Langford, B.J.; So, M.; Raybardhan, S.; Leung, V.; Westwood, D.; MacFadden, D.R.; Soucy, J.-P.R.; Daneman, N. Bacterial co-infection and secondary infection in patients with COVID-19: A living rapid review and meta-analysis. Clin. Microbiol. Infect. 2020. [CrossRef] [PubMed]

73. Davis, B.; Rothrock, A.N.; Swetland, S.; Andris, H.; Davis, P.; Rothrock, S.G. Viral and atypical respiratory co-infections in COVID-19: A systematic review and meta-analysis. J. Am. Coll. Emerg. Phys. Open 2020, 1, 533-548. [CrossRef] [PubMed]

74. Moher, D.; Liberati, A.; Tetzlaff, J.; Altman, D.G.; Group, P. Preferred reporting items for systematic reviews and meta-analyses: The PRISMA statement. PLoS Med. 2009, 6, e1000097. [CrossRef] [PubMed] 
75. Wells, G.; Shea, B.; O'Connell, D.; Peterson, J.; Welch, V.; Losos, M.; Tugwell, P. The Newcastle-Ottawa Scale (NOS) for Assessing the Quality of Nonrandomized Studies in Meta-Analyses; Ottawa Health Research Institute: Ottawa, ON, Canada, 2015.

76. DerSimonian, R.; Kacker, R. Random-effects model for meta-analysis of clinical trials: An update. Contemp. Clin. Trials 2007, 28, 105-114. [CrossRef] [PubMed]

77. Higgins, J.P.; Thompson, S.G. Quantifying heterogeneity in a meta-analysis. Stat. Med. 2002, 21, 1539-1558. [CrossRef]

78. Higgins, J.P.; Thompson, S.G.; Deeks, J.J.; Altman, D.G. Measuring inconsistency in meta-analyses. BMJ 2003, 327, 557-560. [CrossRef]

79. Egger, M.; Smith, G.D.; Schneider, M.; Minder, C. Bias in meta-analysis detected by a simple, graphical test. BMJ 1997, 315, 629-634. [CrossRef]

80. Chen, N.; Zhou, M.; Dong, X.; Qu, J.; Gong, F.; Han, Y.; Qiu, Y.; Wang, J.; Liu, Y.; Wei, Y. Epidemiological and clinical characteristics of 99 cases of 2019 novel coronavirus pneumonia in Wuhan, China: A descriptive study. Lancet 2020, 395, 507-513. [CrossRef]

81. Mo, P.; Xing, Y.; Xiao, Y.; Deng, L.; Zhao, Q.; Wang, H.; Xiong, Y.; Cheng, Z.; Gao, S.; Liang, K. Clinical characteristics of refractory COVID-19 pneumonia in Wuhan, China. Clin. Infect. Dis. 2020. [CrossRef]

82. Zha, L.; Shen, J.; Tefsen, B.; Wang, Y.; Lu, W.; Xu, Q. Clinical features and outcomes of adult COVID-19 patients co-infected with Mycoplasma pneumoniae. J. Infect. 2020. [CrossRef]

83. Al Mutair, A.; Alhumaid, S.; Alhuqbani, W.N.; Zaidi, A.R.Z.; Alkoraisi, S.; Al-Subaie, M.F.; AlHindi, A.M.; Abogosh, A.K.; Alrasheed, A.K.; Alsharafi, A.A. Clinical, epidemiological, and laboratory characteristics of mild-to-moderate COVID-19 patients in Saudi Arabia: An observational cohort study. Eur. J. Med. Res. 2020, 25. [CrossRef] [PubMed]

84. Alhumaid, S.; Al Mutair, A.; Al Alawi, Z.; Al Salman, K.; Al Dossary, N.; Omar, A.; Alismail, M.; Al Ghazal, A.M.; Jubarah, M.B.; Al Shaikh, H. Clinical features and prognostic factors of intensive and non-intensive 1014 COVID-19 patients: An experience cohort from Alahsa, Saudi Arabia. Eur. J. Med. Res. 2021, 26, 47. [CrossRef] [PubMed]

85. Al-Omari, A.; Alhuqbani, W.N.; Zaidi, A.R.Z.; Al-Subaie, M.F.; AlHindi, A.M.; Abogosh, A.K.; Alrasheed, A.K.; Alsharafi, A.A.; Alhuqbani, M.N.; Salih, S. Clinical characteristics of non-intensive care unit COVID-19 patients in Saudi Arabia: A descriptive cross-sectional study. J. Infect. Public Health 2020, 13, 1639-1644. [CrossRef]

86. Sharifipour, E.; Shams, S.; Esmkhani, M.; Khodadadi, J.; Fotouhi-Ardakani, R.; Koohpaei, A.; Doosti, Z.; Golzari, S.E. Evaluation of bacterial co-infections of the respiratory tract in COVID-19 patients admitted to ICU. BMC Infect. Dis. 2020, 20, 646. [CrossRef] [PubMed]

87. Lee, A.; Cheung, Y.S.L.; Joynt, G.M.; Leung, C.C.H.; Wong, W.-T.; Gomersall, C.D. Are high nurse workload/staffing ratios associated with decreased survival in critically ill patients? A cohort study. Ann. Intensive Care 2017, 7, 46. [CrossRef]

88. Dasgupta, S.; Das, S.; Chawan, N.S.; Hazra, A. Nosocomial infections in the intensive care unit: Incidence, risk factors, outcome and associated pathogens in a public tertiary teaching hospital of eastern India. Indian J. Crit. Care Med. 2015, 19, 14.

89. Alhumaid, S.; Al Mutair, A.; Al Alawi, Z.; Alsuliman, M.; Ahmed, G.Y.; Rabaan, A.A.; Al-Tawfiq, J.A.; Al-Omari, A. Knowledge of infection prevention and control among healthcare workers and factors influencing compliance: A systematic review. Antimicrob. Resist. Infect. Control. 2021, 10, 1-32. [CrossRef] [PubMed]

90. Al-Omari, A.; Al Mutair, A.; Alhumaid, S.; Salih, S.; Alanazi, A.; Albarsan, H.; Abourayan, M.; Al Subaie, M. The impact of antimicrobial stewardship program implementation at four tertiary private hospitals: Results of a five-years pre-post analysis. Antimicrob. Resist. Infect. Control. 2020, 9, 95. [CrossRef] [PubMed]

91. Al Mutair, A.; Alhumaid, S.; Al Alawi, Z.; Zaidi, A.R.Z.; Alzahrani, A.J.; Al-Tawfiq, J.; Al-Shammari, H.; Rabaan, A.; Khojah, O.; Al-Omari, A. Five-year resistance trends in pathogens causing healthcare-associated infections at a multi-hospital healthcare system in Saudi Arabia, 2015-2019. J. Glob. Antimicrob. Resist. 2021. [CrossRef]

92. Alhumaid, S.; Al Mutair, A.; Al Alawi, Z.; Alzahrani, A.J.; Tobaiqy, M.; Alresasi, A.M.; Bu-Shehab, I.; Al-Hadary, I.; Alhmeed, N.; Alismail, M.; et al. Antimicrobial susceptibility of gram-positive and gram-negative bacteria: A 5-year retrospective analysis at a multi-hospital healthcare system in Saudi Arabia. Ann. Clin. Microbiol. Antimicrob. 2021, 20, 43. [CrossRef]

93. Uyeki, T.M.; Bernstein, H.H.; Bradley, J.S.; Englund, J.A.; File, T.M., Jr.; Fry, A.M.; Gravenstein, S.; Hayden, F.G.; Harper, S.A.; Hirshon, J.M. Clinical practice guidelines by the Infectious Diseases Society of America: 2018 update on diagnosis, treatment, chemoprophylaxis, and institutional outbreak management of seasonal influenza. Clin. Infect. Dis. 2019, 68, e1-e47. [CrossRef]

94. Unnewehr, M.; Friederichs, H.; Bartsch, P.; Schaaf, B. High diagnostic value of a new real-time Pneumocystis PCR from bronchoalveolar lavage in a real-life clinical setting. Respiration 2016, 92, 144-149. [CrossRef]

95. Byington, C.L.; Ampofo, K.; Stockmann, C.; Adler, F.R.; Herbener, A.; Miller, T.; Sheng, X.; Blaschke, A.J.; Crisp, R.; Pavia, A.T. Community surveillance of respiratory viruses among families in the Utah better identification of germs-longitudinal viral epidemiology (BIG-LoVE) study. Clin. Infect. Dis. 2015, 61, 1217-1224. [CrossRef]

96. Patel, R.; Babady, E.; Theel, E.S.; Storch, G.A.; Pinsky, B.A.; St George, K.; Smith, T.C.; Bertuzzi, S. Report from the American Society for Microbiology COVID-19 international summit, 23 March 2020: Value of diagnostic testing for SARS-CoV-2/COVID-19. Am. Soc. Microbiol. 2020. [CrossRef]

97. Morens, D.M.; Taubenberger, J.K.; Fauci, A.S. Predominant role of bacterial pneumonia as a cause of death in pandemic influenza: Implications for pandemic influenza preparedness. J. Infect. Dis. 2008, 198, 962-970. [CrossRef]

98. Leung, C.-H.; Tseng, H.-K.; Wang, W.-S.; Chiang, H.-T.; Wu, A.Y.-J.; Liu, C.-P. Clinical characteristics of children and adults hospitalized for influenza virus infection. J. Microbiol. Immunol. Infect. 2014, 47, 518-525. [CrossRef] 
99. Cusumano, J.A.; Dupper, A.C.; Malik, Y.; Gavioli, E.M.; Banga, J.; Berbel Caban, A.; Nadkarni, D.; Obla, A.; Vasa, C.V.; Mazo, D. (Eds.) Staphylococcus aureus bacteremia in patients infected with COVID-19: A case series. In Open Forum Infectious Diseases; Oxford University Press: Oxford, UK, 2020.

100. Navarini, A.A.; Recher, M.; Lang, K.S.; Georgiev, P.; Meury, S.; Bergthaler, A.; Flatz, L.; Bille, J.; Landmann, R.; Odermatt, B. Increased susceptibility to bacterial superinfection as a consequence of innate antiviral responses. Proc. Nat. Acad. Sci. USA 2006, 103, 15535-15539. [CrossRef] [PubMed]

101. Didierlaurent, A.; Goulding, J.; Patel, S.; Snelgrove, R.; Low, L.; Bebien, M.; Lawrence, T.; van Rijt, L.S.; Lambrecht, B.N.; Sirard, J.-C. Sustained desensitization to bacterial Toll-like receptor ligands after resolutionof respiratory influenza infection. J. Exp. Med. 2008, 205, 323-329. [CrossRef] [PubMed]

102. Gadi, N.; Wu, S.C.; Spihlman, A.P.; Moulton, V.R. What's sex got to do with COVID-19? Gender-based differences in the host immune response to coronaviruses. Front. Immunol. 2020, 11, 2147. [CrossRef] [PubMed]

103. Rabaan, A.A.; Al-Ahmed, S.H.; Garout, M.A.; Al-Qaaneh, A.M.; Sule, A.A.; Tirupathi, R.; Mutair, A.A.; Alhumaid, S.; Hasan, A.; Dhawan, M. Diverse immunological factors influencing pathogenesis in patients with COVID-19: A review on viral dissemination, immunotherapeutic options to counter cytokine storm and inflammatory responses. Pathogens 2021, 10, 565. [CrossRef] [PubMed]

104. Kamfose, M.M.; Muriithi, F.G.; Knight, T.; Lasserson, D.; Hayward, G. Intravenous ceftriaxone versus multiple dosing regimes of intravenous anti-Staphylococcal antibiotics for methicillin-susceptible Staphylococcus aureus (MSSA): A systematic review. Antibiotics 2020, 9, 39. [CrossRef] [PubMed] 